\title{
Turn it off and on again: characteristics and control of torpor
}

\section{[version 1; peer review: 1 approved, 2 approved with}

\section{reservations, 1 not approved]}

\author{
Michael Ambler (D), Timna Hitrec (iD) Anthony Pickering (iD)
}

School of Physiology, Pharmacology, \& Neuroscience, University of Bristol, Bristol, Bristol, BS8 1TD, UK

V1 First published: 17 Nov 2021, 6:313

https://doi.org/10.12688/wellcomeopenres.17379.1

Latest published: 29 Mar 2022, 6:313

https://doi.org/10.12688/wellcomeopenres.17379.2

\section{Abstract}

Torpor is a hypothermic, hypoactive, hypometabolic state entered into by a wide range of animals in response to environmental challenge. This review summarises the current understanding of torpor. We start by describing the characteristics of the wide-ranging physiological adaptations associated with torpor. Next follows a discussion of thermoregulation, control of food intake and energy expenditure, and the interactions of sleep and thermoregulation, with particular emphasis on how those processes pertain to torpor. We move on to take a critical view of the evidence for the systems that control torpor entry, including both the efferent circulating factors that signal the need for torpor, and the central processes that orchestrate it. Finally, we consider how the putative circuits responsible for torpor induction integrate with the established understanding of thermoregulation under non-torpid conditions and highlight important areas of uncertainty for future studies.

\section{Keywords}

Torpor, Metabolism, Homeostasis, Thermoregulation, Hibernation, Energy balance

\section{Open Peer Review}

Approval Status $\checkmark \times ?$

$\begin{array}{llll}1 & 2 & 3 & 4\end{array}$

version 2

(revision)

29 Mar 2022

$\begin{array}{lcccc}\text { version 1 } & \checkmark & \text { X } & ? \\ 17 \text { Nov 2021 } & \text { view } & \text { view } & \text { view } & \text { view }\end{array}$

1. Sinisa Hrvatin (D), Whitehead Institute for Biomedical Research, Cambridge, USA Massachusetts Institute of Technology, Cambridge, USA

Senmiao Sun ID, Harvard Medical School, Boston, USA

2. Christopher Madden (D), Oregon Health \& Science University, Portland, USA

3. Kelly Drew (iD, University of Alaska Fairbanks, Fairbanks, USA

4. David Bechtold, University of Manchester, Manchester, UK Any reports and responses or comments on the article can be found at the end of the article. 
Corresponding author: Michael Ambler (m.ambler@bristol.ac.uk)

Author roles: Ambler M: Conceptualization, Data Curation, Funding Acquisition, Writing - Original Draft Preparation, Writing - Review \& Editing; Hitrec T: Writing - Review \& Editing; Pickering A: Writing - Review \& Editing

Competing interests: No competing interests were disclosed.

Grant information: This work was supported by Wellcome [211029 https://doi.org/10.35802/211029].

The funders had no role in study design, data collection and analysis, decision to publish, or preparation of the manuscript.

Copyright: $\odot 2021$ Ambler $\mathrm{M}$ et al. This is an open access article distributed under the terms of the Creative Commons Attribution License, which permits unrestricted use, distribution, and reproduction in any medium, provided the original work is properly cited.

How to cite this article: Ambler M, Hitrec $T$ and Pickering A. Turn it off and on again: characteristics and control of torpor [version 1; peer review: 1 approved, 2 approved with reservations, 1 not approved] Wellcome Open Research 2021, 6:313

https://doi.org/10.12688/wellcomeopenres.17379.1

First published: 17 Nov 2021, 6:313 https://doi.org/10.12688/wellcomeopenres.17379.1 


\section{Introduction}

Torpor is a hypothermic, hypometabolic, adaptive response, observed when the metabolic demands of maintaining homeostasis cannot be met. Torpor can be brief, in daily heterotherms such as the mouse, or it can be prolonged, in seasonal hibernators. In small animals undergoing torpor, body temperature typically drops to just a few degrees above ambient. In the hibernating arctic squirrel this can result in core temperatures as low as $-2.9^{\circ} \mathrm{C}$ (Barnes, 1989). Alongside hypothermia are commensurate reductions in metabolic, heart, and respiratory rates (Heldmaier et al., 2004). Torpor therefore represents an intriguing deviation from 'normal' mammalian physiology, and as such there is increasing interest in mimicking it in the context of the critically ill patient (Cerri, 2017; Stanzani et al., 2020), and for long-distance space travel (Cerri et al., 2021a).

Torpor (or aestivation in the case of fish, reptiles, and amphibians) is a remarkably conserved behaviour seen in all classes of vertebrate life, including the three oldest branches of mammals: monotremes, marsupials, and placentals including primates, as illustrated in Figure 1 (Carey et al., 2003; Heldmaier et al., 2004).

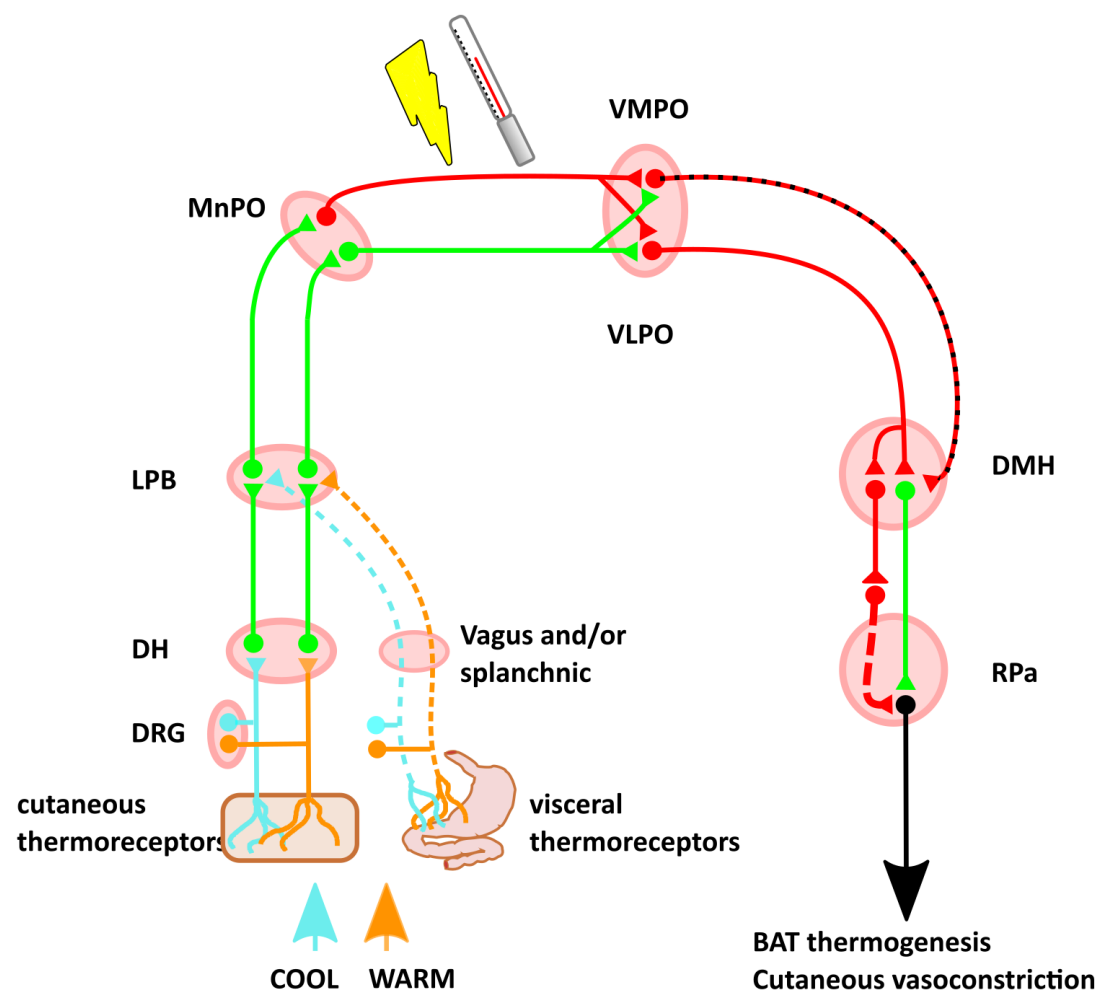

Key:

Pyrogen-sensitive neurons

Central thermosensitive neurons

GABAergic neurons

GABAergic BDNF/PACAP neurons

Putative GABAergic interneuron

Glutamatergic neurons

Figure 1. Schematic of the thermal defence circuit. Inputs include skin surface thermoreceptors, visceral thermoreceptors, intrinsic thermosensitive neurons in the POA, and circulating pyrogens. Warm-sensing neurons increase the inhibitory input from the VMPO and VLPO onto the DMH, which reduces a tonically active thermogenic signal from DMH to RPa. Cool-sensing neurons disinhibit this tonically active DMH to RPa projection, to increase heat production. Abbreviations: DRG, dorsal root ganglion; DH, dorsal horn; LPD, lateral parabrachial nucleus; $\mathrm{MnPO}$, median preoptic area; VLPO, ventrolateral preoptic nucleus; VMPO, ventromedial preoptic nucleus; BDNF, brain-derived neurotrophic factor; PACAP, pituitary adenylate cyclase-activating polypeptide; DMH, dorsomedial hypothalamic nucleus; RPa, raphe pallidus; BAT, brown adipose tissue. 
Those mammals that engage torpor, do so through activation of ubiquitous genes, rather than a complement of genes that are unique to those torpid species (Faherty et al., 2016; Srere et al., 1992; Zhao et al., 2010). Hence, this behaviour may represent a fundamental physiological response that has been relatively recently switched off in those animals for which it is not an extant behaviour. The aim of this review is to provide an overview of the fundamental physiological adaptations associated with torpor, and then to discuss current evidence for how these remarkable adjustments might be achieved. We focus on the physiology of daily torpor in the mouse, primarily because this is the animal that has been most extensively studied. However, where relevant or where data in the mouse are lacking, other species including hamsters, squirrels, bears, and lemurs will be included. The latter group undergo prolonged seasonal hibernation, and an assumption is that the torpor during these hibernation periods is mechanistically equivalent to the brief torpor bouts seen in daily heterotherms such as the mouse. However, this assumption has not been experimentally proven.

\section{Discussion}

\section{Physiological characteristics of torpor}

Due to the large surface area to volume ratio of a mouse, maintenance of normothermia represents a significant energy cost. In mice housed at an ambient temperature of $22^{\circ} \mathrm{C}$, over $30 \%$ of energy expenditure is directed towards thermogenesis (Abreu-Vieira et al., 2015). When mice are unable to access sufficient calories to maintain active physiology and normal body temperature, they will enter periods of torpor lasting several hours (Hudson \& Scott, 1979). Stimuli for torpor in mice include acute fasting (Sunagawa \& Takahashi, 2016), a combination of fasting and reduction in the ambient temperature (Hitrec et al., 2019; Swoap \& Gutilla, 2009) food restriction (van der Vinne et al., 2018), or simply increasing the energy costs of foraging (Schubert et al., 2010). This latter observation supports the hypothesis that it is a relative imbalance of energy supply compared to the demands of maintaining 'normal' physiological homeostasis rather than a response to cold and hunger per se, which triggers torpor. In summary: torpor is engaged in any situation where the available food is insufficient for the metabolic demands of euthermia.

Female mice are more prone to torpor than males, and hence some studies present data from female mice only (for example, Kato et al., 2018; Oelkrug et al., 2010; Swoap \& Gutilla, 2009) although males do enter torpor (Gavrilova et al., 1999; Lo Martire et al., 2018; Solymár et al., 2015; Sunagawa \& Takahashi, 2016). Recent work indicates oestrogen receptor expressing neurons in the pre-optic area contribute to the generation of daily torpor in the mouse, and will be discussed in more detail later (Zhang et al., 2020). Evidence from the pouched mouse, Saccostomus campestris, indicates that testosterone inhibits torpor (Mzilikazi \& Lovegrove, 2002). These gender differences might reflect the relatively lower energetic burden that normal activity and reproduction place on male compared to female mice, hence the need to conserve adipose tissue energy reserves may be greater for females. Alternatively, the relative female predisposition to torpor may be due to lower birth weight, since low birth weight predicts higher torpor tendency irrespective of actual body weight at the time of fasting (Kato et al., 2018).

\section{Definition, timing, and duration of torpor}

The transition to torpor may not be all or nothing: fasted mice exhibit increased variability of both metabolic rate and body temperature, with graded reductions in core body temperature up to full torpor (Brown \& Staples, 2010). Despite the magnitude of the final deviation from normal physiology, there is no consensus on the definition of torpor in mice. Examples include a core body temperature below $34^{\circ} \mathrm{C}$ proceeded by least fifteen minutes of consecutive decline (Iliff \& Swoap, 2012; Willis, 2007); body temperature below $31^{\circ} \mathrm{C}$ for at least 30 minutes (Brown \& Staples, 2010); body temperature below $32^{\circ} \mathrm{C}$ (Braulke \& Heldmaier, 2010); a metabolic rate 25\% below expected (Hudson \& Scott, 1979); the duration of a period of monotonic cooling resulting in a reduction in body temperature of at least $5^{\circ} \mathrm{C}$ followed by a period of monotonic increase up to at least $5^{\circ} \mathrm{C}$ above the nadir (Lo Martire et al., 2018); or, deviation from a Bayesian estimate of individual basal metabolic rate or core temperature (Sunagawa \& Takahashi, 2016). These approaches vary in their complexity, as well as their ability to account for individual and/or circadian fluctuations in body temperature or metabolic rate.

Although the trigger for torpor entry in mice usually originates from a fluctuating rather than predictable environmental stimulus, the timing of torpor entry is under circadian control. Torpor in mice generally occurs during the latter part of the lights off period (Brown \& Staples, 2010; Webb et al., 1982). Timing of torpor entry is primarily under the control the circadian clock, but can be adjusted by the timing or expected timing of food (van der Vinne et al., 2018), or entrained to food in mice or hamsters lacking endogenous circadian clocks (Paul et al., 2004; van der Vinne et al., 2018). Duration of torpor in mice is inversely proportional to the weight of the mouse (Hudson \& Scott, 1979), with some evidence that torpor is engaged when food restriction or fasting decreases body weight to approximately 20g (Solymár et al., 2015), although this experiment was performed only in male mice. Torpor typically persists for between four and six hours, often preceded by shallow, aborted or shorter bouts (Hudson \& Scott, 1979; Webb et al., 1982). Bouts may last 12 hours or more depending on the intervention used to induce torpor (Kato et al., 2018).

\section{Thermoregulation during torpor}

During torpor bouts, thermoregulation is not simply suspended: mice maintain active control of their temperature, usually tracking approximately two degrees above ambient temperature, but defending a minimum body temperature of $16-19^{\circ} \mathrm{C}$ (Hudson \& Scott, 1979). Further evidence for the continued - albeit adjusted - thermoregulatory control comes from the observation that the rate of decline in body temperature is lower in torpor than when hypothermia is induced pharmacologically or physically (Vicent et al., 2017b), that is to say, temperature decreases during entry into torpor are 
controlled. Indeed, a very low ambient temperature may reduce the probability of torpor entry, again indicating ongoing but adjusted thermoregulation (Sunagawa \& Takahashi, 2016). Hypothermia in a torpid animal could be achieved through three distinct mechanisms: increased thermal conductance to the environment; reduced target temperature; or reduced gain in the regulatory feedback system. Hibernating marmots appear to reduce both the gain and the target of the thermoregulatory system (Florant \& Heller, 1977), while daily torpor in mice may predominantly involve reduction in its gain (Sunagawa \& Takahashi, 2016). Whether these observations reflect mechanistic differences between the hypothermia seen during daily torpor and that during torpor in hibernation is not clear.

\section{Cardiovascular function during torpor}

The suppression of metabolism associated with torpor allows animals to tolerate profound reductions in cardiac output, respiratory rate, and, presumably, organ perfusion. Heart rates of torpid mice typically reach a nadir of approximately 150 beats per minute (bpm) from resting rates of around $600 \mathrm{bpm}$ (Swoap \& Gutilla, 2009). Hypothermia alone generates a degree of bradycardia, such as is seen clinically during therapeutic hypothermia (Stær-Jensen et al., 2014). However, heart rates are slower at any given core body temperature during entry into, compared to arousal from torpor (Swoap \& Gutilla, 2009). This indicates a dominance of the parasympathetic nervous system during entry, followed by sympathetic nervous system activation during arousal from torpor, at least in terms of the heart. For a given body temperature, pharmacologically-induced hypothermia generates a less profound bradycardia than that seen in torpor, which again supports the hypothesis that heart rate is actively suppressed during torpor entry (Vicent et al., 2017b).

Given that heart rate in torpid mice drops by $75 \%$ from resting values, and mean arterial blood pressure is determined by the product of cardiac output vascular resistance, if all other parameters remained the same a $75 \%$ drop in mean arterial pressure would be predicted during torpor. However, systolic, diastolic, and mean arterial pressure drop by only $25-30 \%$ during torpor (Swoap \& Gutilla, 2009). The maintenance of blood pressure at values only $25-30 \%$ below those seen in euthermic mice despite the profound bradycardia suggests significantly increased vascular resistance.

Hence, during torpor there appears to be simultaneous activation of the sympathetic and parasympathetic nervous system with the former driving vasoconstriction and the latter driving bradycardia. Simultaneous activation of both the sympathetic and parasympathetic limbs of the autonomic nervous system has been proposed as a means to optimise cardiac function when pumping blood into a constricted vascular tree (Paton et al., 2005), and is observed for example in the diving reflex (Panneton, 2013).

\section{Metabolic rate and respiratory function during torpor}

Respiratory function in torpid mice is less well studied, however, in the little pocket mouse Perognathus longimembris (a 7-11 gram rodent from the family Heteromyidae) daily torpor is associated with a reduction in respiratory minute volume to less than 2\% of basal levels (Withers, 1977). Dormice (Glis glis) exhibit similar characteristics during torpor (Elvert \& Heldmaier, 2005). Both species increase the rate and decrease the depth of ventilation during entry and exit from torpor, a pattern that resembles panting. The purpose of this panting is unclear, but it may serve to increase heat loss during torpor entry, reduce the partial pressure of carbon dioxide in the blood prior to torpor, or expel accumulated carbon dioxide following torpor.

The assessment of acid-base balance and partial pressures of $\mathrm{O}_{2}$ and $\mathrm{CO}_{2}$ in hypothermic hibernating animals is complex: the $p \mathrm{H}$ of pure water is dependent on temperature, as are the dissociation constants of biological buffers, and the partial pressure of a fixed amount of carbon dioxide $\left(\mathrm{PCO}_{2}\right)$ in a solution decreases with decreasing temperature. One approach for assessing acid-base balance in hypothermic or hibernating animals is to take a sample of blood held in a sealed container, normalise the temperature and then measure the $p \mathrm{H}$. This allows comparison with 'normal' values taken at $37^{\circ} \mathrm{C}$. Blood taken from hibernating hamsters (Cricetus cricetus) and warmed to $37^{\circ} \mathrm{C}$ in a sealed syringe, tends to have a $p \mathrm{H}$ between 6.9 and 7.15 compared to euthermic $p \mathrm{H}$ of approximately 7.36, and an arterial $\mathrm{PCO}_{2}$ between 17 and 24 kilopascals (kPa) compared to euthermic values of approximately $6 \mathrm{kPa}$, indicating a respiratory acidosis. Alternatively, one can measure the dissociation ratio of imidazole groups on proteins $\left(\alpha_{\mathrm{im}}\right)$ : acid conditions reduce the dissociation ratio (as does reduced temperature). Using this measure also indicates an acidic intracellular state during hibernation in blood, brain and muscle of hibernating hamsters (Malan et al., 1985; Malan, 1988). In contrast to the observation of a respiratory acidosis in hibernating hamsters, hibernating arctic ground squirrels appear to have reduced $\mathrm{PCO}_{2}$ compared to euthermic ground squirrels and rats (Ma et al., 2005). This difference may reflect differences in the body temperature of these hibernating species, with greater metabolic suppression in the colder artic ground squirrel leading to less $\mathrm{CO}_{2}$ production, differences in the physiology of the species, or differences in the method for analysing the blood gases taken from hypothermic animals. The partial pressure of oxygen $\left(\mathrm{PO}_{2}\right)$ in hibernating arctic ground squirrels is actually higher than in euthermic animals, reflecting presumably the reduced oxygen consumption, and only dips below normal euthermic values during arousal when metabolic activity is at a peak (Ma et al., 2005).

Oxygen consumption decreases to between 0.04 and $0.05 \mathrm{ml}$ $\mathrm{O} 2 . \mathrm{g}^{-1} \cdot \mathrm{hr}^{-1}$ in torpid pocket mice and dormice, which in the former is less than $1 \%$ of levels when housed at an ambient temperature of $10^{\circ} \mathrm{C}$ (Elvert \& Heldmaier, 2005; Withers, 1977). Larger mammals such as the Alaskan black bear, whose basal metabolic rate is generally lower than that observed in smaller animals, suppress metabolism to $25 \%$ of resting levels. Notably, the minimum oxygen consumption seen in hibernating bears is very similar to that seen in smaller mammals, reaching a nadir of $0.06 \mathrm{ml} \mathrm{O} 2 . \mathrm{g}^{-1} \cdot \mathrm{hr}^{-1}$ (Toien et al., 2011). The 
fact that large seasonal hibernators achieve similar metabolic suppression despite significantly higher body temperature during hibernation compared to small daily heterotherms, indicates that the reduction in metabolic rate is not simply a passive consequence of lowered body temperature, but rather that metabolism is actively suppressed. This hypothesis is further supported by several observations: reductions in heart rate, respiratory rate and oxygen consumption precede decreases in core temperature in all animals studied, and is largely independent of ambient temperature (Elvert \& Heldmaier, 2005; Toien et al., 2011; Withers, 1977). Metabolic rate in torpid dunnarts is several times lower than that seen in a similar sized rat pup rendered hypothermic by exposure to a cold ambient temperature, with reversal of the normal relationship between body warming or cooling and metabolic rate during torpor (Geiser et al., 2014). Respiration in mitochondria taken from torpid mice is suppressed even when assessed at $37^{\circ} \mathrm{C}$ (Brown \& Staples, 2010).

While metabolism is clearly suppressed during torpor, there is evidence that it increases immediately prior to torpor entry in the mouse (Lo Martire et al., 2018), the dormouse (Elvert \& Heldmaier, 2005), and the Djungarian hamster (Heldmaier et al., 1999). The significance of this is not clear, but it may represent incomplete switching from euthermia to torpor with resultant episodes of shivering, or perhaps there is a need to clear metabolic substrates from the mitochondria prior to torpor in order to suppress metabolism and reduce free radical production during torpor.

Remarkably, despite the dramatically reduced cardiac output and respiratory rate, hence presumably reduced oxygen delivery, the concentration of blood lactate in hibernating arctic ground squirrels is no different from that seen in euthermic controls (Ma et al., 2005). This demonstrates the remarkable fine-tuning of metabolic supply and demand during torpor such that in the face of reduced supply there is no overall deficit.

\section{Physiology of mammalian thermoregulation}

In order to understand the physiological adaptations of torpor, it is useful to understand the normal control of body temperature. Mammalian thermoregulation presumably evolved to enable control of the core temperature such that cellular and tissue function is optimised to the survival and reproductive benefit of the animal. The considerable energy cost of maintaining a core temperature several degrees above ambient implies homeothermy brings a significant survival advantage, allowing continued activity in the face of diurnal or seasonal reductions in the ambient temperature, and therefore allowing the occupation of a wider range of environmental niches (Abreu-Vieira et al., 2015).

Despite this investment and its benefits, there are times when mammalian body temperature deviates from the normal range. This deviation can be physiological, such as during fever, sleep, ovulation, stress, or of course, torpor (Landolt et al., 1995). Additionally, deviations of core temperature can be pathological due to poisoning or environmental challenges. Internal sources of heat in mammals include those that generate heat as a by-product, for example basal metabolism with heat generated as a consequence of pumping ions across membranes, and heat generated by muscles during movement. Additional internal sources of heat include those for which heat production is the primary goal. Examples of this include shivering, and brown adipose thermogenesis where mitochondrial proton flux is uncoupled from adenosine triphosphate (ATP) production in brown adipose tissue (reviewed in (Nicholls \& Rial, 1999)). In addition, mammals can take steps to reduce heat loss including piloerection, peripheral vasoconstriction, and nest building. Heat defence responses include cutaneous vasodilation with visceral constriction and increased cardiac output to direct blood towards the cooler skin surface, evaporative losses through sweating, panting, and grooming. Despite their mutually antagonistic effects, both the autonomic warm and cold defence responses are under the control of the sympathetic nervous system (reviewed in ((Morrison, 2016b)).

Early models of thermoregulation proposed a temperature target, or set-point, against which incoming signals of core and external temperature were compared, with a homeostatic response generated to drive the core temperature back towards the set-point (Hammel \& Pierce, 1968). More recently, with advances in our understanding of the physiology of thermoregulation, a model of multiple independent mechanisms each with their own threshold has emerged (McAllen et al., 2010).

\section{Afferent thermoregulation signals}

Signals encoding skin temperature arise from primary somatosensory neurons that express transient receptor potential (TRP) channels: the transducing receptor that converts temperature into electrochemical signals for neuronal transmission. Once transduced, the signal is passed to second order somatosensory neurons in the spinal dorsal horn (Lumpkin \& Caterina, 2007). Hot and cold information from the skin flows centrally in parallel streams, both relaying information from the dorsal horn via the parabrachial nucleus to the preoptic area of the hypothalamus (POA). Relatively little is known about the inputs from thermosensitive receptors in the viscera, although it is thought they enter the central nervous system (CNS) via splanchnic and vagal afferents, and follow a similar path through the lateral parabrachial nucleus to the preoptic area (Morrison, 2016b)

The circuit controlling thermogenic responses to changes in skin temperature was identified by combining the use of retrograde tracer (cholera toxin B-subunit $(\mathrm{CTb})$ ), anterograde tracer (Phaseolus vulgaris leucoagglutinin (PHA-L)), and immunohistochemistry against the c-Fos protein (Nakamura \& Morrison, 2008), a surrogate for neuronal activation (Sagar et al., 1988). This anatomical analysis, as well as in-vivo electrophysiological recordings, indicate that the projection that travels via the external lateral and central parts of the lateral parabrachial nucleus (LPBel, LPBc, respectively) responds to skin cooling. Activation of this input to the preoptic area results in increased brown adipose tissue (BAT) thermogenesis, shivering, and increased metabolic and heart rate. The response is blocked by blockade of lateral parabrachial glutamate transmission, 
and does not require an intact spinothalamic tract. In contrast, skin warming induces c-Fos expression and increases firing in POA-projecting neurons in the dorsal part of the lateral parabrachial nucleus (LPBd). Activation of this pathway results in increased heart rate, suppressed BAT sympathetic nerve activity, and cutaneous vasodilatation, effects that are also dependent on glutamatergic transmission in the LPBd (Nakamura \& Morrison, 2010). Thermal-sensitive parabrachial neurons predominantly project to the median preoptic nucleus (MnPO) (Nakamura \& Morrison, 2008).

\section{Efferent thermoregulation signals}

The POA can be viewed as sitting at the top of a thermoregulatory arc. It integrates information about both the internal and external temperature, and contributes to the autonomic response to thermal challenge by modulating BAT thermogenesis, shivering, and vasoconstriction (Morrison et al., 2012; Morrison, 2016a). Early experiments established that local heating of the POA induced vasodilatation, sweating, and panting responses akin to those seen when heating the entire animal, indicating the existence of intrinsically warm-sensing POA neurons in central thermoregulatory circuits (Clark et al., 1939b; Magoun et al., 1938; Nakayama et al., 1961). Lesioning the POA disrupts thermoregulatory responses to thermal challenge (Clark et al., 1939a). In the 1970s, electrophysiological recordings confirmed that the POA not only responds to local brain temperature changes, but also responds to increases or decreases in skin surface or spinal temperature (Boulant \& Hardy, 1974). More recently, the application of agonists or antagonists to cultured POA neurons that express calcium-sensitive fluorescent dyes established that central temperature-sensing mechanisms are mediated by the transient receptor potential M2 channel (TRPM2). This channel, when exposed to increasing temperatures within the physiological range, allows influx of extracellular calcium (Song et al., 2016). In summary, the POA receives thermal information from the skin and viscera, as well as directly sensing the local brain temperature, and then uses this information to control down-stream thermoregulation as discussed below.

Chemo- or optogenetic excitation of a warm-activated GABAergic projection from the ventral part of the lateral POA (vLPO) to the dorsomedial hypothalamic nucleus (DMH) suppresses thermogenesis and locomotion, while inhibiting the same projection induces the opposite effects. Data from in-vivo calcium imaging reveals the targets of this GABAergic projection are both glutamatergic and GABAergic neurons within the $\mathrm{DMH}$, both of which increase their activity in response to low ambient temperature. Chemo- or optogenetic activation of either the GABAergic or the glutamatergic DMH neurons increases core temperature and activity (Zhao et al., 2017). There is presumably a second inhibitory neuron between the DMH GABAergic neuron identified by Zhao et al., and the BAT-activating sympathetic premotor neurons in the raphe pallidus (RPa). This could in principle lie within either the DMH or the RPa or in a relay elsewhere (see Figure 1).

Another GABAergic projection to the DMH arises from the ventromedial preoptic area (VMPO). These VMPO neurons express brain-derived neurotrophic fact (BDNF) and pituitary adenylate cyclase-activating polypeptide (PACAP/PACAP). Again, in-vivo calcium imaging reveals that these VMPO neurons are activated by exposure to a warm environment. Opto-activation of the warm-sensing GABAergic BDNF and PACAP-expressing cell bodies in the VMPO induces a drop in core body temperature, vasodilatation, and preference for a cooler environment. Optoactivation in the $\mathrm{DMH}$ of the GABAergic terminals of these VMPO neurons results in a drop in core body temperature but no vasodilation or cool ambient preference. This implies that the $\mathrm{DMH}$ is responsible for the inhibition of BAT thermogenesis, whereas VMPO projections elsewhere generate the vasodilation and behavioural preference (Tan et al., 2016).

The DMH then sends projections to the rostral raphe nucleus of the medulla that in turn project to, and activate, BAT via the spinal intermediolateral nucleus (Cao et al., 2004; DiMicco \& Zaretsky, 2007). This DMH-Raphe-BAT projection is involved in thermal defence and also in the thermogenic response to stress (Kataoka et al., 2014). This implies that either the $\mathrm{DMH}$ receives inputs from additional regions beyond the POA thermo-sensitive circuit that mediate the stress response, or else that the POA also responds to stress.

Taken together, this work establishes the principle that the POA sends a GABAergic projection to the DMH to inhibit thermogenesis. With increasing ambient, hypothalamic, or core temperature, these signals increase to inhibit thermogenesis. Likewise, when internal and/or ambient temperature drops, activity in these GABAergic POA to DMH projections reduces, disinhibiting the DMH and leading to increased BAT thermogenesis. An additional principle that emerges is that the physiological effects of changes in temperature may be sensed at one level (e.g. the POA), with projections to several downstream sites evoking independent physiological responses. This pattern is seen in the projection from the VMPO to the DMH where activation of this pathway inhibits BAT thermogenesis but does not induce the additional vasodilation or cool environment preference seen when activating the VMPO itself (Tan et al., 2016). It remains to be established why the DMH contains both excitatory and inhibitory neurons that drive thermogenesis (Zhao et al., 2017), but a plausible explanation would be that it ensures tight or fail-safe control of this vital homeostatic process.

\section{Thermoregulation, food intake and body weight}

There must be at least two processes that link food intake, thermoregulation, and maintenance of body weight. The first ensures that as changes in ambient temperature drive changes in energy expenditure, a commensurate adjustment of food intake occurs to maintain bodyweight. In this case, energy expenditure and food intake move together in parallel. Hence, cold exposure increases both BAT thermogenesis and food intake while warm exposure reduces both (Kaiyala et al., 2012; Ravussin et al., 2014; Xiao et al., 2015). The second process is driven by the need to maintain a steady body weight. In this scenario, energy expenditure and food intake move in 
opposite directions: calorie-restriction drives food intake and suppresses body temperature, whereas calorie excess increases body temperature and suppresses food intake in humans (Soare et al., 2011), as well as rodents (Duffy et al., 1989; Rothwell \& Stock, 1997).

The following section is not an exhaustive review of the regulation of appetite and food intake, but rather focuses on the mechanisms and anatomical regions in which the control of food intake interacts with thermoregulation and energy expenditure (Figure 2). For a review of the central control of appetite, see here (Andermann \& Lowell, 2017).

Amongst several hypothalamic nuclei that contribute to control of food intake, the arcuate nucleus (ARC) is central and contains two distinct but intermingled populations of cells that

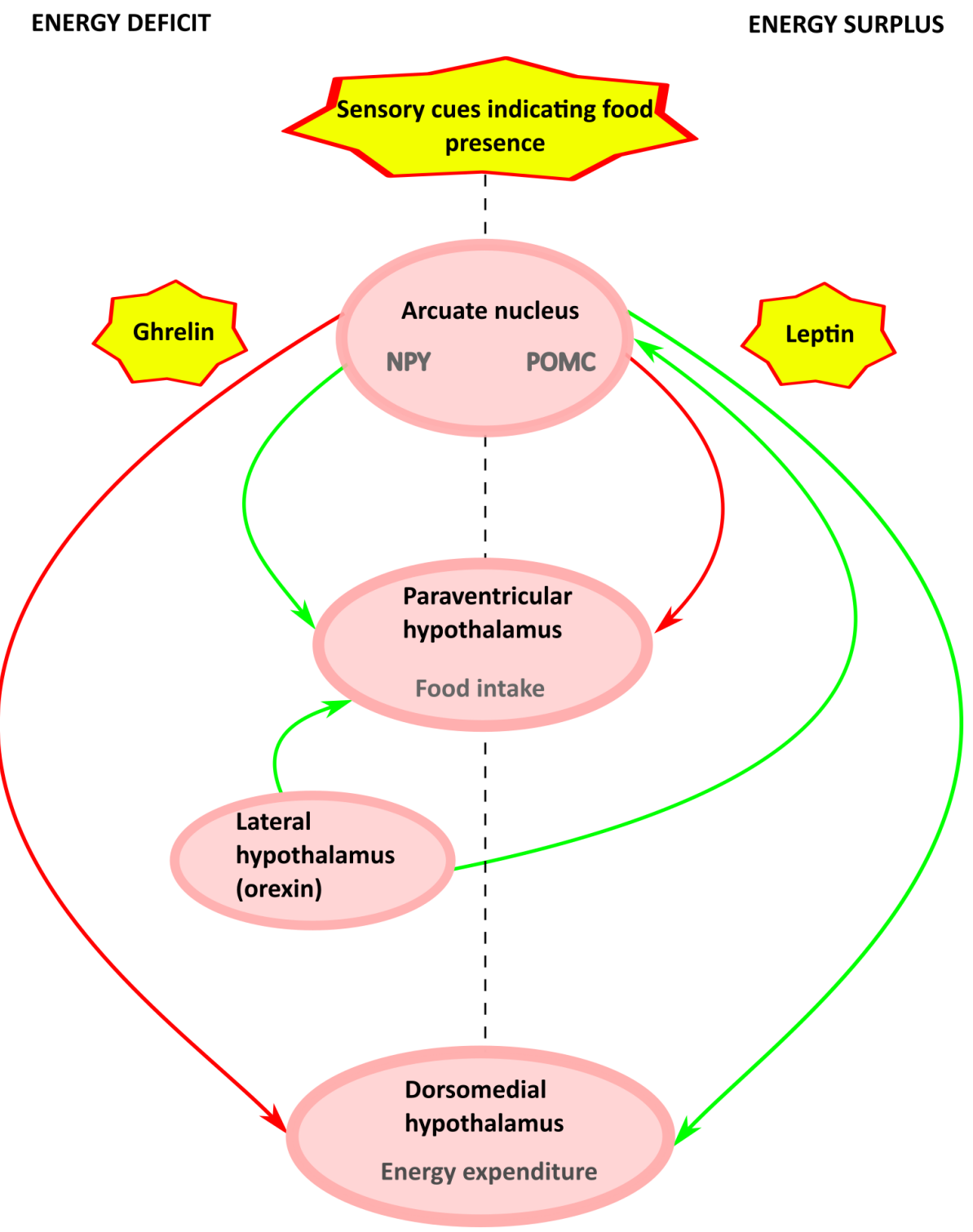

Figure 2. Schematic of the circuits controlling food intake and energy expenditure. Fasting stimulates the release of ghrelin from the gastrointestinal tract, which acts on arcuate NPY neurons. NPY-expressing neurons in the arcuate project to the PVH to stimulate food intake, and to the DMH to inhibit thermogenesis and reduce energy expenditure. Conversely, leptin, released from WAT in proportion to the amount of stored fat, acts on arcuate POMC neurons. Arcuate POMC neurons project to the PVH, where they inhibit food intake, and to the $\mathrm{DMH}$, where they increase thermogenesis and energy expenditure. Orexin released from the lateral hypothalamus stimulates both food intake and thermogenesis. Sensory signals modulate the activity of arcuate NPY and POMC neurons in anticipation of food intake. At each level in the hypothalamus, the ghrelin-NPY circuits and the leptin-POMC circuits inhibit each other. Abbreviations: NPY, neuropeptide Y; PVH, paraventricular hypothalamic nucleus; DMH, dorsomedial hypothalamic nucleus; WAT, white adipose tissue; POMC, pro-opiomelanocortin; 
perform opposing functions. One population responds to leptin, which is released from white adipose tissue (WAT) to signal satiety and replete WAT stores. These neurons express the neuropeptide pro-opiomelanocortin (POMC), which is cleaved into $\alpha$-melanocyte stimulating hormone $(\alpha-\mathrm{MSH})$, which in turn acts on melanocortin receptors (Cone, 2005; Dodd et al., 2015). The second population express neuropeptide $Y$ and agouti-related peptide (NPY and AgRP, respectively). This group is activated by ghrelin, a hormone secreted by the gastrointestinal tract during fasting that stimulates food intake (Hahn et al., 1998; Müller et al., 2015), and is inhibited by leptin. NPY/AgRP neurons, therefore, signal energy deficit and hunger. These two populations are mutually antagonistic: leptin depolarises ARC POMC neurons while hyperpolarising NPY/AgRP neurons, which reduces their inhibitory input onto the POMC population (Cowley et al., 2001; Myers et al., 2008). Meanwhile, AgRP is a potent antagonist at melanocortin receptors (reviewed here (Andermann \& Lowell, 2017)). Each population and their interactions will be summarised below.

\section{Leptin, pro-opiomelanocortin, and a-melanocyte stimulating hormone}

Leptin is a peptide hormone released by WAT in proportion to the size of the adipose tissue reserve, reflecting long-term food intake and energy stores (Frederich et al., 1995). In addition to reflecting WAT stores, leptin release is suppressed during periods of fasting in mice (Swoap et al., 2006) and in humans (Bergendahl et al., 2000). Leptin receptors are widespread, but of particular relevance here, are found in the ARC, PVH, DMH, POA, and the nucleus of the solitary tract (NTS) (Myers et al., 2008; Zhang et al., 2011). Leptin release is also inhibited by exposure to a short photoperiod in hamsters (Freeman et al., 2004), an observation that may account for the observation that humans eat more as winter approaches (de Castro, 1991).

\section{Physiology of leptin}

As a signal of replete WAT stores, leptin inhibits food intake and increases energy expenditure through BAT thermogenesis, growth, and reproductive behaviours (Frederich et al., 1995; Myers et al., 2008; Schwartz et al., 1996). Exogenous leptin blunts the neuroendocrine consequences of starvation (Ahima et al., 1996) and suppresses food intake (Mistry et al., 1997). Leptin deficient $(o b / o b)$ mice are obese, due to both increased ad-libitum food intake (Welton et al., 1973) and reduced basal metabolic rate, such that $o b / o b$ mice pair-fed with lean littermates maintain a higher body mass with increased fat stores (Trayhurn \& James, 1978).

In keeping with a role linking energy balance and thermoregulation, leptin-deficient mice show defects in thermoregulation: hypothermic at sub-thermoneutral ambient temperatures and fatally incapable of defending body temperature with acute exposure to low ambient temperatures (Kaiyala et al., 2015; Trayhurn et al., 1977). In addition to a central deficit in leptin signalling, ob/ob mice show reduced BAT response to electrical or noradrenergic stimulation, indicating a role for peripheral leptin in priming BAT thermogenesis (Seydoux et al., 1982). Hence, the $o b / o b$ mice are unable to recognise their ample fat stores and adapt as if in a starved state by suppressing thermogenesis and increasing food intake.

\section{Functional anatomy of leptin}

Leptin receptors are highly-expressed in the ARC, which is a central hub in the processing of signals regarding the energy state of an animal (Chen et al., 2015; Cone, 2005). Leptin's actions here suppress food intake and, when combined with high circulating insulin, increase the sympathetically-mediated browning of WAT (Dodd et al., 2015). Leptin's effects in the ARC are mediated by a coordinated increase in the activity of POMC neurons, and reduction in the activity of neurons that co-express NPY and AgRP (Cowley et al., 2001; Myers et al., 2008). POMC-expressing ARC neurons project to diverse brain regions including $\mathrm{PVH}$, where they release $\alpha-\mathrm{MSH}$, which acts on melanocortin receptors (Cone, 2005).

In-vivo calcium imaging reveals that the ARC POMC neurons react to both the presence of food and the sensory anticipation of food availability. This suggests that leptin-responsive POMC neurons have a role in acute satiety and foraging, in addition to long-term energy balance (Chen et al., 2015). Transgenic mice lacking the melanocortin 4 receptor show a similar phenotype to $o b / o b$ mice: obese with increased food intake and suppressed energy expenditure. Selective reintroduction of melanocortin 4 receptors in the PVH normalises the excess food intake but not the suppressed energy expenditure seen in these mice (Balthasar et al., 2005).

In addition to running through circuits that modulate food intake, leptin receptors are also expressed in regions involved in thermoregulation: neurons that express leptin receptors are trans-synaptically labelled by pseudorabies virus injected into BAT. This delineates the presence of leptin receptors throughout the efferent thermoregulatory circuit from BAT, up to the $\mathrm{RPa}$, the DMH, and finally, the median POA (MnPO). Leptin receptor-expressing neurons in the $\mathrm{DMH}$ produce $\mathrm{c}$-Fos in response to acute cold exposure (Zhang et al., 2011). Chemogenetic activation of these DMH leptin receptor-expressing neurons stimulates BAT thermogenesis and locomotor activity without affecting food intake, resulting in decreased body weight (Rezai-Zadeh et al., 2014). Hence there is overlap between the circuits mediating the thermogenic effects of leptin and those mediating the thermogenic effect of acute cold exposure.

Neurons in the POA that express leptin receptors also respond to exposure to a warm environment. Chemogenetic activation of these neurons inhibits feeding and reduces energy expenditure by inhibiting BAT thermogenesis (Yu et al., 2016). The simultaneous inhibition of feeding and thermogenesis is not usually a role attributed to leptin. Rather, leptin is usually associated with suppression of feeding and stimulation of thermogenesis (Myers et al., 2008). Hence one might anticipate that the effect of leptin on these neurons would be to inhibit their activity. Indeed, the leptin receptor has been shown to be capable of inhibiting synaptic transmission (Thompson \& Borgland, 2013). These observations were dependent on ambient temperature, which suggests a role for POA leptin receptor-expressing 
neurons linking the necessary alterations of food intake that must accompany changes in the energy demands of thermogenesis. It would be interesting to establish the effects of leptin at its receptors in these neurons, and to identify their projection targets.

In conclusion, the picture that emerges from the literature is that leptin tends to move energy expenditure and food intake in opposite directions: increased leptin drives weight loss by suppressing food intake and increasing energy expenditure. This suggests that its primary role is to control body mass and / or WAT stores. It may also contribute to suppressing both thermogenesis and food intake following exposure to a warm environment, although this is less well established.

\section{Neuropeptide $Y$ and agouti-related peptide}

NPY is one of the most highly expressed neuropeptides found in the brain, where it is commonly co-expressed with AgRP. It is involved in energy homeostasis, circadian rhythms, the stress response, and cognition. NPY production is widespread, but of particular relevance to energy homeostasis, it is expressed in the ARC, the NTS, the DMH, and the PVH (Bi et al., 2003; Chronwall et al., 1985; Elmquist et al., 1999). There are three main NPY receptors in humans and rodents: Y1, Y2, and Y5. Expression of these receptors is also widespread, but densities occur in areas related to homeostasis, thermoregulation, and energy expenditure including: PVH, ARC, lateral hypothalamus, NTS and DMH. As introduced above, NPY and AgRP respond to fasting or WAT store depletion by suppressing energy expenditure and increasing food intake. Hence, NPY/AgRP have opposite and antagonistic functions to leptin (reviewed in Cone, 2005; Reichmann \& Holzer, 2016).

\section{Physiology of NPY and AgRP}

Peripheral administration of ghrelin induces c-Fos expression in, and depolarises, ARC NPY/AgRP neurons (Chen et al., 2015; Cowley et al., 2003; Wang et al., 2002). These ARC NPY/AgRP neurons also express leptin receptors, the action of which reduces NPY and AgRP expression (Wang et al., 1997), and causes hyperpolarisation (Cowley et al., 2001). Hence, NPY and AgRP neurons are activated by low WAT energy stores and hunger. As with POMC neurons, NPY/AgRP neurons are modulated by the sensory anticipation of food, such that in foodrestricted mice, presentation of sensory cues indicating food availability reduces firing (Chen et al., 2015). Adult ablation of NPY/AgRP neurons leads to mice with low body weight, reduced food intake, and increased BAT activity (Bewick et al., 2005; Gropp et al., 2005; Luquet et al., 2005). Intra-cerebroventricular (ICV) administration of NPY acutely increases food intake and decreases BAT activity. ICV NPY also increases WAT lipoprotein lipase activity (indicating increased lipid deposition), an effect that persists in food-restricted rats, suggesting a direct effect rather than as a consequence of increased metabolic substrate availability (Billington et al., 1991).

The effects of NPY on both BAT and WAT are mediated by sympathetic innervation, rather than via a circulating factor (Egawa et al., 1991). NPY's ability to drive lipoprotein lipase is an interesting observation since one might anticipate that NPY would liberate fat stores in an animal that is hungry. Instead, the activation of lipoprotein lipase suggests that the role of NPY is directed primarily towards replenishing fat stores rather than providing energy for immediate metabolism.

\section{Functional anatomy of NPY and AgRP}

Local injections of NPY into discrete hypothalamic nuclei has at times produced contradictory findings. Injection into the ARC induces hypothermia, as might be expected (Jolicoeur et al., 1995). NPY injection into the PVH may inhibit BAT sympathetic nerve activity (Egawa et al., 1991), and yet it has also been shown to induce hyperthermia (Jolicoeur et al., 1995). Likewise, injection into the medial preoptic area (MPA) can increase sympathetic nerve activity (Egawa et al., 1991), but may also induce hypothermia (Jolicoeur et al., 1995). This bidirectional response might indicate that high doses of NPY activate autoreceptors in a negative feedback loop to block transmission. This could result in increased BAT thermogenesis. This hypothesis is supported by the observation that ICV injection of NPY at low doses induces hypothermia and at higher doses causes hyperthermia (Jolicoeur et al., 1995). Inhibition of NPY release by activation of presynaptic Y2 receptors has been observed in-vitro (King et al., 1999). This is an important consideration with implications for experiments that use agonist injections or opto- or chemogenetics to activate circuits in a potentially supra-physiological manner.

ARC NPY /AgRP neurons project to the DMH and PVH, both of which also contain cell bodies that express NPY (Chao et al., 2011; Chronwall et al., 1985; Tiesjema et al., 2007; Wang et al., 1997). While both acute and chronic food restriction induce NPY mRNA expression in the ARC, only chronic food-restriction induces NPY mRNA in the DMH (Bi et al., 2003). Knock-down of DMH NPY expression increases WAT browning, lipolysis, and BAT UCP1. This increased BAT thermogenesis combined with observed increases in locomotor activity is not accompanied by increases in food intake, and therefore results in weight loss (Chao et al., 2011). The effect of NPY knockdown in the DMH mimics the effect of leptin in this nucleus, with a tendency to affect thermogenesis and energy expenditure more than food intake (Rezai-Zadeh et al., 2014). The DMH, however, may be capable of increasing food intake via a cholinergic input to the $\mathrm{ARC}$, which increases inhibitory tone on ARC POMC neurons (Jeong et al., 2017). One might speculate that this projection forms the basis for the link that drives increased food intake when the energetic costs of thermogenesis are high. Opto- and chemogenetic manipulation of ARC NPY/AgRP neurons that project to the PVH indicates that this circuit stimulates feeding via GABAergic input on PVH oxytocin neurons (Atasoy et al., 2012; Chen et al., 2015).

\section{Food intake and thermoregulation: summary}

The ARC, DMH, and PVH form a circuit that integrates information about the past, the present, and the future energy state. These signals are generated by leptin, ghrelin, and sensory inputs, respectively. Leptin signals long-term energy balance 
as reflected by WAT stores. Ghrelin signals recent food intake and time since last meal. Sensory inputs signal the approaching likelihood of food. The system comprises parallel antagonistic and mutually inhibitory branches: elevated leptin indicates replete energy stores and releases the brakes on energy expenditure while inhibiting further food intake by activating POMC neurons and inhibiting ARGP/NPY neurons; suppressed leptin and/or elevated ghrelin signals depletion of energy stores, driving food intake and suppression of energy expenditure through activation of NPY/AgRP and inhibition of POMC neurons.

At each level neurons that are activated by ghrelin are generally inhibited by leptin and vice versa. A model that emerges from review of the literature is that the ARC to PVH projection responds rapidly to cues regarding acute energy requirements and food availability to drive changes in food intake. On the other hand, the ARC to DMH projection appears more concerned with adjusting energy expenditure so that WAT stores are maintained within a target range. Within this putative framework, the PVH might modulate feeding through the NTS, while the DMH would modulate energy expenditure via the RPa.

\section{Thermoregulation and sleep}

In humans intracranial temperature reaches a peak in the period one to two hours prior to the onset of darkness, and drops by approximately $1^{\circ} \mathrm{C}$ during sleep (Landolt et al., 1995). The cooling associated with sleep is an active process, in humans driven at least in part by peripheral vasodilation and heat dissipation through sweating (Kräuchi et al., 2000). Similar alterations in core and brain temperature during sleep are seen in rodents (Harding et al., 2019; Zhang et al., 2015).

Non rapid-eye-movement (NREM) sleep is characterised by a controlled reduction in body temperature such that while core body temperature reduces, changes in ambient or hypothalamic temperature continue to induce thermoregulatory responses, including sweating (Geschickter et al., 1966), panting, and shivering (Parmeggiani \& Rabini, 1967). During NREM sleep, the temperature threshold for inducing metabolic heating is reduced, and the slope of the response also reduced compared to wake (Glotzbach \& Heller, 1976). In contrast, rapid-eye-movement (REM) sleep appears to involve total cessation of thermoregulation such that (in small animals at least) body temperature follows changes in ambient temperature, and does not respond to changes in local hypothalamic temperature by increasing metabolic heat production (Glotzbach \& Heller, 1976; Heller \& Glotzbach, 1977; Walker et al., 1983). This abandonment of thermoregulation during REM may be a factor limiting the duration of REM epochs in sub-thermoneutral environments (Heller \& Glotzbach, 1977). REM sleep is also characterised by cerebral oxygen consumption similar to that seen during waking, which is in stark contrast with NREM sleep (Madsen et al., 1991).

The interaction between sleep and body temperature is reciprocal: sleep is associated with a reduction in body temperature, and increased body or hypothalamus temperature or a warm ambient environment promotes sleep (Bunnell et al., 1988; Kräuchi et al., 1999; Lo Martire et al., 2012; McGinty \& Szymusiak, 1990; Romeijn et al., 2012). This relationship has led some to hypothesise that sleep is fundamentally a thermoregulatory homeostatic process (McGinty \& Szymusiak, 1990). The observation that vasodilation and a rapid rate of body cooling is associated with sleep onset appears somewhat at odds with the fact that prior to sleep humans and rodents seek out warmth (Harding et al., 2018). The reason behind this apparent paradox may lie in the observations that while increased temperature, be that core, brain, or ambient is associated with increased sleep, in particular NREM sleep, it is not the elevated temperature but rather the subsequent high rate of heat loss that seems to be most predictive of sleep initiation.

In humans, increasing peripheral vasodilation associated with a falling core body temperature from its peak in the hours prior to sleep onset predicts latency to sleep (Kräuchi et al., 1999; Kräuchi et al., 2000). Humans also tend to select a bed time that coincides with the maximum rate of circadian body temperature reduction (Campbell \& Broughton, 1994). A similar observation has been made in mice: reactivating warm-sensing POA neurons induces a drop in core temperature and increased NREM sleep (Harding et al., 2018). The tendency to seek warm environments prior to sleep may therefore help to activate these sleep-inducing POA neurons.

On the other hand, the high rate of heat loss and relative unresponsiveness of the thermoregulatory system may reflect an undesirable but inevitable side-effect of the process of sleep induction. In this case, seeking out warm environments prior to sleep would be a means to mitigate some of the heat loss that results from those side-effects. For example, if reduced sympathetic tone is required to allow the animal to enter a low vigilance state prior to sleep onset, then a corollary of that might be increased vasodilation and reduced BAT thermogenesis.

\section{Functional anatomy linking sleep and}

thermoregulation: the preoptic hypothalamus

The POA acts as a critical hub linking thermoregulation and sleep. In mice, recovery sleep following a period of deprivation is associated with a drop in core temperature of between 1.5 and $2^{\circ} \mathrm{C}$, and increased delta power, indicating NREM sleep. Chemogenetic reactivation of median and lateral POA neurons that are active during recovery sleep recapitulates both this increased NREM sleep and drop in core body temperature. Lateral POA (LPO) neurons are also the target of the $\alpha-2$ agonist dexmedetomidine, which induces sedation that mimics recovery sleep (Kroeger et al., 2018; Zhang et al., 2015).

The population of neurons in the region of the LPO and VLPO that are capable of inducing NREM and hypothermia express galanin: chemo- or optogenetic stimulation of GABA- and galanin-expressing neurons in the ventrolateral preoptic nucleus (VLPO) induces NREM and a drop in body temperature (Kroeger et al., 2018); knock-out of lateral preoptic (LPO) galanin neurons significantly attenuates the sedation and hypothermia 
associated with dexmedetomidine administration, and causes a rise in body temperature with disrupted sleep homeostasis (Ma et al., 2019).

These findings support the hypothesis that reduced sympathetic tone associated with activation of presynaptic $\alpha-2$ receptors disinhibits sleep- and hypothermia-promoting galanin neurons in the lateral and/or ventrolateral preoptic area. VLPO neurons that are active during sleep project monosynaptically to the tuberomammillary nucleus, which is known to modulate arousal (Sherin et al., 1996). In a related study, warm sensitive neurons in the region of the MnPO/MPO were reactivated using activity-dependent tagging. While reactivation of a GABAergic subpopulation of these neurons induced NREM sleep without a significant change in body temperature, reactivation of the glutamatergic/nitrergic subpopulation induced both, indicating that they may be part of the circuit that coordinates NREM sleep induction with body temperature reduction (Harding et al., 2018).

In all these experiments, the drop in body temperature during chemogenetic-driven sleep was deeper than that seen in natural sleep (Harding et al., 2018; Kroeger et al., 2018; Zhang et al., 2015). This observation may reflect the somewhat abnormal nature of the stimulation (Armbruster et al., 2007), or may reflect an additional role for these regions in torpor.

\section{Sleep and adenosine}

The role of adenosine in sleep is complex and beyond the scope of this review; presented here is a summary of some key aspects, as they relate to torpor (a more comprehensive review is provided here (Silvani et al., 2018)). The G protein-coupled adenosine receptors $\mathrm{A} 1 \mathrm{R}$, and $\mathrm{A} 2 \mathrm{R}$ are widely expressed throughout the brain. The A1R is inhibitory and generally considered to be neuroprotective through suppression of glutamate release and hyperpolarisation (reviewed here (Cunha, 2005)), and by modulating cerebral blood flow and metabolic rate (Blood et al., 2003). In addition to their central effects, adenosine receptors in the cardiovascular system mediate negative inotropic, chronotropic, dromotropic, and anti-adrenergic effects via A1Rs, and vasodilatation via A2Rs (reviewed here (Shryock \& Belardinelli, 1997)). Central activation of A1Rs promotes sleep, hypothermia, sedation, and reduced locomotor activity (Anderson et al., 1994).

Sleep deprivation increases the homeostatic drive for sleep, and is reflected in elevated time spent in NREM and by increased EEG delta power during subsequent recovery sleep (reviewed here (Borbély et al., 2016)). Expression of this rebound increase in NREM sleep is dependent on the presence of neuronal A1Rs, via an interaction with glia (Bjorness et al., 2009; Bjorness et al., 2016), although additional mechanisms may also be capable of providing this function, for example in whole-animal A1R knockouts (Stenberg et al., 2003). In this way, adenosine links the homeostatic drive for sleep with suppression of metabolic and cardiovascular systems, and induction of NREM sleep.

\section{Sleep and torpor}

Preserved thermoregulatory control despite altered body temperature is characteristic of both torpor and NREM sleep. Both also probably reduce overall energy expenditure. An obvious question is to ask what is the link between torpor and NREM sleep?

Ground squirrels and pocket mice enter torpor through sleep (Berger, 1984; Heller \& Glotzbach, 1977; Walker et al., 1977). Electroencephalogram (EEG) recordings during torpor display the characteristics of NREM sleep provided brain temperature is above about $25^{\circ} \mathrm{C}$. At brain temperatures below $25^{\circ} \mathrm{C}$, EEG power is globally reduced but delta waves associated with NREM sleep are discernible. EEG power decreases (and with it, the ability to discern sleep states) with brain temperatures below $20^{\circ} \mathrm{C}$, and becomes isoelectric below about $10^{\circ} \mathrm{C}$ (Larkin \& Heller, 1996; Walker et al., 1981).

Consistent with the observation that low brain temperatures are associated with the loss of NREM EEG pattern, there is evidence that prolonged torpor such as that seen in seasonal hibernators is associated with accumulation of sleep debt. During prolonged seasonal hibernation periods, arctic ground squirrels periodically arouse to euthermia through NREM sleep. The duration of the post-arousal NREM sleep correlates with the minimum brain temperature reached during the preceding torpor (Larkin \& Heller, 1996; Trachsel et al., 1991). These observations indicate that while torpor at intermediate core temperatures resembles NREM sleep, some of the vital functions of sleep are depressed during torpor at very low body temperature, and must be performed at or close to euthermia.

\section{Efferent signals triggering torpor entry}

\section{The sympathetic nervous system and leptin in torpor}

Dopamine beta-hydroxylase (DBH) knock-out mice (DBH-/-) lack norepinephrine and epinephrine, while their heterozygous littermates appear essentially normal. Norepinephrine can be at least partially restored by the administration of L-threo-3,4-dihydroxyphenyserine (DOPS) (Thomas et al., 1995; Thomas et al., 1998). DBH-/- mice fail to enter torpor after 12 hours of fasting at $20^{\circ} \mathrm{C}$. This impairment in torpor can be reversed by the administration of DOPS to restore adrenergic signalling, or by selective activation of beta- 3 adrenoceptors. Serum leptin is elevated in both the fed and fasting state in DBH-/- compared to DBH+/- mice. Fasting does not significantly reduce serum leptin in DBH-/- mice, but fasting in combination with administration of DOPS or a beta- 3 agonist reduces serum leptin to levels comparable to fasted $\mathrm{DBH}+/$ - mice (Swoap et al., 2006).

The model that emerges from this series of experiments is that activation of beta-3 receptors on WAT suppresses leptin release, which serves as a signal for torpor induction. There are additional studies that support this model. Firstly, DBH-/- mice that also lack leptin signalling (by crossing with $o b / o b$ mice to generate double-mutant mice) regain the ability to enter torpor, 
albeit displaying unusually early and shallow bouts. The proposal is that in lacking leptin, these modifications bypass the need for sympathetic action on WAT. Once torpid, these double knock-out mice are unsurprisingly slow to rouse given they lack both leptin, which is BAT thermogenic, and norepinephrine, which acts on beta-3 receptors in BAT to stimulate thermogenesis (Swoap \& Weinshenker, 2008). Secondly, exogenous leptin reduces leptin mRNA expression in WAT of $\mathrm{DBH}+/-$ mice but does not suppress expression in DBH-/- WAT, indicating that the autoregulation of leptin is dependent on norepinephrine (or perhaps epinephrine) (Commins et al., 1999). Thirdly, torpor in short photoperiod-adjusted Djungarian hamsters can be blocked by chemical sympathectomy with 6-Hydroxydopamine (Braulke \& Heldmaier, 2010).

This is an appealing model, but there are some caveats:

1. While the torpor bouts generated by administration of DOPS to fasted DBH-/- mice appeared similar to those seen in $\mathrm{DBH}+/-$ controls, administration of a beta-3 agonist (CL 316243) produced a hypothermia so profound that the animals did not spontaneously arouse (Swoap et al., 2006). It is not entirely clear, then, that this was the same as natural torpor.

2. If activation of beta-3 receptors on WAT serves as the first step towards torpor induction, then administration of a beta-3 agonist to wild type mice should increase the probability and or depth of torpor: this has not been reported.

3. Fasted DBH+/- mice given a selective beta-3 receptor antagonist appear to enter torpor normally, with a rate of decline in core body temperature that is comparable to controls (Swoap et al., 2006). The difference between this and control torpor bouts appears to be that the beta-3 receptor antagonist caused the torpor bout to be terminated, before core temperature reaches a 'normal' nadir. This does not fit with the model that beta-3 receptor suppression of WAT leptin release is the initiating trigger for torpor.

4. Given that leptin acts on POMC/ $\alpha$-MSH neurons in the arcuate, blocking this pathway should mimic a drop in leptin and therefore be pro-torpor. However Ay mice, which display ectopic AgRP production and through the antagonist effect of AgRP on melanocortin 4 receptors, impaired $\alpha$-MSH melanocortin signalling, in fact show a reduced tendency to torpor (Gluck et al., 2006).

Although there is a correlation between the ability to suppress leptin and the ability to enter torpor, a causal nature for this relationship has not been exhaustively demonstrated. An implication of this model is that exogenous leptin should prevent torpor, and that interfering with leptin signalling should induce torpor even in a fed state. These have been difficult to demonstrate, and will be discussed in more detail below.

Mice lacking leptin, the $o b / o b$ mice, are prone to deeper and longer torpor bouts than wild type (WT) mice on fasting or food restriction, despite their large adipose tissue stores (Gavrilova et al., 1999; Himms-Hagen, 1985). However, it is worth pointing out that the $o b / o b$ mouse is not permanently torpid, and neither are A-ZIP/F-1 mice, which have both dramatically reduced WAT and BAT and persistently low leptin levels. While A-ZIP/F-1 mice will readily enter torpor on fasting, exogenous leptin administration does not prevent fasting-induced torpor in these mice. In contrast to this, leptin administration to $o b / o b$ mice may block torpor entry (Gavrilova et al., 1999). Interpreting the effects of leptin administration to transgenic mice that have adapted to absent leptin signalling is challenging, especially given that the expression of torpor in these mice, even without the additional complexity of adding exogenous leptin, is not the same as torpor seen in WT mice.

Studying the effect of leptin on torpor in WT mice has also produced contradictory findings. One study reports no effect of leptin treatment on core temperature of WT mice during a 24 hour fast (Gavrilova et al., 1999). In this study leptin administration to male WT mice fasted for 24 hours did not prevent the drop in core temperature seen in saline-treated mice. However, while the core temperature of both leptin-treated and control male WT mice during 24 hours of fasting did decrease, it remained above $30^{\circ} \mathrm{C}$, and therefore above commonly accepted thresholds for torpor. Hence, while leptin prevented any core temperature response to fasting in $o b / o b$ mice, it had no effect on WT mice. Why leptin might abolish torpor in $o b / o b$ mice but not affect temperature responses to fasting in WT mice is unclear, but may reflect differences in the sensitivity of $o b / o b$ mice to exogenous leptin.

In another study, male WT mice fasted for up to 48 hours showed fasting-induced suppression of metabolism and core temperature, but not full torpor. Leptin treatment reduced fasting-induced hypometabolism in these WT mice (Bechtold et al., 2012). The reasons for these different results are not clear, but may reflect differences in the administration of leptin: in the former study, in (Gavrilova et al., 1999), leptin was administered via continuous subcutaneous (SC) infusion whereas in the latter study (Bechtold et al., 2012), leptin was delivered in a single ICV injection. Whatever the reason for these differing results, neither have confirmed that leptin delivery to WT mice prevents full torpor bouts.

Leptin treatment in fasted marsupial mammal (Sminthopsis macroura) reduces the duration and depth of daily torpor bouts (Geiser et al., 1998), but again the effect of leptin in this species appears to be predominantly to impair the maintenance rather than the initiation of torpor. It seems that exogenous leptin might reduce the probability of torpor entry in Siberian hamsters although in those leptin-treated hamsters that did enter torpor, the torpor bout depth, duration, and frequency remained comparable to torpor bouts in control hamsters. Comparing hamsters housed under identical conditions that did or did not enter torpor revealed no difference in endogenous serum leptin levels. Likewise, the serum leptin levels were the same in individual animals on days in which the animal did or did 
not enter torpor. Finally, while animals that entered torpor tended to have low leptin, the lowest levels were recorded in hamsters that did not enter torpor (Freeman et al., 2004).

In summary, the evidence for leptin's role in torpor garnered from transgenic models varies depending on whether the model used is the primarily leptin-deficient $o b / o b$ line, or the A-ZIP/F-1 line in which absent leptin is secondary to persistently depleted adipose tissue stores. While both models result in low leptin and increased propensity to torpor, only the $o b / o b$ mice are sensitive to leptin replacement. That mice from neither line are in a permanent state of torpor would suggest either adaptive mechanisms appear during development, or else a permissive rather than a sufficient role of low leptin in torpor. Attempts to establish the effects of leptin administration to WT mice have been hampered by the fact that the WT control mice in these experiments were not entering full torpor. That said, converging evidence both from studies specifically examining leptin and torpor, as well as studies looking at the role of leptin under more 'normal' physiological settings, indicates that it is likely that high leptin would inhibit torpor and conversely low leptin likely forms at least part of the signal for torpor. Finally, evaluation of the studies to date raises the possibility that the beta- 3 adrenoceptor-driven suppression of leptin plays a greater role in maintaining than initiating torpor.

\section{NPY, ghrelin, and torpor}

Since ghrelin and NPY act as the counterbalance to leptin, signalling hunger and energy deficit (see section 1.3.4), it is reasonable to hypothesise that they contribute to the signal for torpor. Ghrelin injection during a fast in a cool ambient temperature deepens and prolongs torpor bouts in mice but does not induce torpor in the fed state. NPY-/- mice exhibit shallow and aborted torpor bouts, which are not rescued by peripheral ghrelin. This indicates that ghrelin exerts its effects on torpor via NPY neurons (Gluck et al., 2006).

ICV injection of NPY in cold-acclimated Siberian hamsters (small, heterothermic mammals) reduces core body temperature and can increase the probability of torpor. This effect in hamsters is mediated by Y1 receptors (Dark \& Pelz, 2008). ICV NPY may also inhibit food intake, in proportion to its effects on body temperature or torpor (Paul et al., 2005). This latter finding is surprising given NPY is usually considered orexigenic. At some point, in order to enter torpor, the normal response to hunger, which is to forage and increase food intake, is presumably switched to a signal to cease locomotor activity and enter torpor; perhaps this observation reflects that transition. It is also relevant to note that hamsters undergo both fastinginduced torpor, which is triggered by energy deficit at any seasonal time, and short photoperiod-induced torpor, which is seasonal and does not necessarily involve an energy deficit. These distinct torpor phenotypes may involve different regulatory mechanisms (Cubuk et al., 2017), which could account for the observed effect of NPY on food intake in these animals.

The arcuate is a key locus for NPY signalling, and selective ablation of ARC neurons with monosodium glutamate (MSG), supports a role for this nucleus in torpor. For example, in contrast to controls, ARC-ablated mice do not enter torpor after 24 hours of fasting, although they do show a degree of fasting-induced hypothermia (Gluck et al., 2006). In Siberian hamsters, ARC ablation impairs short photoperiod-induced torpor, reducing the probability, and slightly reducing the depth and length of torpor bouts. However, torpor was still seen in these hamsters and there was no difference in residual ARC NPY immunoreactivity between ARC-ablated hamsters that did and those that did not enter torpor. Likewise, ARC ablation reduced the probability of torpor in food restricted hamsters but had no effect on the quality or frequency of those torpor bouts in animals in which torpor was seen.

Although NPY receptor antagonists have been shown to prevent NPY-induced hypothermia (Dark \& Pelz, 2008), the same has not been demonstrated for natural torpor. This raises questions about whether the hypothermia seen following NPY injection is torpor, or rather an exaggerated form of the starvation-induced drop in temperature that is seen in non-hibernators (Billington et al., 1991), although of course the two may lie on a continuum.

In summary, there is evidence indicating roles for ghrelin and NPY within the ARC as signals for the conditions that are associated with torpor. There is also some evidence supporting direct roles in torpor, and a functioning ARC nucleus may be a requisite for the expression of torpor in mice. However, this necessity has not been demonstrated in hamsters, indicating either that alternative mechanisms might exist, capable of bypassing the ARC, or else suggesting that torpor in hamsters and mice is generated through distinct mechanisms. To date, there is no evidence that activity of ARC neurons is sufficient to induce a torpor bout.

\section{Adenosine, orexin, and torpor}

Adenosine, which was introduced above, is a natural candidate to link many of the functions associated with torpor (Silvani et al., 2018). Central infusion of the A1R agonist $\mathrm{N}^{6}$ cyclohexyladenosine (CHA) into rats exposed to cold ambient temperature generates a state that has many features of torpor, including vagally mediated skipped beats and bradycardia, inhibition of BAT and shivering thermogenesis, and decreased EEG power (Tupone et al., 2013). Accumulation of adenosine during periods when demands for ATP outstrip supply, and the consequent engagement of a repertoire of responses that limit ATP consumption (reviewed here (Newby, 1984)), make it an appealing candidate for signalling the drive for torpor.

Prolonged subcutaneous infusion of aminophylline, a non-specific adenosine receptor antagonist, significantly impairs torpor in male mice, resulting in delayed, shallow, and brief torpor bouts. Aminophylline infusion initiated during torpor triggers emergence (Iliff \& Swoap, 2012). In animals that enter torpor in response to seasonal cues, the response to adenosine is dependent on those cues. For example, central A1R blockade in Syrian hamsters causes arousal during the induction phase of seasonal torpor (Tamura et al., 2005). In arctic ground squirrels, ICV infusion of CHA induces torpor or a similar state, in a manner that was modulated by the season, and was blocked by 
central A1R antagonists (Jinka et al., 2011). Calorie restriction by alternate day feeding suppresses core temperature and respiratory rate in rats, and increases the sensitivity to CHA by increasing the expression of A1Rs in the hypothalamus (Jinka et al., 2010). Hence, modulation of the central sensitivity to adenosine provides a means for both hibernators and non-hibernators to adjust temperature responses to environmental cues.

Despite the striking similarities between torpor and the physiological response to central A1R activation, there are some features that remain distinct. Changes in heart rate with torpor occur rapidly and display frequent skipped beats and asystoles, whereas those changes occur over several hours following CHA treatment and involve predominant extension of the inter-beat interval and rarely display asystoles. Temperature changes are slower in natural torpor compared to CHA-driven hypothermia, with no evidence of shivering in the latter. Finally, c-Fos is induced in the liver and heart of mice treated with CHA, but not in natural torpor, indicating calcium influx and potentially signalling cellular stress following CHA treatment (Vicent et al., 2017a). Perhaps most importantly, fasting-induced torpor persists in mice lacking AR1 and AR3 (Carlin et al., 2017).

Orexinergic neurons may mediate some of the thermoregulatory adaptations seen following central adenosine administration, since orexin -/- mice are less sensitive to the effects of central CHA administration. However, these same mice also recover more slowly from the hypothermia induced by CHA, and are prone to deeper, longer, and more frequent torpor bouts than WT controls. In-vivo calcium imaging in this study indicated that orexin neurons are active immediately prior to and after fasting-induced torpor (Futatsuki et al., 2018). It is interesting to note that the interaction between orexin and $\mathrm{CHA}$ appears to be bidirectional: orexin enhances CHA-induced hypothermia initiation and overcomes it during recovery. Likewise, the effect of orexin on body temperature appears to depend on the sleep/wake cycle: promoting thermogenesis during waking and heat loss during sleep (Mochizuki et al., 2006).

In summary, adenosine represents a candidate signal for torpor initiation but, once again, must be designated as 'contributing' or 'permissive' and not a necessary and sufficient master switch. One might expect orexin to reduce the likelihood of torpor, and to assist in arousals, and while this role is supported by the observation of increased torpor depth and duration in orexin -/- mice, the role in WT mice or other species is not clear. There is currently no accepted explanation for the apparent bidirectional effects of orexin on body temperature and following CHA administration.

\section{Torpor and endogenous opioids}

The endogenous opioid system contributes to pain modulation, reward, the stress response, and several autonomic functions including digestion, arousal, and control of heart and respiratory rate. It comprises three groups of peptide transmitters: $\beta$-endorphin, enkephalins, and dynorphins, which act predominantly but not exclusively at $\mu-, \delta$-, and $\kappa$ - opioid receptors, respectively. Of note, $\beta$-endorphin is produced in POMC neurons, by an alternate cleaving of the precursor POMC (reviewed here (Benarroch, 2012)). Early investigations into the thermoregulatory effects of intracerebral $\beta$-endorphin injection reported that the effects depended on both the location of the injection and the dose used. For example, injection into the POA, anterior hypothalamus (AH), periaqueductal grey (PAG), nucleus accumbens (NAcc), reliably produced an initial hypothermia, with core temperature dropping by approximately $1^{\circ} \mathrm{C}$. This was generally followed by a period of hyperthermia, except when high doses were injected into the NAcc, where high doses appeared to produce a sustained hypothermia (Tseng et al., 1980). A similar effect is seen following administration of morphine to rats at increasing doses. These biphasic responses might be the result of time- and dose- dependent activation of different opioid receptor classes. Studying the effects of various opioid receptor-specific agonists and antagonists in rats and mice suggests that activation of $\kappa$ - or $\delta$-opioid receptors results in hypothermia, whereas the $\mu$-opioid receptor mediates hyperthermia (reviewed here (Rawls \& Benamar, 2011)).

Some have argued for the existence of a 'hibernation induction trigger' (HIT) that circulates in blood of seasonal hibernators, and can be transfused from a hibernating individual into a non-hibernating individual with the effect of inducing hibernation (Dawe \& Spurrier, 1969), although this is controversial (Wang et al., 1988). The apparent induction of hibernation via HIT transfusion is impaired by infusion of $\mu$ or $\kappa$ agonists, whereas infusion of the $\delta$ agonist DADLE ([D-Ala, D-Leu]-Enkephalin) appeared to mimic the effects of HIT infusion by inducing hibernation in summer-active ground squirrels. It has therefore been argued that natural hibernation generates a circulating $\delta$-receptor agonist that is capable of triggering hibernation (Oeltgen et al., 1988).

Less controversial observations of the role of the endogenous opioid system in torpor derive from experiments infusing agonists or antagonists either locally or ICV in hibernating hamsters. Arousal from the maintenance but not the induction phase of torpor can be triggered by ICV naloxonazine (a $\mu 1$ opioid receptor antagonist) in hibernating Syrian hamsters (Tamura et al., 2005). Thus maintained suppression of body temperature may depend on POMC neurons in the ARC that project to regions including $\mathrm{DMH}, \mathrm{AH}$, posterior hypothalamus $(\mathrm{PH})$, and ventromedial hypothalamus (VMH) (Tamura et al., 2012).

In summary, there is conflicting evidence from these experiments. In rats, and non-torpid mice, the evidence suggests that $\delta$-opioid receptor activation induces hypothermia whereas $\mu$-opioid receptors induce hyperthermia. One might therefore expect $\delta$-opioid receptor activation to be involved in inducing or maintaining torpor. Experiments using HIT infusion to induce torpor or a torpor-like state in ground squirrels support this model, with a role for $\delta$-opioid receptor activation in torpor induction, while $\mu$ - and $\kappa$-opioid receptors appear to inhibit torpor entry. In contrast to this, and out of keeping with the findings in rats and non-torpid mice, in Syrian hamster undergoing seasonal hibernation, the evidence would suggest that POMC neurons in the ARC activate $\mu$-opioid receptors in several hypothalamic areas to maintain low body temperature in seasonal hibernation. It is difficult to draw any synergy from 
these findings: it is possible that different opioid receptors are involved in both promoting and inhibiting torpor, perhaps as part of a system that prevents excessively long or deep torpor bouts. Alternatively, it is worth considering whether the doses of agonists and antagonists used resulted in non-specific activation of several opioid receptor subtypes. It would be interesting to test the effects of modulating endogenous opioid pathways in mice undergoing daily torpor, as the data above only describes effects on seasonal hibernators or euthermic mice and rats.

\section{Neural control of torpor}

In the 13-lined ground squirrel, a seasonal hibernator, in-situ hybridisation (ISH) reveals distinct patterns of c-fos expression during different phases of the hibernation cycle (Bratincsák et al., 2007). Entrance into torpor is associated with increased c-fos mRNA in the ventrolateral part of the MPA, whereas arousal from torpor is associated with increased expression in the ventromedial part of the MPA. In awake animals during interbout arousals, the ARC and dorsolateral hypothalamus were active. The SCN and reticular thalamus were active throughout all stages of torpor, areas involved in circadian rhythm generation and inhibition of motor activity, respectively. In torpid mice the combination of c-Fos immunohistochemistry and retrograde tracer expression identifies a group of neurons in the $\mathrm{DMH}$ that project to the $\mathrm{RPa}$, which are specifically activated during torpor (Hitrec et al., 2019). It is anticipated that activating this pathway would inhibit thermogenesis by reducing the output from RPa to BAT, and indeed pharmacological inhibition of the rostral ventromedial medulla (a region that includes the RPa) induces a torpor-like state in the rat (Cerri et al., 2013).

Three recent publications significantly furthered our understanding of the neural control of torpor entry, all converging on the preoptic area of the mouse hypothalamus as a key region, potentially containing neurons that represent a torpor 'master switch'. One of these studies (Hrvatin et al., 2020) used activity-dependent recombination ('TRAPing', (Allen et al., 2017; DeNardo et al., 2019)) to selectively express designer receptors exclusively activated by designer drugs (DREADDs (Alexander et al., 2009)) in neurons that were active during daily torpor in the mouse. Chemogenetic reactivation of neurons within the anterior and ventral portions of the medial and lateral preoptic area (avMLPA) generated a profound hypothermia and reduction in locomotor activity that appeared to mimic torpor.

These torpor-TRAPed avMLPA neurons project to several regions likely to be involved in torpor including the dorsomedial hypothalamus. Further experiments suggested that within the population of TRAPed preoptic area neurons, a subset of glutamatergic, PACAP expressing neurons generate the drop in temperature and activity observed during both natural and synthetic torpor. Blocking synaptic transmission in either glutamatergic or PACAP expressing neurons within the avMLPA impaired the expression of natural fasting-induced torpor (Hrvatin et al., 2020).

The second paper, from the Sakurai group in Japan (Takahashi et al., 2020), used a different approach but came to similar conclusions. They targeted expression of excitatory DREADDs to hypothalamic neuropeptide pyroglutamylated RFamide peptide (Qrfp) neurons. This neuropeptide was previously implicated in the modulation of food intake, adrenal activity, and anxiety, but not torpor (Okamoto et al., 2016; Takayasu et al., 2006). Chemoactivation of Qrfp-expressing neurons in the medial preoptic area (MPA) and the anteroventral periventricular nucleus (AVPe, together termed AVPe/MPA) induced a long-lasting torpor-like hypothermic state in mice, with suppressed core temperature, oxygen consumption, heart rate, respiratory rate, and locomotor activity (termed QIH, for Q-neuron-induced hypothermia and hypometabolism).

QIH was recapitulated by selective optogenetic activation of the terminals of AVPe/MPA Qrfp neurons in the DMH. It was predominantly dependent on glutamatergic transmission within the Qrfp neurons population, although GABAergic Qrfp neurons appear to contribute to a smaller extent. Blocking synaptic transmission in Qrfp neurons impaired normal fasting-induced torpor resulting in a more gradual reduction in body temperature on fasting, and reduced the normal diurnal fluctuation in body temperature.

Hence, the authors identified a population of Qrfp-expressing neurons whose cell bodies lie in the preoptic area, which appear to have a role in generating the usual rapid decrease in core temperature associated with torpor induction, and whose terminals project to the DMH. Activation of this Qrfp neuron projection from the AVPe/MPA to the DMH generates a torpor-like state in mice. RNA in-situ hybridisation revealed that approximately $80 \%$ of Qrfp neurons also express PACAP, indicating significant overlap with the torpor-induing neurons identified by Hrvatin et al.

It is worth noting that Takahashi et al. did not demonstrate that the Qrfp neurons were active during torpor. Indeed, there were some differences between natural torpor and QIH induced by Takahashi et al., which appear to relate to whether the mouse is attempting to lose heat to the environment. During natural torpor, the mouse adopts a curled-up posture consistent with attempts to conserve heat, irrespective of the ambient temperature. During QIH at high ambient temperature, the mouse adopts an extended posture, consistent with attempts to lose heat. In addition, at $21^{\circ} \mathrm{C}$ ambient temperature, QIH is associated with an initial increase in tail surface temperature, indicating vasodilatation. In contrast, natural torpor may be associated with increased total peripheral resistance, which suggests at least on the whole-body scale, vasoconstriction (Swoap \& Gutilla, 2009). Hence, there remains a question regarding the degree of overlap between QIH and natural torpor.

Furthermore, Takahashi et al. did not confirm that the Qrfp neurons projecting from POA to DMH were glutamatergic or GABAergic. This is an important question, since the observed hypothermia might, for example, be the result of activating the established POA to DMH GABAergic projection that is involved in warm-sensing and thermoregulatory homeostasis (Tan et al., 2016), rather than a specific torpor-inducing pathway.

Finally, Zhang et al. (Zhang et al., 2020) demonstrated a population of oestrogen-sensitive neurons within the medial preoptic 
area whose activity increases during fasting-induced torpor in the mouse. Selective ablation of these neurons using Cre-dependent Caspase 3 expression impaired fasting induced torpor in these mice, suggesting a role in natural torpor. Chemogenetic activation of these neurons generated hypothermia and bradycardia as well as suppressed locomotor activity and oxygen consumption: all features of natural daily torpor in the mouse. However, they too noted peripheral tail vasodilatation associated with this DREADD-driven torpor-like state. Importantly, these oestrogen sensitive MPA neurons did not appear to respond to increased ambient temperature, indicating that they are not part of the thermal defence circuit (Morrison \& Nakamura, 2019).

\section{Towards a torpor circuit}

The data presented in the studies of Hrvatin, Takahashi, and Zhang represent significant advances in our understanding of torpor. From this data, a model that emerges is that glutamatergic neurons in the preoptic area, which express PACAP and/or Qrfp, and perhaps oestrogen receptors, generate torpor. The preoptic area is well-placed for the role attributed to it in this model. It is a key site involved in thermoregulation and energy balance, receiving information regarding the external environmental temperature as well as directly sensing hypothalamic temperature (Song et al., 2016), this information is then used to modulate BAT thermogenesis (Tan et al., 2016; Zhao et al., 2017).

Warm-sensing glutamatergic POA neurons also play a role in coordinating the parallel decrease in core temperature observed with the onset of NREM sleep (Harding et al., 2018). NREM sleep has several characteristics in common with torpor: it is a hypoactive, hypometabolic, bradycardic state, with maintained thermoregulation despite a reduced core body temperature (Glotzbach \& Heller, 1976; Heller \& Glotzbach, 1977; Kräuchi, 2007; Schwimmer et al., 2010). Supposing that torpor is induced by the same circuit that links reduced body temperature with NREM sleep onset, then the distinction between the two states might rest upon the degree to which these POA glutamatergic neurons are activated. This could be either in terms of firing frequency, or duration.

A drop in core temperature preceding sleep onset is also observed in humans (Campbell \& Broughton, 1994; Kräuchi, 2007; Landolt et al., 1995). Hence, glutamatergic neurons in the medial preoptic area might represent a common circuit that links NREM sleep onset, the core body temperature alterations associated with sleep, and torpor. In keeping with this hypothesis, Takahashi et al. (Takahashi et al., 2020) observed disrupted diurnal temperature variation in mice in which POA Qrfp neurotransmission was blocked. It would be very interesting to establish the degree of overlap between the POA glutamatergic neurons that drive NREM sleep and cooling as identified by Harding et al. (Harding et al., 2018), and the torpor-inducing neurons identified by Hrvatin et al., and Takahashi et al.

In order to contribute to torpor induction, POA circuits with a role in thermoregulation and sleep induction within the POA would need to also receive information regarding the nutritional status of the animal. Such information might come from circulating leptin, receptors for which are indeed found on hypothermia-inducing glutamatergic neurons in the POA (Yu et al., 2016).

The dorsomedial hypothalamus is also well-placed to contribute to torpor, and a projection from the POA to DMH is capable of driving reduced body temperature (Takahashi et al., 2020; Tan et al., 2016; Zhao et al., 2017). As well as playing a role in thermoregulation (Jeong et al., 2015; Liedtke, 2017; Zhao et al., 2017), the DMH also adjusts circadian rhythms based on the timing of food availability (Gooley et al., 2006). One might speculate that the dorsomedial hypothalamus integrates information about the availability and timing of food in order to optimise the timing of torpor, which is known to be under circadian control but can be adjusted according to food availability (van der Vinne et al., 2018).

This proposal that POA to DMH projections may be involved in torpor induction differs from the more established model of thermoregulation in several interesting ways (Saper \& Machado, 2020). Current understanding of homeostatic thermoregulation proposes that a predominantly GABAergic warm-sensing projection from the POA synapses on both GABAergic and glutamatergic neurons in the DMH (Tan et al., 2016; Zhao et al., 2017). Activation of either the glutamatergic or the GABAergic neurons in the $\mathrm{DMH}$ drives thermogenesis (Zhao et al., 2017). Hence, core temperature is determined by the balance between, on the one hand, the activity of DMH glutamatergic and GABAergic neurons, both of which drive thermogenesis, and on the other hand, the inhibitory input from the POA GABAergic neurons, which suppresses this thermogenic activity in the DMH (Figure 1). In contrast, the POA to $\mathrm{DMH}$ projection that has been implicated in torpor appears to involve predominantly glutamatergic neurons, which express PACAP and / or Qrfp (Hrvatin et al., 2020; Takahashi et al., 2020) (Figure 3). Activation of this presumably excitatory POA to DMH pathway may contribute to the hypothermia associated with torpor (Takahashi et al., 2020). The nature of the $\mathrm{DMH}$ neurons targeted by this projection is unknown, but they appear to have antagonistic effects to the populations of glutamatergic and GABAergic DMH neurons implicated in homeostatic thermoregulation (Zhao et al., 2017). That is to say, previously identified DMH neurons - be they glutamatergic or GABAergic - are thought to drive thermogenesis (Zhao et al., 2017), whereas the population targeted by the excitatory PACAP / Qrfp projection from the POA appear to induce hypothermia and torpor. One possibility is that these hypothermia-inducing DMH neurons are cholinergic (Jeong et al., 2015).

\section{Conclusions}

The field is gaining momentum as new techniques, particularly in the field of systems neuroscience, allow manipulation of the activity of specific hypothalamic neurons. There are, however, several outstanding questions. The lack of an agreed definition of torpor is problematic for the field. While a simple 


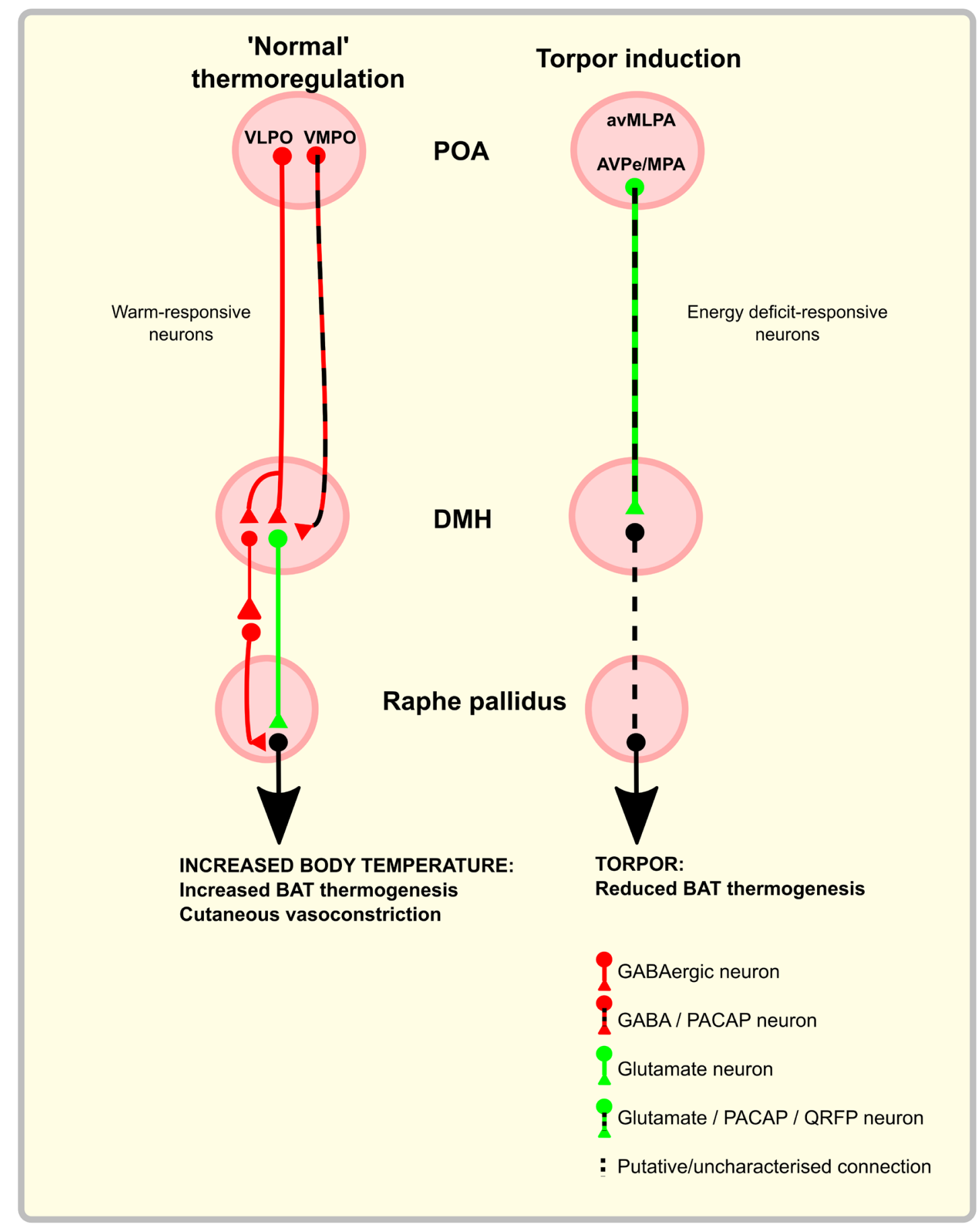

Figure 3. Schematic comparing thermoregulation with torpor induction pathways. The current thermoregulatory model (left) proposes predominantly GABAergic projections from POA to DMH. These GABAergic projections are activated by skin, viscera, or CNS warming and pyrogens. DMH contains both glutamatergic and GABAergic neurons, the activation of which causes increased BAT thermogenesis, vasoconstriction, and increased core temperature. The location of the second GABAergic neuron in the relay from DMH to raphe pallidus has not been established. The emerging model for torpor induction (right) suggests glutamatergic / PACAP / QRFP neurons project from POA to DMH. Similar to the effects of activating the GABAergic POA to DMH, activating this excitatory POA to DMH pathway reduces body temperature, and in this case, induces torpor. The nature of the $\mathrm{DMH}$ neurons that are activated by the excitatory POA to DMH projection remains unknown. Abbreviations: GABA, gamma-aminobutyric acid; POA, preoptic area; DMH, dorsomedial hypothalamic area; CNS, central nervous system; BAT, brown adipose tissue; PACAP, Pituitary adenylate-cyclase-activating polypeptide; QRFP, pyroglutamylated RFamide peptide (QRFP). 
threshold of core temperature has been used, this approach fails to account for the circadian fluctuations in body temperature and fails to distinguish torpor from pathological hypothermia induced by disturbances to normal thermoregulation. This approach also ignores the many additional characteristics of torpor such as active cardiorespiratory suppression, suppression of mitochondrial oxygen consumption, and behavioural changes.

We propose that there are two key features of torpor, which are relatively easily measured, and which might serve as a pragmatic proxy for identifying torpor: reduced body temperature with ongoing active thermoregulation such that a minimum (albeit adjusted) core temperature is defended; and controlled cardiovascular depression such that a characteristic heart rate versus body temperature hysteresis curve is observed (Vicent et al., 2017b).

Another outstanding question is whether daily torpor and seasonal hibernation are manifestations of the same process. While some groups argue that these are mechanistically distinct (Sunagawa \& Takahashi, 2016), this is not widely agreed. It is also unclear whether there exists a torpor 'master switch' capable of triggering the full spectrum of associated physiological adaptations, or whether several parallel regions detect the signal for torpor entry and independently trigger components of the response. While current evidence converges on the POA playing a key role (Hrvatin et al., 2020; Takahashi et al., 2020; Zhang et al., 2020), these studies have tended to focus on body temperature as a proxy for the more complex adaptations associated with natural torpor. If the POA does indeed contain the torpor master switch, whether a projection from here to the DMH (Takahashi et al., 2020) is sufficient for inducing all aspects of torpor is also unknown, and represents an important question.

Finally, although we are beginning to identify some of the neuronal circuits responsible for torpor entry, the mechanism that transduces the signal from deplete energy stores to the POA and wider central nervous system remains unknown. Possible candidates include leptin, ghrelin, NPY, and adenosine, but a necessary and sufficient role for any of these signals has not been demonstrated. Furthermore, we do not yet know whether a single mechanism induces and maintains torpor, with arousal occurring when that mechanism ceases to be engaged, or on the other hand, whether separate processes govern these different stages of torpor.

Better understanding of the characteristics or torpor and the neural and endocrine mechanisms that control it may pave the way to mimicking this intriguing physiological state in humans, with potentially profound applications in medicine (Aslami \& Juffermans, 2010; Lee, 2008; Stanzani et al., 2020) and long distance space travel (Cerri et al., 2021b) .

\section{Data availability}

No data are associated with this article.
Abreu-Vieira G, Xiao C, Gavrilova O, et al.: Integration of body temperature into the analysis of energy expenditure in the mouse. Mol Metab. Elsevier $\mathrm{GmbH}, 2015 ; 4(6)$ : 461-470.

PubMed Abstract | Publisher Full Text | Free Full Text

Ahima RS, Prabakaran D, Mantzoros C, et al: Role of leptin in the neuroendocrine response to fasting. Nature. 1996; 382(6588): 250-252. PubMed Abstract | Publisher Full Text

Alexander GM, Rogan SC, Abbas AI, et al.: Remote Control of Neuronal Activity in Transgenic Mice Expressing Evolved G Protein-Coupled Receptors. Neuron. 2009; 63(1): 27-39.

PubMed Abstract | Publisher Full Text | Free Full Text

Allen WE, DeNardo LA, Chen MZ, et al.: Thirst-associated preoptic neurons encode an aversive motivational drive. Science. Department of Biology, Stanford University, Stanford, CA 94305, USA., 2017; 357(6356): 1149-1155. PubMed Abstract | Publisher Full Text | Free Full Text

Andermann ML, Lowell BB: Toward a Wiring Diagram Understanding of Appetite Control. Neuron. 2017; 95(4): 757-778.

PubMed Abstract | Publisher Full Text | Free Full Text

Anderson R, Sheehan MJ, Strong P: Characterization of the adenosine receptors mediating hypothermia in the conscious mouse. $\mathrm{Br} J$ Pharmacol. 1994; 113(4): 1386-1390.

PubMed Abstract | Publisher Full Text | Free Full Text

Armbruster BN, Li X, Pausch MH, et al.: Evolving the lock to fit the key to create a family of $\mathrm{G}$ protein-coupled receptors potently activated by an inert ligand. Proc Natl Acad Sci U S A. 2007; 104(12): 5163-5168.

PubMed Abstract | Publisher Full Text | Free Full Text

Aslami H, Juffermans NP: Induction of a hypometabolic state during critical illness - a new concept in the ICU? Neth J Med. Laboratory of Experimental Intensive Care and Anesthesiology (L.E.I.C.A.), Academic Medical Centre, Amsterdam, the Netherlands. h.aslami@amc.uva.nl, 2010; 68(5): 190-198. PubMed Abstract

Atasoy D, Betley JN, Su HH, et al.: Deconstruction of a neural circuit for hunger. Nature. 2012; 488(7410): 172-177.

PubMed Abstract | Publisher Full Text | Free Full Text

Balthasar N, Dalgaard LT, Lee CE, et al.: Divergence of melanocortin pathways in the control of food intake and energy expenditure. Cell. 2005; 123(3): 493-505.

PubMed Abstract | Publisher Full Text

Barnes BM: Freeze avoidance in a mammal: body temperatures below $\mathbf{O}$ degree $\mathbf{C}$ in an Arctic hibernator. Science. 1989; 244(4912): 1593-1595. PubMed Abstract | Publisher Full Text

Bechtold DA, Sidibe A, Saer BRC, et al.: A role for the melatonin-related receptor GPR50 in leptin signaling, adaptive thermogenesis, and torpor. Curr Biol. University of Manchester, Manchester M13 9PT, UK. david.bechtold@ manchester.ac.uk: Elsevier, 2012; 22(1): 70-77.

PubMed Abstract | Publisher Full Text

Benarroch EE: Endogenous opioid systems: Current concepts and clinical correlations. Neurology. 2012; 79(8): 807-814.

PubMed Abstract | Publisher Full Text

Bergendahl M, Iranmanesh A, Evans WS, et al:: Short-term fasting selectively suppresses leptin pulse mass and 24-hour rhythmic leptin release in healthy midluteal phase women without disturbing leptin pulse frequency or its entropy control (pattern orderliness). J Clin Endocrinol Metab. 2000; 85(1): 207-213.

PubMed Abstract | Publisher Full Text

Berger RJ: Slow wave sleep, shallow torpor and hibernation: homologous states of diminished metabolism and body temperature. Biol Psychol. 1984 19(3-4): 305-326.

PubMed Abstract | Publisher Full Text

Bewick GA, Gardiner JV, Dhillo WS, et al.: Postembryonic ablation of AgRP neurons in mice leads to a lean, hypophagic phenotype. FASEB J. 2005; 19(12): 1680-1682.

PubMed Abstract | Publisher Full Text

Bi S, Robinson BM, Moran TH: Acute food deprivation and chronic food 
restriction differentially affect hypothalamic NPY mRNA expression. Am J Physiol Regul Integr Comp Physiol. 2003; 285(5): 1030-1036. PubMed Abstract | Publisher Full Text

Billington CJ, Briggs JE, Grace M, et al.: Effects of intracerebroventricular injection of neuropeptide Y on energy metabolism. Am J Physiol. 1991; 260(2 Pt 2): R321-7.

PubMed Abstract | Publisher Full Text

Bjorness TE, Dale N, Mettlach F, et al.: An adenosine-mediated glial-neuronal circuit for homeostatic sleep. J Neurosci. 2016; 36(13): 3709-3721.

PubMed Abstract | Publisher Full Text | Free Full Text

Bjorness TE, Kelly CL, Gao T, et al.: Control and function of the homeostatic sleep response by adenosine A1 receptors. J Neurosci. 2009; 29(5): 1267-1276. PubMed Abstract | Publisher Full Text | Free Full Text

Blood AB, Hunter CJ, Power GG: Adenosine mediates decreased cerebral metabolic rate and increased cerebral flow during acute moderate hypoxia in the near-term fetal sheep. J Physiol. 2003; 553(Pt 3): 935-945.

PubMed Abstract | Publisher Full Text | Free Full Text

Borbély AA, Daan S, Wirz-Justice A, et al.: The two-process model of sleep regulation: A reappraisal. J Sleep Res. 2016; 25(2): 131-143.

PubMed Abstract | Publisher Full Text

Boulant JA, Hardy JD: The effect of spinal and skin temperatures on the firing rate and thermosensitivity of preoptic neurones.J Physiol. 1974; 240(3): 639-660

PubMed Abstract | Publisher Full Text | Free Full Text

Bratincsák A, McMullen D, Miyake $S$, et al:: Spatial and temporal activation of brain regions in hibernation: c-fos expression during the hibernation bout in thirteen-lined ground squirrel. J Comp Neurol. 2007; 505(4): 443-458. PubMed Abstract | Publisher Full Text | Free Full Text

Braulke LJ, Heldmaier G: Torpor and ultradian rhythms require an intact signalling of the sympathetic nervous system. Cryobiology. Elsevier Inc., 2010; 60(2): 198-203.

PubMed Abstract | Publisher Full Text

Brown JCL, Staples JF: Mitochondrial metabolism during fasting-induced daily torpor in mice. Biochim Biophys Acta. Elsevier B.V., 2010; 1797(4): 476-486. PubMed Abstract | Publisher Full Text

Bunnell DE, Agnew JA, Horvath SM, et al.: Passive body heating and sleep: Influence of proximity to sleep. Sleep. 1988; 11(2): 210-219.

PubMed Abstract | Publisher Full Text

Campbell SS, Broughton RJ: Rapid Decline in Body Temperature Before Sleep: Fluffing the Physiological Pillow? Chronobiol Int. 1994; 11(2): 126-131. PubMed Abstract | Publisher Full Tex

Cao WH, Fan W, Morrison SF: Medullary pathways mediating specific sympathetic responses to activation of dorsomedial hypothalamus. Neuroscience. 2004; 126(1): 229-240.

PubMed Abstract | Publisher Full Text

Carey HV, Andrews MT, Martin SL: Mammalian Hibernation: Cellular and Molecular Responses to Depressed Metabolism and Low Temperature. Physiol Rev. 2003; 83(4): 1153-1181.

PubMed Abstract | Publisher Full Text

Carlin JL, Jain S, Gizewski E, et al.: Hypothermia in mouse is caused by adenosine $A_{1}$ and $A_{3}$ receptor agonists and AMP via three distinct mechanisms. Neuropharmacology. 2017; 114: 101-113.

PubMed Abstract | Publisher Full Text | Free Full Text

Cerri M: The Central Control of Energy Expenditure: Exploiting Torpor for

Medical Applications. Annu Rev Physiol. 2017; 79(1): 167-186.

PubMed Abstract | Publisher Full Text

Cerri M, Hitrec T, Luppi M, et al.: Be cool to be far: Exploiting hibernation for space exploration. Neurosci Biobehav Rev. Elsevier Ltd, 2021a; 128: 218-232. PubMed Abstract | Publisher Full Text

Cerri M, Hitrec T, Luppi M, et al.: Be cool to be far: Exploiting hibernation for space exploration. Neurosci Biobehav Rev. Elsevier Ltd, 2021b; 128: 218-232. PubMed Abstract | Publisher Full Text

Cerri M, Mastrotto M, Tupone $\mathrm{D}$, et al.: The inhibition of neurons in the central nervous pathways for thermoregulatory cold defense induces a suspended animation state in the rat. J Neurosci. Department of Biomedical and NeuroMotor Sciences, Alma Mater Studiorum-University of Bologna, 40126 Bologna Italy. matteo.cerri@unibo.it, 2013; 33(7): 2984-2993.

PubMed Abstract | Publisher Full Text | Free Full Text

Chao PT, Yang L, Aja S, et al.: Knockdown of NPY Expression in the Dorsomedial Hypothalamus Promotes Development of Brown Adipocytes and Prevents Diet-Induced Obesity. Cell Metab. 2011; 13(5): 573-583. PubMed Abstract | Publisher Full Text | Free Full Text

Chen Y, Lin YC, Kuo TW, et al.: Sensory Detection of Food Rapidly Modulates Arcuate Feeding Circuits. Cell. Elsevier Inc., 2015; 160(5): 829-841.

PubMed Abstract | Publisher Full Text | Free Full Text

Chronwall BM, DiMaggio DA, Massari VJ, et al.: The anatomy of neuropeptidey-containing neurons in rat brain. Neuroscience. 1985; 15(4): 1159-1181. PubMed Abstract | Publisher Full Text

Clark G, Magoun HW, Ranson SW: HYPOTHALAMIC REGULATION OF BODY TEMPERATURE. J Neurophysiol. 1939a; 2(1): 61-80. Publisher Full Text

Clark G, Magoun HW, Ranson SW: HYPOTHALAMIC REGULATION OF BODY TEMPERATURE. / Neurophysiol. 1939b; 2(1): 61-80.

Publisher Full Text
Commins SP, Marsh DJ, Thomas SA, et al.: Norepinephrine is required for leptin effects on gene expression in brown and white adipose tissue. Endocrinology. 1999; 140(10): 4772-4778.

PubMed Abstract | Publisher Full Text

Cone RD: Anatomy and regulation of the central melanocortin system. Nat Neurosci. 2005; 8(5): 571-578.

PubMed Abstract | Publisher Full Text

Cowley MA, Smart JL, Rubinstein M, et al: : Leptin activates anorexigenic POMC neurons through a neural network in the arcuate nucleus. Nature. 2001; 411(6836): 480-484.

PubMed Abstract | Publisher Full Text

Cowley MA, Smith RG, Diano S, et al.: The Distribution and Mechanism of Action of Ghrelin in the CNS Demonstrates a Novel Hypothalamic Circuit Regulating Energy Homeostasis. Neuron. 2003; 37(4): 649-661.

PubMed Abstract | Publisher Full Text

Cubuk C, Markowsky H, Herwig A: Hypothalamic control systems show differential gene expression during spontaneous daily torpor and fasting induced torpor in the Djungarian hamster (Phodopus sungorus). PLoS One. 2017: 12(10): e0186299.

PubMed Abstract | Publisher Full Text | Free Full Text

Cunha RA: Neuroprotection by adenosine in the brain: From $A(1)$ receptor activation to A (2A) receptor blockade. Purinergic Signal. 2005; 1(2): 111-134. PubMed Abstract | Publisher Full Text | Free Full Text

Dark J, Pelz KM: NPY Y1 receptor antagonist prevents NPY-induced torporlike hypothermia in cold-acclimated Siberian hamsters. Am J Physiol Regul Integr Comp Physiol. 2008; 294(1): R236-245.

PubMed Abstract | Publisher Full Text

Dawe AR, Spurrier WA: Hibernation induced in ground squirrels by blood transfusion. Science. 1969; 163(3864): 298-299.

PubMed Abstract | Publisher Full Text

de Castro JM: Seasonal rhythms of human nutrient intake and meal pattern. Physiol Behav. 1991; 50(1): 243-248.

PubMed Abstract | Publisher Full Text

DeNardo LA, Liu CD, Allen WE, et al.: Temporal evolution of cortical ensembles promoting remote memory retrieval. Nat Neurosci. 2019; 22(3): 460-469.

PubMed Abstract | Publisher Full Text | Free Full Text

DiMicco JA, Zaretsky DV: The dorsomedial hypothalamus: A new player in thermoregulation. Am J Physiol Regul Integr Comp Physiol. 2007; 292(1): R47-63. PubMed Abstract | Publisher Full Text

Dodd GT, Decherf S, Loh K, et al.: Leptin and Insulin Act on POMC Neurons to Promote the Browning of White Fat. Cell. 2015; 160(1-2): 88-104.

PubMed Abstract | Publisher Full Text | Free Full Text

Duffy PH, Feuers RJ, Leakey JA, et al.: Effect of chronic caloric restriction on physiological variables related to energy metabolism in the male Fischer

344 rat. Mech Ageing Dev. 1989; 48(2): 117-133.

PubMed Abstract | Publisher Full Text

Egawa M, Yoshimatsu H, Bray GA: Neuropeptide Y suppresses sympathetic activity to interscapular brown adipose tissue in rats. Am J Physiol. 1991;

260(2 Pt 2): R328-34.

PubMed Abstract | Publisher Full Text

Elmquist JK, Elias CF, Saper CB: From lesions to leptin: Hypothalamic contro of food intake and body weight. Neuron. 1999; 22(2): 221-232.

PubMed Abstract | Publisher Full Text

Elvert R, Heldmaier G: Cardiorespiratory and metabolic reactions during entrance into torpor in dormice, Glis glis. J Exp Biol. 2005; 208(Pt 7):

1373-1383.

PubMed Abstract | Publisher Full Text

Faherty SL, Villanueva-Cañas JL, Klopfer PH, et al.: Gene Expression Profiling in the Hibernating Primate, Cheirogaleus Medius. Genome Biol Evol. Oxford University Press, 2016; 8(8): 2413-26.

PubMed Abstract | Publisher Full Text | Free Full Text

Florant GL, Heller HC: CNS regulation of body temperature in euthermic and hibernating marmots (Marmota flaviventris). Am J Physiol. 1977; 232(5): R203-8.

PubMed Abstract | Publisher Full Text

Frederich RC, Hamann A, Anderson S, et al.: Leptin levels reflect body lipid content in mice: Evidence for diet-induced resistance to leptin action. Nat Med. 1995; 1(12): 1311-1314.

PubMed Abstract | Publisher Full Text

Freeman DA, Lewis DA, Kauffman AS, et al:: Reduced leptin concentrations are permissive for display of torpor in Siberian hamsters. Am J Physiol Regul Integr Comp Physiol. 2004; 87(1): 97-103.

PubMed Abstract | Publisher Full Tex

Futatsuki T, Yamashita A, Ikbar KN, et al.: Involvement of orexin neurons in fasting- and central adenosine-induced hypothermia. Sci Rep. Springer US. 2018; 8(1): 2717 .

PubMed Abstract | Publisher Full Text | Free Full Text

Gavrilova O, Leon LR, Marcus-Samuels B, et al.: Torpor in mice is induced by both leptin-dependent and -independent mechanisms. Proc Natl Acad SCI U S A. Diabetes Branch, National Institute of Diabetes and Digestive and Kidney Diseases, National Institutes of Health, Bethesda, MD 20892, USA.: National

Academy of Sciences, 1999; 96(25): 14623-14628.

PubMed Abstract | Publisher Full Text | Free Full Text 
Geiser F, Currie SE, O'Shea KA, et al.: Torpor and hypothermia: reversed hysteresis of metabolic rate and body temperature. Am J Physiol Regul Integr Comp Physiol. 2014; 307(11): R1324-R1329.

PubMed Abstract | Publisher Full Text

Geiser F, Körtner G, Schmidt I: Leptin increases energy expenditure of a marsupial by inhibition of daily torpor. Am J Physiol. 1998; 275(5): 1627-1632. PubMed Abstract | Publisher Full Text

Geschickter EH, Andrews PA, Bullard RW: Nocturnal body temperature regulation in man: a rationale for sweating in sleep. J Appl Physiol. 1966; 21(2): 623-630.

PubMed Abstract | Publisher Full Text

Glotzbach SF, Heller HC: Central nervous regulation of body temperature during sleep. Science. 1976; 194(4264): 537-539.

PubMed Abstract | Publisher Full Text

Gluck EF, Stephens N, Swoap SJ: Peripheral ghrelin deepens torpor bouts in mice through the arcuate nucleus neuropeptide $Y$ signaling pathway. $A m$ Physiol Regul Integr Comp Physiol. 2006; 291(5): R1303-9.

PubMed Abstract | Publisher Full Text

Gooley IJ, Schomer A, Saper CB: The dorsomedial hypothalamic nucleus is critical for the expression of food-entrainable circadian rhythms. Nat Neurosci. 2006; 9(3): 398-407.

PubMed Abstract | Publisher Full Text

Gropp E, Shanabrough M, Borok E, et al.: Agouti-related peptide-expressing neurons are mandatory for feeding. Nat Neurosci. 2005; 8(10): 1289-1291. PubMed Abstract | Publisher Full Text

Hahn TM, Breininger JF, Baskin DG, et al.: Coexpression of Agrp and NPY in fasting-activated hypothalamic neurons. Nat Neurosci. 1998; 1(4): 271-272. PubMed Abstract | Publisher Full Text

Hammel HT, Pierce JB: Regulation of Internal Body Temperature. Annu Rev Physiol. 1968; 30(1): 641-710.

PubMed Abstract | Publisher Full Text

Harding EC, Franks NP, Wisden W: The temperature dependence of sleep. Front Neurosci. 2019; 13: 336.

PubMed Abstract | Publisher Full Text | Free Full Text

Harding EC, Yu X, Miao A, et al:: A Neuronal Hub Binding Sleep Initiation and Body Cooling in Response to a Warm External Stimulus. Curr Biol. Elsevier Ltd., 2018; 28(14): 2263-2273.e4.

PubMed Abstract | Publisher Full Text | Free Full Text

Heldmaier $\mathrm{G}$, Klingenspor M, Werneyer M, et al.: Metabolic adjustments during daily torpor in the Djungarian hamster. Am J Physiol. 1999; 276(5). PubMed Abstract | Publisher Full Text

Heldmaier G, Ortmann S, Elvert R: Natural hypometabolism during

hibernation and daily torpor in mammals. Respir Physiol Neurobiol. 2004;

141(3): 317-329.

PubMed Abstract | Publisher Full Text

Heller HC, Glotzbach SF: Thermoregulation during sleep and hibernation. Int Rev Physiol. 1977; 15: 147-88.

PubMed Abstract

Himms-Hagen J: Food restriction increases torpor and improves brown adipose tissue thermogenesis in ob/ob mice. Am J Physiol. 1985; 248(5 Pt 1): E531-9.

PubMed Abstract | Publisher Full Text

Hitrec T, Luppi M, Bastianini S, et al.: Neural control of fasting-induced torpor in mice. Sci Rep. Springer US. 2019; 9(1): 15462.

PubMed Abstract | Publisher Full Text | Free Full Text

Hrvatin S, Sun S, Wilcox OF, et al.: Neurons that regulate mouse torpor.

Nature. Springer US. 2020; 583(7814): 115-121.

PubMed Abstract | Publisher Full Text | Free Full Text

Hudson JW, Scott IM: Daily Torpor in the Laboratory Mouse, Mus musculus

Var. Albino. 1Physiological zoology. 1979; 52(2): 205-218.

Publisher Full Text

Iliff BW, Swoap S]: Central adenosine receptor signaling is necessary for daily torpor in mice. Am J Physiol Regul Integr Comp Physiol. Department of Biology, Williams College, Williamstown, MA 01267, USA., 2012; 303(5): R477-84

PubMed Abstract | Publisher Full Text

Jeong JH, Lee DK, Blouet $\mathrm{C}$, et al.: Cholinergic neurons in the dorsomedial hypothalamus regulate mouse brown adipose tissue metabolism. Molecular Metabolism. Elsevier GmbH, 2015; 4(6): 483-492.

PubMed Abstract | Publisher Full Text | Free Full Text

Jeong JH, Lee DK, Jo YH: Cholinergic neurons in the dorsomedial hypothalamus regulate food intake. Mol Metab. Elsevier GmbH, 2017; 6(3): 306-312.

PubMed Abstract | Publisher Full Text | Free Full Text

Jinka TR, Carlson ZA, Moore JT, et al: Altered thermoregulation via sensitization of $A$ adenosine receptors in dietary-restricted rats. Psychopharmacology (Berl). 2010; 209(3): 217-224.

PubMed Abstract | Publisher Full Text | Free Full Text

Jinka TR, Tøien O, Drew KL: Season primes the brain in an arctic hibernator to facilitate entrance into torpor mediated by adenosine $A(1)$ receptors. I Neurosci. 2011; 31(30): 10752-10758.

PubMed Abstract | Publisher Full Text | Free Full Text

Jolicoeur FB, Bouali SM, Fournier A, et al.: Mapping of hypothalamic sites involved in the effects of NPY on body temperature and food intake. Brain
Res Bull. 1995; 36(2): 125-129.

PubMed Abstract | Publisher Full Text

Kaiyala KJ, Morton GJ, Thaler JP, et al.: Acutely decreased thermoregulatory energy expenditure or decreased activity energy expenditure both acutely reduce food intake in mice. PLoS One. 2012; 7(8): e41473.

PubMed Abstract | Publisher Full Text | Free Full Text

Kaiyala KJ, Ogimoto K, Nelson JT, et al.: Leptin Signaling Is Required for Adaptive Changes in Food Intake, but Not Energy Expenditure, in Response to Different Thermal Conditions. PLOS One. Edited by J. A. Chowen, 2015; 10(3): e0119391.

PubMed Abstract | Publisher Full Text | Free Full Text

Kataoka N, Hioki H, Kaneko T, et al.: Psychological stress activates a dorsomedial hypothalamus-medullary raphe circuit driving brown adipose tissue thermogenesis and hyperthermia. Cell Metab. Elsevier Inc., 2014; 20(2): 346-358.

PubMed Abstract | Publisher Full Text

Kato GA, Sakamoto SH, Eto T, et al.: Individual differences in torpor expression in adult mice are related to relative birth mass. J Exp Biol. 2018; 221(Pt 12): jeb171983.

PubMed Abstract | Publisher Full Text

King PJ, Widdowson PS, Doods HN, et al.: Regulation of neuropeptide $Y$ release by neuropeptide $Y$ receptor ligands and calcium channel antagonists in hypothalamic slices. J Neurochem. 1999; 73(2): 641-646. PubMed Abstract | Publisher Full Text

Kräuchi K: The thermophysiological cascade leading to sleep initiation in relation to phase of entrainment. Sleep medicine reviews. Centre for Chronobiolgy, Psychiatric University Clinics, Wilhelm Klein Strasse 27, 4025 Basel, Switzerland. kurt.kraeuchi@upkbs.ch, 2007: 11(6): 439-451.

PubMed Abstract | Publisher Full Text

Kräuchi K, Cajochen C, Werth E, et al.: Warm feet promote the rapid onset of sleep. Nature. 1999; 401(6748): 36-37.

PubMed Abstract | Publisher Full Text

Kräuchi K, Cajochen C, Werth E, et al.: Functional link between distal vasodilation and sleep-onset latency? Am J Physiol Regul Integr Comp Physiol. 2000; 278(3): 741-748.

PubMed Abstract | Publisher Full Text

Kroeger D, Absi G, Gagliardi C, et al.: Galanin neurons in the ventrolateral preoptic area promote sleep and heat loss in mice. Nat Commun. 2018; 9(1): 4129.

PubMed Abstract | Publisher Full Text | Free Full Text

Landolt HP, Moser S, Wieser HG, et al.: Intracranial temperature across 24hour sleep-wake cycles in humans. Neuroreport. England, 1995; 6(6): 913-917. PubMed Abstract | Publisher Full Text

Larkin JE, Heller HC: Temperature sensitivity of sleep homeostasis during hibernation in the golden-mantled ground squirrel. Am J Physiol. 1996; 270(4 Pt 2): R777-84.

PubMed Abstract | Publisher Full Text

Lee CC: Is human hibernation possible? Annu Rev Med. Department of Biochemistry and Molecular Biology, University of Texas Health Science Center, Houston, Texas 77030, USA. cheng.c.lee@uth.tmc.edu: Annual Reviews, 2008; 59(1): 177-186.

PubMed Abstract | Publisher Full Text

Liedtke WB: Deconstructing mammalian thermoregulation. Proc Natl Acad Sci U S A. Department of Neurology, Duke University School of Medicine, Durham, NC 27710; wolfgang@neuro.duke.edu., 2017; 114(8): 1765-1767. PubMed Abstract | Publisher Full Text | Free Full Text

Lo Martire V, Silvani A, Bastianini S, et al.: Effects of Ambient Temperature on Sleep and Cardiovascular Regulation in Mice: The Role of Hypocretin/ Orexin Neurons. PLoS One. 2012; 7(10): e47032.

PubMed Abstract | Publisher Full Text | Free Full Text

Lo Martire V, Valli A, Bingaman MJ, et al.: Changes in blood glucose as a function of body temperature in laboratory mice: implications for daily torpor. Am J Physiol Endocrinol Metab. 2018; 315(4): E662-E670.

PubMed Abstract | Publisher Full Text | Free Full Text

Lumpkin EA, Caterina MJ: Mechanisms of sensory transduction in the skin. Nature. 2007; 445(7130): 858-865.

PubMed Abstract | Publisher Full Text

Luquet S, Perez FA, Hnasko TS et al.: NPY/AgRP Neurons Are Essential for Feeding in Adult Mice but Can Be Ablated in Neonates. Science. 2005; 310(5748): 683-685.

PubMed Abstract | Publisher Full Text

Ma Y, Miracca G, Harding EC, et al.: Galanin Neurons Unite Sleep Homeostasis and a 2-Adrenergic Sedation. Curr Biol. Elsevier Ltd., 2019; 29(19): 3315-3322.e3.

PubMed Abstract | Publisher Full Text | Free Full Text

Ma YL, Zhu X, Rivera PM, et al:: Absence of cellular stress in brain after hypoxia induced by arousal from hibernation in Arctic ground squirrels Am J Physiol Regul Integr Comp Physiol. 2005; 289(5): R1297-R1306. PubMed Abstract | Publisher Full Text

Madsen PL, Schmidt JF, Wildschiødtz G, et al.: Cerebral 02 metabolism and cerebral blood flow in humans during deep and rapid-eye-movement sleep. J Appl Physiol (1985). 1991; 70(6): 2597-2601.

PubMed Abstract | Publisher Full Text

Magoun HW, Harrison F, Brobeck JR, et al.: ACTIVATION OF HEAT LOSS 
MECHANISMS BY LOCAL HEATING OF THE BRAIN. J Neurophysiol. 1938; 1(2): 101-114. Publisher Full Text

Malan A: pH and hypometabolism in mammalian hibernation. Can J Zool. 1988; 66(1): 95-98. Publisher Full Text

Malan A, Rodeau JL, Daull F: Intracellular pH in hibernation and respiratory acidosis in the European hamster. J Comp Physiol B. 1985; 156(2): 251-258. PubMed Abstract | Publisher Full Text

McAllen RM, Tanaka M, Ootsuka Y, et al.: Multiple thermoregulatory effectors with independent central controls. Eur J Appl Physiol. 2010; 109(1): 27-33. PubMed Abstract | Publisher Full Text

McGinty D, Szymusiak R: Keeping cool: a hypothesis about the mechanisms and functions of slow-wave sleep. Trends Neurosci. 1990; 13(12): 480-487. PubMed Abstract | Publisher Full Text

Mistry AM, Swick AG, Romsos DR: Leptin Rapidly Lowers Food Intake and Elevates Metabolic Rates in Lean and ob/ob Mice. J Nutr. 1997: 127(10): 2065-2072.

PubMed Abstract | Publisher Full Text

Mochizuki T, Klerman EB, Sakurai T, et al.: Elevated body temperature during sleep in orexin knockout mice. Am J Physiol Regul Integr Comp Physiol. 2006; 291(3): R533-40.

PubMed Abstract | Publisher Full Text | Free Full Text

Morrison SF: Central control of body temperature [version 1; peer review: 3 approved]. F1000Res. 2016a; 5: F1000 Faculty Rev-880.

PubMed Abstract | Publisher Full Text | Free Full Text

Morrison SF: Central neural control of thermoregulation and brown

adipose tissue. Auton Neurosci. Department of Neurological Surgery, Oregon

Health \& Science University, Portland, OR 97239, Unites States. Electronic

address: morrisos@ohsu.edu.,2016b; 196: 14-24.

PubMed Abstract | Publisher Full Text | Free Full Text

Morrison SF, Madden CJ, Tupone D: Central Control of Brown Adipose Tissue

Thermogenesis. Front Endocrinol (Lausanne). 2012; 3(5): 5.

PubMed Abstract | Publisher Full Text | Free Full Text

Morrison SF, Nakamura K: Central Mechanisms for Thermoregulation. Annu Rev Physiol. Annual Reviews Inc., 2019; 81: 285-308.

PubMed Abstract | Publisher Full Text

Müller TD, Nogueiras R, Andermann ML, et al.: Ghrelin. Mol Metab. 2015; 4(6): 437-460.

PubMed Abstract | Publisher Full Text | Free Full Text

Myers MG, Cowley MA, Munzberg H: Mechanisms of Leptin Action and Leptin Resistance. Annu Rev Physiol. 2008; 70: 537-556.

PubMed Abstract | Publisher Full Text

Mzilikazi N, Lovegrove BG: Reproductive activity influences

thermoregulation and torpor in pouched mice, Saccostomus campestris.

J Comp Physiol B. 2002; 172(1): 7-16.

PubMed Abstract | Publisher Full Text

Nakayama T, Eisenman JS, Hardy JD: Single Unit Activity of Anterior

Hypothalamus during Local Heating. Science. 1961; 134(3478): 560-561.

PubMed Abstract | Publisher Full Text

Nakamura K, Morrison SF: A thermosensory pathway that controls body

temperature. Nat Neurosci. 2008; 11(1): 62-71.

PubMed Abstract | Publisher Full Text | Free Full Text

Nakamura K, Morrison SF: A thermosensory pathway mediating heat-

defense responses. Proc Natl Acad Sci U S A. 2010; 107(19): 8848-8853.

PubMed Abstract | Publisher Full Text | Free Full Text

Newby AC: Adenosine and the concept of "retaliatory metabolites". Trends

Biochem Sci. 1984; 9(2): 42-44.

Publisher Full Text

Nicholls DG, Rial E: A history of the first uncoupling protein, UCP1. J Bioenerg Biomembr. 1999: 31(5): 399-406.

PubMed Abstract | Publisher Full Tex

Oelkrug R, Heldmaier G, Meyer CW: Torpor patterns, arousal rates, and temporal organization of torpor entry in wildtype and UCP1-ablated mice.

J Comp Physiol B. 2010; 181(1): 137-145.

PubMed Abstract | Publisher Full Text

Oeltgen PR, Nilekani SP, Nuchols PA, et al.: Further studies on opioids and

hibernation: Delta opioid receptor ligand selectively induced hibernation

in summer-active ground squirrels. Life Sci. 1988; 43(19): 1565-1574.

PubMed Abstract | Publisher Full Text

Okamoto K, Yamasaki M, Takao K, et al.: QRFP-Deficient mice are hypophagic,

lean, hypoactive and exhibit increased anxiety-Like behavior. PLOS One.

2016; 11(11): e0164716.

PubMed Abstract | Publisher Full Text | Free Full Text

Panneton WM: The mammalian diving response: an enigmatic reflex to preserve life? Physiology (Bethesda). American Physiological Society, 2013; 28(5): 284-97.

PubMed Abstract | Publisher Full Text | Free Full Text

Parmeggiani PL, Rabini C: Shivering and panting during sleep. Brain Res. 1967; 6(4): 789-791.

PubMed Abstract | Publisher Full Text

Paton JFR, Boscan P, Pickering AE, et al.: The yin and yang of cardiac autonomic control: Vago-sympathetic interactions revisited. Brain Res Brain Res Rev. 2005; 49(3): 555-565.

PubMed Abstract | Publisher Full Tex

Paul MJ, Freeman DA, Park JH, et al:: Neuropeptide $Y$ induces torpor-like

hypothermia in Siberian hamsters. Brain Res. 2005: 1055(1-2): 83-92. PubMed Abstract | Publisher Full Text

Paul MJ, Kauffman AS, Zucker I: Feeding Schedule Controls Circadian Timing of Daily Torpor in SCN-Ablated Siberian Hamsters. J Biol Rhythms. 2004; 19(3): 226-237.

PubMed Abstract | Publisher Full Text

Ravussin Y, Xiao C, Gavrilova O, et al.: Effect of intermittent cold exposure on brown fat activation, obesity, and energy Homeostasis in mice. PLoS One.

2014; 9(1): e85876.

PubMed Abstract | Publisher Full Text | Free Full Text

Rawls SM, Benamar K: Effects of opioids, cannabinoids, and vanilloids on

body temperature. Front Biosci (Schol Ed). 2011; 3S(3): 822-845.

PubMed Abstract | Publisher Full Text | Free Full Text

Reichmann F, Holzer P: Europe PMC Funders Group Neuropeptide Y: A

stressful review. Neuropeptides. 2016; 55: 99-109.

PubMed Abstract | Publisher Full Text | Free Full Text

Rezai-Zadeh K, Yu S, Jiang Y, et al.: Leptin receptor neurons in the

dorsomedial hypothalamus are key regulators of energy expenditure and

body weight, but not food intake. Mol Metab. Elsevier, 2014; 3(7): 681-93.

PubMed Abstract | Publisher Full Text | Free Full Text

Romeijn N, Raymann RJEM, Møst E, et al.: Sleep, vigilance, and

thermosensitivity. Pflugers Arch. 2012; 463(1): 169-176.

PubMed Abstract | Publisher Full Text | Free Full Text

Rothwell NJ, Stock MJ: A role for brown adipose tissue in diet-induced

thermogenesis. Obes Res. 1997; 5(6): 650-6.

PubMed Abstract | Publisher Full Text

Sagar SM, Sharp FR, Curran T: Expression of c-fos protein in brain: metabolic mapping at the cellular level. Science. 1988; 240(4857): 1328-1331.

PubMed Abstract | Publisher Full Text

Saper CB, Machado NLS: Flipping the switch on the body's

thermoregulatory system. Nature. 2020; 583(7814): 34-35.

PubMed Abstract | Publisher Full Text

Schubert KA, Boerema AS, Vaanholt LM, et al.: Daily torpor in mice: high

foraging costs trigger energy-saving hypothermia. Biol Lett. Departmen

of Behavioural Biology, Centre for Behaviour and Neurosciences, University

of Groningen, PO Box 14, 9750 Haren, The Netherlands. k.a.schubert@rug.nl,

2010; 6(1): 132-135.

PubMed Abstract | Publisher Full Text | Free Full Text

Schwartz MW, Peskind E, Raskind M, et al.: Cerebrospinal fluid leptin levels: Relationship to plasma levels and to adiposity in humans. Nat Med. 1996; 2(5): 589-593.

PubMed Abstract | Publisher Full Text

Schwimmer H, Stauss HM, Abboud F, et al.: Effects of sleep on the

cardiovascular and thermoregulatory systems: a possible role for

hypocretins. J Appl Physiol (1985). 2010; 109(4): 1053-1063.

PubMed Abstract | Publisher Full Text | Free Full Text

Seydoux J, Assimacopoulos-Jeannet F, Jeanrenaud B, et al.: Alterations of

Brown Adipose Tissue in Genetically Obese (ob/ob) Mice. I. Demonstration of Loss of Metabolic Response to Nerve Stimulation and Catecholamines and Its Partial Recovery after Fasting or Cold Adaptation. Endocrinology.

1982; 110(2): 432-438.

PubMed Abstract | Publisher Full Text

Sherin JE, Shiromani PJ, McCarley RW, et al.: Activation of ventrolateral

preoptic neurons during sleep. Science. 1996; 271(5246): 216-9.

PubMed Abstract | Publisher Full Text

Shryock JC, Belardinelli L: Adenosine and adenosine receptors in the cardiovascular system: Biochemistry, physiology, and pharmacology. Am Cardiol. 1997; 79(12A): 2-10.

PubMed Abstract | Publisher Full Text

Silvani A, Cerri M, Zoccoli G, et al.: Is adenosine action common ground for nrem sleep, torpor, and other hypometabolic states? Physiology (Bethesda). 2018; 33(3): 182-196.

PubMed Abstract | Publisher Full Text | Free Full Text

Soare A, Cangemi R, Omodei $\mathrm{D}$, et al.: Long-term calorie restriction, but not endurance exercise, lowers core body temperature in humans. Aging (Albany NY). 2011; 3(4): 374-379.

PubMed Abstract | Publisher Full Text | Free Full Text

Solymár M, Pétervári E, Balaskó M, et al.: The onset of daily torpor is

regulated by the same low body mass in lean mice and in mice with dietinduced obesity. Temperature (Austin). 2015; 2(1): 129-134.

PubMed Abstract | Publisher Full Text | Free Full Text

Song $\mathrm{K}$, Wang $\mathrm{H}$, Wang GB, et al.: The TRPM2 channel is a hypothalamic heat sensor that limits fever and can drive hypothermia. Science. Department

of Pharmacology, University of Heidelberg, Im Neuenheimer Feld 366, 69120

Heidelberg, Germany., 2016; 353(6306): 1393-1398.

PubMed Abstract | Publisher Full Text

Srere HK, Wang LCH, Martin SL: Central role for differential gene expression in mammalian hibernation. Proc Natl Acad Sci US A. 1992; 89(15): 7119-7123. PubMed Abstract | Publisher Full Text | Free Full Text

Stær-Jensen $\mathrm{H}$, Sunde $\mathrm{K}$, Olasveengen TM, et al.: Bradycardia during 
therapeutic hypothermia is associated with good neurologic outcome in comatose survivors of out-of-hospital cardiac arrest. Crit Care Med. 2014; 42(11): 2401-2408.

PubMed Abstract | Publisher Full Text

Stanzani G, Tidswell R, Singer M: Do critical care patients hibernate? Theoretical support for less is more. Intensive Care Med. Springer Berlin Heidelberg, 2020; 46(3): 495-497.

PubMed Abstract | Publisher Full Text

Stenberg $D$, Litonius $E$, Halldner $L$, et al.: Sleep and its homeostatic regulation in mice lacking the adenosine A receptor.J Sleep Res. 2003; 12(4): 283-290. PubMed Abstract | Publisher Full Text

Sunagawa GA, Takahashi M: Hypometabolism during Daily Torpor in Mice is Dominated by Reduction in the Sensitivity of the Thermoregulatory System. Sci Rep. Laboratory for Retinal Regeneration, RIKEN Center for Developmental Biology, 2-2-3 Minatojimaminami-machi, Chuo-ku, Kobe, Hyogo 650-0047, Japan., 2016; 6(1): 37011.

PubMed Abstract | Publisher Full Text | Free Full Text

Swoap SJ, Gutilla MJ: Cardiovascular changes during daily torpor in the laboratory mouse. Am J Physiol Regul Integr Comp Physiol. Dept. of Biology, Williams College, Williamstown, MA 01267, USA. sswoap@williams.edu, 2009; 297(3): R769-74.

PubMed Abstract | Publisher Full Text | Free Full Text

Swoap SJ, Gutilla MJ, Liles LC, et al.: The full expression of fasting-induced torpor requires beta 3-adrenergic receptor signaling.J Neurosci. Department of Biology, Williams College, Williamstown, Massachusetts 01267, USA. sswoap@williams.edu: Society for Neuroscience, 2006; 26(1): 241-245. PubMed Abstract | Publisher Full Text | Free Full Text

Swoap SJ, Weinshenker D: Norepinephrine controls both torpor initiation and emergence via distinct mechanisms in the mouse. PLOS One. Edited by A. Bartolomucci. Department of Biology, Williams College, Williamstown, Massachusetts, United States of America. sswoap@williams.edu: Public Library of Science, 2008; 3(12): e4038.

PubMed Abstract | Publisher Full Text | Free Full Text

Takahashi TM, Sunagawa GA, Soya S, et al:: A discrete neuronal circuit induces a hibernation-like state in rodents. Nature. Springer US, 2020; 583(7814): 109-114.

PubMed Abstract | Publisher Full Text

Takayasu S, Sakurai T, Iwasaki S, et al.: A neuropeptide ligand of the G

protein-coupled receptor GPR103 regulates feeding, behavioral arousal,

and blood pressure in mice. Proc Natl Acad Sci U S A. 2006; 103(19): 7438-7443. PubMed Abstract | Publisher Full Text | Free Full Text

Tamura Y, Shintani M, Nakamura A, et al.: Phase-specific central regulatory systems of hibernation in Syrian hamsters. Brain Res. 2005; 1045(1-2): 88-96. PubMed Abstract | Publisher Full Text

Tamura $Y$, Shintani M, Inoue $H$, et al.: Regulatory mechanism of body temperature in the central nervous system during the maintenance phase of hibernation in Syrian hamsters: Involvement of $\beta$-endorphin. Brain Res. Elsevier B.V., 2012; 1448: 63-70.

PubMed Abstract | Publisher Full Text

Tan CL, Cooke EK, Leib DE, et al.: Warm-Sensitive Neurons that Control Body Temperature. Cell. Elsevier Inc., 2016; 167(1): 47-59.e15.

PubMed Abstract | Publisher Full Text | Free Full Tex

Thomas SA, Marck BT, Palmiter RD, et al.: Restoration of Norepinephrine and

Reversal of Phenotypes in Mice Lacking Dopamine $\beta$-Hydroxylase.

J Neurochem. 1998; 70(6): 2468-2476.

PubMed Abstract | Publisher Full Text

Thomas SA, Matsumoto AM, Palmiter RD: Noradrenaline is essential for mouse fetal development. Nature. 1995; 374(6523): 643-646.

PubMed Abstract | Publisher Full Text

Thompson JL, Borgland SL: Presynaptic leptin action suppresses excitatory

synaptic transmission onto ventral tegmental area dopamine neurons. Biol

Psychiatry. Elsevier, 2013; 73(9): 860-868.

PubMed Abstract | Publisher Full Text

Tiesjema B, la Fleur SE, Luijendijk CM, et al.: Viral mediated neuropeptide $Y$ expression in the rat paraventricular nucleus results in obesity. Obesity (Silver Spring). 2007; 15(10): 2424-35.

PubMed Abstract | Publisher Full Text

Toien O, Blake J, Edgar DM, et al.: Hibernation in Black Bears: Independence of Metabolic Suppression from Body Temperature. Science. 2011: 331(6019): 906-909.

PubMed Abstract | Publisher Full Tex

Trachsel L, Edgar DM, Heller HC: Are ground squirrels sleep deprived during hibernation? Am J Physiol. Department of Biological Sciences, Stanford University, California 94305-5020., 1991; 260(6 Pt 2): R1123-9.

PubMed Abstract | Publisher Full Text

Trayhurn P, James WP: Thermoregulation and non-shivering thermogenesis in the genetically obese (ob/ob) mouse. Pflugers Arch. 1978; 373(2): 189-193. PubMed Abstract | Publisher Full Text

Trayhurn P, Thurlby PL, James WPT: Thermogenic defect in pre-obese ob/ob mice. Nature. 1977; 266(5597): 60-62.

PubMed Abstract | Publisher Full Text

Tseng, et al.: Central Sites of Analgesia, Changes in Rats1 Catalepsy and

Body instrument. Journal of Pharmacology and Experimental Therapeutics. 1980; 214(2): 328-332.
Tupone D, Madden CJ, Morrison SF: Central activation of the $\mathbf{A} 1$ adenosine receptor (A1AR) induces a hypothermic, torpor-like state in the rat. J Neurosci. Department of Neurological Surgery, Oregon Health \& Science University, Portland, Oregon 97239-3098, USA. tupone@ohsu.edu: Society for Neuroscience, 2013; 33(36): 14512-14525.

PubMed Abstract | Publisher Full Text | Free Full Text

van der Vinne V, Bingaman MJ, Weaver DR, et al.: Clocks and meals keep mice from being cool.J Exp Biol. 2018; 221(Pt 15): jeb179812.

PubMed Abstract | Publisher Full Text | Free Full Text

Vicent M, et al.: Optogenetic Activation of AgRP Neurons Lengthens and

Deepens Daily Torpor in the Mouse. Undergraduate Thesis. 2017a.

Vicent MA, Borre ED, Swoap S]: Central activation of the $A$ adenosine receptor in fed mice recapitulates only some of the attributes of daily torpor. J Comp Physiol B. 2017b; 187(5-6): 835-845.

PubMed Abstract | Publisher Full Text | Free Full Text

Walker JM, Glotzbach SF, Glotzbach RJ, et al:: Sleep and hibernation in ground squirrels (Citellus spp): electrophysiological observations. Am J Physiol. 1977: 233(5): R213-21.

PubMed Abstract | Publisher Full Text

Walker JM, Haskell EH, Berger RJ, et al:: Hibernation at moderate temperatures: a continuation of slow wave sleep. Experientia. 1981; 37(7): 726-728.

PubMed Abstract | Publisher Full Text

Walker JM, Walker LE, Harris DV, et al.: Cessation of thermoregulation during REM sleep in the pocket mouse. Am J Physiol. 1983; 244(1): R114-8. PubMed Abstract | Publisher Full Text

Wang LC, Belke D, Jourdan ML, et al.: The "hibernation induction trigger": Specificity and validity of bioassay using the 13-lined ground squirrel. Cryobiology. 1988; 25(4): 355-362.

PubMed Abstract | Publisher Full Text

Wang L, Saint-Pierre DH, Taché Y: Peripheral ghrelin selectively increases Fos expression in neuropeptide $Y$ - synthesizing neurons in mouse hypothalamic arcuate nucleus. Neurosci Lett. 2002; 325(1): 47-51.

PubMed Abstract | Publisher Full Text

Wang Q, Bing C, Al-Barazanji K, et al.: Interactions Between Leptin and Hypothalamic Neuropeptide $Y$ Neurons in the Control of Food Intake and Energy Homeostasis in the Rat. Diabetes. 1997; 46(3): 335-341.

PubMed Abstract | Publisher Full Text

Webb GP, Jagot SA, Jakobson ME: Fasting-induced torpor in Mus musculus and its implications in the use of murine models for human obesity studies. Comp Biochem Physiol A Comp Physiol. 1982; 72(1): 211-219. PubMed Abstract | Publisher Full Text

Welton RF, Martin RJ, Baumgardt BR: Effects of Feeding and Exercise Regimens on Adipose Tissue Glycerokinase Activity and Body Composition of Lean and Obese Mice. J Nutr. 1973; 103(8): 1212-1219.

PubMed Abstract | Publisher Full Text

Willis CKR: An energy-based body temperature threshold between torpor and normothermia for small mammals. Physiol Biochem Zool. 2007; 80(6): $643-651$

PubMed Abstract | Publisher Full Text

Withers PC: Metabolic, respiratory and haematological adjustments of the little pocket mouse to circadian torpor cycles. Respir Physiol. 1977; 31(3): 295-307.

PubMed Abstract | Publisher Full Text

Xiao C, Goldgof M, Gavrilova O, et al.: Anti-obesity and metabolic efficacy of the $\beta$ 3-adrenergic agonist, CL316243, in mice at thermoneutrality compared to $22^{\circ} \mathrm{C}$. Obesity (Silver Spring). 2015; 23(7): 1450-1459. PubMed Abstract | Publisher Full Text | Free Full Text Yu S, Qualls-Creekmore E, Rezai-Zadeh K, et al.: Glutamatergic Preoptic Area Neurons That Express Leptin Receptors Drive Temperature-Dependent Body Weight Homeostasis. J Neurosci. Departments of Central Leptin Signaling Heike.Munzberg@pbrc.edu Sangho.Yu@pbrc.edu., 2016; 36(18): 5034-5046. PubMed Abstract | Publisher Full Text | Free Full Text

Zhang $Y$, Kerman IA, Laque A, et al.: Leptin-receptor-expressing neurons in the dorsomedial hypothalamus and median preoptic area regulate sympathetic brown adipose tissue circuits. J Neurosci. 2011; 31(5): 1873-1884.

PubMed Abstract | Publisher Full Text | Free Full Text

Zhang Z, Ferretti V, Güntan I, et al:: Neuronal ensembles sufficient for recovery sleep and the sedative actions of $\alpha 2$ adrenergic agonists. Nat Neurosci. Department of Life Sciences, Imperial College London, South Kensington, UK.: Nature Publishing Group, 2015; 18(4): 553-561.

PubMed Abstract | Publisher Full Text | Free Full Text

Zhang Z, Reis FMCV, He Y, et al.: Estrogen-sensitive medial preoptic area neurons coordinate torpor in mice. Nat Commun. Springer US 2020; 11(1): 6378. PubMed Abstract | Publisher Full Text | Free Full Text

Zhao S, Shao C, Goropashnaya AV, et al.: Genomic analysis of expressed sequence tags in American black bear Ursus americanus. BMC genomics. CAS-MPG Partner Institute for Computational Biology, Shanghai Institutes of Biological Sciences, 320 Yue Yang Road, Shanghai, 200031, China.: BioMed Central Ltd, 2010; 11(1): 201

PubMed Abstract | Publisher Full Text | Free Full Text

Zhao ZD, Yang WZ, Gao C, et al.: A hypothalamic circuit that controls body temperature. Proc Natl Acad Sci U S A. 2017; 114(8): 2042-2047.

PubMed Abstract | Publisher Full Text | Free Full Text 


\section{Open Peer Review}

\section{Current Peer Review Status: $\checkmark$ ? $\mathrm{X}$}

Version 1

Reviewer Report 17 January 2022

https://doi.org/10.21956/wellcomeopenres.19215.r47146

(C) 2022 Bechtold D. This is an open access peer review report distributed under the terms of the Creative Commons Attribution License, which permits unrestricted use, distribution, and reproduction in any medium, provided the original work is properly cited.

\section{David Bechtold}

Centre for Biological Timing, Faculty of Biology, Medicine and Health, University of Manchester, Manchester, UK

Ambler and colleagues provide an extensive review on daily torpor - a dramatic state of hypothermia and hypometabolism employed by a range of animals in response to challenging environmental conditions. Despite recent advances, there remain fundamental gaps in our understanding about how torpor is regulated, including the physiological conditions and neural circuits that may control entry into and emergence from the torpid state. This review draws together a range of studies on seasonal and fast-induced torpor to consider what putative processes may be involved. The review provides a valuable resource for researchers covering many aspects of torpor regulation (from defining basic characteristic of the torpor state, discussing physiological and/or hormonal factors which may contribute to torpor biology, through to neural pathways that have recently been linked to the expression of torpor in mice).

As with any review, there is a more that could have been included. For example, inclusion of some earlier torpor research detailing the thermodynamic and physiological adaptions observed during torpor entry may help to inform on what processes are primary drivers vs secondary consequences of the hypometabolic state. Also more direct comparisons throughout the review between natural seasonal torpor (such as observed in hamsters) and fast-induced torpor in mice would be valuable. Nevertheless, the review is impressive and, overall, achieves its purpose of summarising current understanding of how torpor may be regulated.

I have some comments and suggestions for the authors' consideration -

1. The authors should take much more care in their early discussions about what defines torpor and its characteristics. In the first line of the introduction, the authors state that torpor is observed "when the metabolic demands of maintaining homeostasis cannot be met". This is not accurate as stated. In the first paragraph of the discussion 'physiological characteristics of torpor', there is similar generalisation which will not be helpful for readers who are not well acquainted with torpor biology. As the authors subsequently point out and discuss, torpor is much more complex process, which is highly regulated and timed. The intro and this first discussion paragraph should contain a more nuanced description of 
why/when animals may engage torpor as a means of energy conservation.

2. Similar to point 1 , the authors should be careful about mixing observations from different models and generalising findings. For example, "duration of torpor is inversely proportional to the weight of the mouse", "torpor typically persists for between four to six hours..." "bouts may last up to 12 hours or more..." "low birth weight predicts higher torpor tendency..." "...evidence that torpor is engaged when...fasting decreases body weight below $20 \mathrm{~g}$ ". The relationship between overall body weight, body weight loss, fat mass etc are all important factors involved in manifestation of torpor. However, these independent observations cannot necessarily be generalised (e.g. CD1 mice have a relatively large body size compared to C57B6 mice, but more readily exhibit torpor upon fasting). Similarly, robust daily torpor can often be observed during chronic food entrainment studies in mice, where steady body weight can be maintained. Clearly, not all studies and findings across different models can be integrated, but where possible the authors could try to draw together important conceptual considerations. For example, in the case of body weight loss - a key aspect is likely to be the development of a 'torpor permissive' metabolic state, rather than achieving any absolute threshold of body weight or weight loss.

3. An important issue discussed by the authors is how torpor can be (or should be) defined in experimental studies. In the final section of the review, the author provide some potential criteria - "reduced body temperature with ongoing thermoregulation such that a minimum (albeit adjusted) core temperature is defended; and controlled cardiovascular depression...". In my opinion, this first criteria is an important one. Torpor is a highly regulated process, and a relatively stable low body temperature is a clear feature of a 'full' torpor bout. This may be an important point of distinction between simple fasting-induced reductions in body temperature and metabolic rate versus entry into a state of torpor. However, why do the authors not then use this criteria when assessing and comparing studies included in their review. For example, when discussing the potential role of leptin in torpor, the authors compare studies of Gavrilova et al 1999 and Bechtold et al 2012. However, they are trying to draw conclusions from wild-type mice which do not appear to enter torpor in either study (as expected from normal mice under short term fasting, they show reduced BT and metabolism, but not torpor). Similar consideration should be applied to studies discussed in the context of NPY signalling, adenosine signalling, etc. With regard to the second criteria (related to the temporal dynamics of heart rate and body temperature change), this is a valuable suggestion, although there are additional considerations required. This relationship needs to be studied in more detail and under additional experimental conditions (species, ambient temperature, fasting vs seasonal torpor, etc). In addition, many laboratories may not have the facilities to collect continuous heart rate in undisturbed animals (e.g. via radio telemetry).

4. The review includes a number of sections which do not directly discuss torpor. For example, pages 5-11 are principally summarising aspects of general physiology. While agreeing with the authors' comments about a need to understand basic neural and hormonal control mechanisms (e.g. involved in feeding and/or thermoregulation) in order to evaluate how torpor may be controlled, in its current form these relatively long background sections detract somewhat from the review. These sections provide some context, but they do not really provide a level of depth required to add significant insight. Shortening these sections (with references to point the reader to recent in-depth reviews on the subjects) and 
integrating essential information more directly into discussions on torpor would be beneficial.

5. The most valuable parts of the review are the 'in summary' paragraphs which conclude each section. These offer good insight and draw findings together. It would be valuable to give these even more emphasis, while perhaps cutting down on some of the preceding information. This is especially true of discussions around the concept of a 'torporpermissive' physiological states. Accumulated evidence suggests that employment of torpor requires a permissive metabolic state and optimal circadian time window, within which neural drivers of the torpid state can act. This concept is highlighted at a few points during the review, but this could be discussed in more depth and earlier in the review.

6. Fasting induced torpor in mice raises an intriguing issue - the animals undergo a major (and relatively rapid) switch in behaviour and physiology away from foraging into profound energy conservation. The authors may want to more directly discuss this physiological 'switch' and how the neural circuitry discussed may be involved.

7. There are some good studies (e.g. by Vladyslav Vyazovskiy and colleagues) exploring the relationship between torpor and sleep in both seasonal (hamster) and mouse studies. These could be included for increased insight. It seems clear that torpor is not a modified state of sleep, but as the authors suggest in the review, there is an important interaction between these processes. For example, could sleep be a necessary transition state into torpor?

8. Figure 2 - the bubble at the top related to "sensory cues indicating food" is perhaps too limited, or need further explanation. Numerous contextual and environmental factors will contribute to foraging drive and/or expectation of feeding. Further, there are a large number of nutrient, hormonal and neural inputs to the hypothalamus and brainstem which influence metabolic control centres in the brain. The authors may want to add more inputs to this circuit. The figure title should also specify 'hypothalamic circuits' as other areas are not included. Including the $\mathrm{VMH}$ would be appropriate, as circuits for rhythmic regulation of thermogenesis and feeding control have been demonstrated.

9. Figure 3 could include some indication that circadian input and metabolic state can enhance or oppose the 'torpor-inducing' pathway.

10. The authors may consider discussing findings related to Gpr50 and torpor. Mice lacking this receptor do not exhibit any major metabolic or physiological phenotype under normal fed conditions, but readily employ deep torpor when fasted. Moreover, the expression of torpor in response to fasting is extremely consistent and shows strong circadian timing. Beyond the specific function of Gpr50, this suggests that torpor may be a 'default' response of mice to fasting, but one that is opposed/suppressed under sub-optimal internal or external conditions. It is also noteworthy that the receptor is highly expressed in the $\mathrm{DMH}$ and tanycytes of the $3^{\text {rd }}$ ventricle - areas which play a major role in seasonal adaptation and torpor.

11. Discussion of circadian rhythmicity in ghrelin and leptin production could be included (could this contribute switch from foraging to conservation, and the associated timing of torpor)? 
12. In discussion of NPY administration causing a decrease in food intake (pg 13; in reference to Paul et al 2005), the authors should acknowledge that in these studies food intake was assessed 24 hour after administration, and therefore may reflect secondary effects (rather than direct action of NPY on orexigenic circuits).

13. Discussion of A-Zip/F-1 mice should be included with caution. This is a model of extreme lipodystrophy and many animals die during fasting.

14. It seems odd to have the reference appearing at the end of a series of sentences discussing a particular studies (rather than at the first mention). Unless this is standard for the journal, it should be addressed to ensure that the source and context of the information is clear (e.g. final paragraph of page 12 , the source of the Siberian hamster studies are not clear until the following page).

15. References should not include an undergraduate thesis (Vincent et al 2017a). Also, formatting across citations in the reference list is not consistent. Some include contact information for the corresponding authors and some do not.

Is the topic of the review discussed comprehensively in the context of the current literature?

Partly

Are all factual statements correct and adequately supported by citations? Partly

Is the review written in accessible language?

Yes

Are the conclusions drawn appropriate in the context of the current research literature? Yes

Competing Interests: No competing interests were disclosed.

Reviewer Expertise: Animal physiology, circadian biology, energy metabolism, neural controls of energy balance.

I confirm that I have read this submission and believe that I have an appropriate level of expertise to confirm that it is of an acceptable scientific standard, however I have significant reservations, as outlined above.

Author Response 24 Jan 2022

Mike Ambler, University of Bristol, Bristol, UK

We thank the reviewer for their comments, while the manuscript has now reached the point of publication, we will nevertheless incorporate the suggestions and attempt to address the comments in an updated manuscript. 
Competing Interests: No competing interests were disclosed.

Author Response 09 Mar 2022

Mike Ambler, University of Bristol, Bristol, UK

Ambler and colleagues provide an extensive review on daily torpor - a dramatic state of hypothermia and hypometabolism employed by a range of animals in response to challenging environmental conditions. Despite recent advances, there remain fundamental gaps in our understanding about how torpor is regulated, including the physiological conditions and neural circuits that may control entry into and emergence from the torpid state. This review draws together a range of studies on seasonal and fast-induced torpor to consider what putative processes may be involved. The review provides a valuable resource for researchers covering many aspects of torpor regulation (from defining basic characteristic of the torpor state, discussing physiological and/or hormonal factors which may contribute to torpor biology, through to neural pathways that have recently been linked to the expression of torpor in mice).

As with any review, there is a more that could have been included. For example, inclusion of some earlier torpor research detailing the thermodynamic and physiological adaptions observed during torpor entry may help to inform on what processes are primary drivers vs secondary consequences of the hypometabolic state. Also more direct comparisons throughout the review between natural seasonal torpor (such as observed in hamsters) and fast-induced torpor in mice would be valuable. Nevertheless, the review is impressive and, overall, achieves its purpose of summarising current understanding of how torpor may be regulated.

I have some comments and suggestions for the authors' consideration -

1. The authors should take much more care in their early discussions about what defines torpor and its characteristics. In the first line of the introduction, the authors state that torpor is observed "when the metabolic demands of maintaining homeostasis cannot be met". This is not accurate as stated. In the first paragraph of the discussion 'physiological characteristics of torpor', there is similar generalisation which will not be helpful for readers who are not well acquainted with torpor biology. As the authors subsequently point out and discuss, torpor is much more complex process, which is highly regulated and timed. The intro and this first discussion paragraph should contain a more nuanced description of why/when animals may engage torpor as a means of energy conservation.

We have adjusted the phrasing in these sections taking into account these comments, and removing the generalisation that torpor is engaged in simply in response to food restriction.

1. Similar to point 1, the authors should be careful about mixing observations from different models and generalising findings. For example, "duration of torpor is inversely proportional to the weight of the mouse", "torpor typically persists for between four to six hours..." "bouts may last up to 12 hours or more..." "low birth weight predicts higher torpor tendency..." "...evidence that torpor is engaged 
when...fasting decreases body weight below $20 \mathrm{~g}$ ". The relationship between overall body weight, body weight loss, fat mass etc are all important factors involved in manifestation of torpor. However, these independent observations cannot necessarily be generalised (e.g. CD1 mice have a relatively large body size compared to C57B6 mice, but more readily exhibit torpor upon fasting). Similarly, robust daily torpor can often be observed during chronic food entrainment studies in mice, where steady body weight can be maintained. Clearly, not all studies and findings across different models can be integrated, but where possible the authors could try to draw together important conceptual considerations. For example, in the case of body weight loss - a key aspect is likely to be the development of a 'torpor permissive' metabolic state, rather than achieving any absolute threshold of body weight or weight loss.

We have added these nuances to the section discussing the timing of / triggers for torpor.

1. An important issue discussed by the authors is how torpor can be (or should be) defined in experimental studies. In the final section of the review, the author provide some potential criteria - "reduced body temperature with ongoing thermoregulation such that a minimum (albeit adjusted) core temperature is defended; and controlled cardiovascular depression...". In my opinion, this first criteria is an important one. Torpor is a highly regulated process, and a relatively stable low body temperature is a clear feature of a 'full' torpor bout. This may be an important point of distinction between simple fasting-induced reductions in body temperature and metabolic rate versus entry into a state of torpor. However, why do the authors not then use this criteria when assessing and comparing studies included in their review. For example, when discussing the potential role of leptin in torpor, the authors compare studies of Gavrilova et al 1999 and Bechtold et al 2012. However, they are trying to draw conclusions from wild-type mice which do not appear to enter torpor in either study (as expected from normal mice under short term fasting, they show reduced BT and metabolism, but not torpor).Similar consideration should be applied to studies discussed in the context of NPY signalling, adenosine signalling, etc.

We have pointed out in the section discussing these studies that in the WT mice what is observed is a reduction in metabolic rate and temperature but probably not torpor.

With regard to the second criteria (related to the temporal dynamics of heart rate and body temperature change), this is a valuable suggestion, although there are additional considerations required. This relationship needs to be studied in more detail and under additional experimental conditions (species, ambient temperature, fasting vs seasonal torpor, etc). In addition, many laboratories may not have the facilities to collect continuous heart rate in undisturbed animals (e.g. via radio telemetry).

We agree that temporal dynamics of heart rate vs temperature during torpor entry vs exit is important, and have added an acknowledgement that measuring heart rate is not always possible. However, we do feel that this feature is of sufficient importance to justify the proposal that it could form part of a criteria for defining torpor.

1. The review includes a number of sections which do not directly discuss torpor. For example, pages 5-11 are principally summarising aspects of general physiology. While agreeing with the authors' comments about a need to understand basic neural and hormonal control mechanisms (e.g. involved in feeding and/or thermoregulation) 
in order to evaluate how torpor may be controlled, in its current form these relatively long background sections detract somewhat from the review. These sections provide some context, but they do not really provide a level of depth required to add significant insight. Shortening these sections (with references to point the reader to recent in-depth reviews on the subjects) and integrating essential information more directly into discussions on torpor would be beneficial.

We have edited down these sections but have kept them as an introduction for those less familiar. We hope that by using specific headings, readers will be able to choose whether or not to concentrate on the sections discussing general physiology.

1. The most valuable parts of the review are the 'in summary' paragraphs which conclude each section. These offer good insight and draw findings together. It would be valuable to give these even more emphasis, while perhaps cutting down on some of the preceding information. This is especially true of discussions around the concept of a 'torpor-permissive' physiological states. Accumulated evidence suggests that employment of torpor requires a permissive metabolic state and optimal circadian time window, within which neural drivers of the torpid state can act. This concept is highlighted at a few points during the review, but this could be discussed in more depth and earlier in the review.

2. Fasting induced torpor in mice raises an intriguing issue - the animals undergo a major (and relatively rapid) switch in behaviour and physiology away from foraging into profound energy conservation. The authors may want to more directly discuss this physiological 'switch' and how the neural circuitry discussed may be involved.

We have added reference to this profound switch in the introduction.

1. There are some good studies (e.g. by Vladyslav Vyazovskiy and colleagues) exploring the relationship between torpor and sleep in both seasonal (hamster) and mouse studies. These could be included for increased insight. It seems clear that torpor is not a modified state of sleep, but as the authors suggest in the review, there is an important interaction between these processes. For example, could sleep be a necessary transition state into torpor?

We have included reference to these studies from Vlad Vyazovskiy, and discussed the idea that NREM is a transition state.

1. Figure 2 - the bubble at the top related to "sensory cues indicating food" is perhaps too limited, or need further explanation. Numerous contextual and environmental factors will contribute to foraging drive and/or expectation of feeding. Further, there are a large number of nutrient, hormonal and neural inputs to the hypothalamus and brainstem which influence metabolic control centres in the brain. The authors may want to add more inputs to this circuit. The figure title should also specify 'hypothalamic circuits' as other areas are not included. Including the VMH would be appropriate, as circuits for rhythmic regulation of thermogenesis and feeding control have been demonstrated

We have edited the figure but are reluctant to add too many new inputs without discussing them in the body of the text, and do not wish to over-burden the reader with more general physiology beyond what is already included.

1. Figure 3 could include some indication that circadian input and metabolic state can enhance or oppose the 'torpor-inducing' pathway.

We have edited the figure to highlight the sensitivity to metabolic state and circadian 
time.

1. The authors may consider discussing findings related to Gpr50 and torpor. Mice lacking this receptor do not exhibit any major metabolic or physiological phenotype under normal fed conditions, but readily employ deep torpor when fasted. Moreover, the expression of torpor in response to fasting is extremely consistent and shows strong circadian timing. Beyond the specific function of Gpr50, this suggests that torpor may be a 'default' response of mice to fasting, but one that is opposed/suppressed under sub-optimal internal or external conditions. It is also noteworthy that the receptor is highly expressed in the $\mathrm{DMH}$ and tanycytes of the $3^{\text {rd }}$ ventricle - areas which play a major role in seasonal adaptation and torpor.

We have included a discussion of these experiments in the leptin and torpor section.

1. Discussion of circadian rhythmicity in ghrelin and leptin production could be included (could this contribute switch from foraging to conservation, and the associated timing of torpor)?

2. In discussion of NPY administration causing a decrease in food intake (pg 13; in reference to Paul et al 2005), the authors should acknowledge that in these studies food intake was assessed 24 hour after administration, and therefore may reflect secondary effects (rather than direct action of NPY on orexigenic circuits).

We have added this useful point.

1. Discussion of A-Zip/F-1 mice should be included with caution. This is a model of extreme lipodystrophy and many animals die during fasting.

2. It seems odd to have the reference appearing at the end of a series of sentences discussing a particular studies (rather than at the first mention). Unless this is standard for the journal, it should be addressed to ensure that the source and context of the information is clear (e.g. final paragraph of page 12, the source of the Siberian hamster studies are not clear until the following page).

3. References should not include an undergraduate thesis (Vincent et al 2017a). Also, formatting across citations in the reference list is not consistent. Some include contact information for the corresponding authors and some do not.

We have corrected this and the point above.

Competing Interests: No competing interests were disclosed.

Reviewer Report 24 December 2021

https://doi.org/10.21956/wellcomeopenres.19215.r47150

(C) 2021 Drew K. This is an open access peer review report distributed under the terms of the Creative Commons Attribution License, which permits unrestricted use, distribution, and reproduction in any medium, provided the original work is properly cited.

\section{Kelly Drew}


Department of Chemistry and Biochemistry, Institute of Arctic Biology, Center for Transformative Research in Metabolism, University of Alaska Fairbanks, Fairbanks, AK, USA

This is a comprehensive review aimed at introducing readers to torpor and bringing them up to speed on current knowledge of the central processes that coordinate torpor onset. Overall, the manuscript is well written, easy to follow and provides a timely update on the CNS control of torpor. Major concerns stem primarily from an attempt to squeeze all types of torpor into a single box and errors made in describing some of the nuances of hibernation.

\section{Major concerns that must be addressed to make the article sound are as follows:}

1. The authors write, "...an assumption is that the torpor during these hibernation periods is mechanistically equivalent to the brief torpor bouts seen in daily hetereotherms such as the mouse. However, this assumption has not been experimentally proven."

This statement distracts from the otherwise careful consideration of the literature that is reviewed. A preferred approach would be to create a table that compares and contrasts daily torpor, facultative hibernation and obligate hibernation and identify what, if any, attributes these three types of torpor share.

2. The authors discuss hibernation in hamsters as "seasonal" and suggest that hibernation is a response to environmental challenge:

Syrian hamsters are termed facultative hibernators. The authors should investigate this term, define it for readers and apply the definition in their review. In particular, consider describing facultative and obligate hibernation with reference to gonadal regression; one of many features the authors will find distinguishes hibernation from daily heterothermy.

Note that obligate hibernators do NOT 'respond" to environmental challenge. No degree of environmental challenge will induce hibernation in the summer season in an obligate hibernator.

Alternatively, limit the review to fasting-induced torpor in mice.

The authors suggest in the abstract that they offer a "critical' view of evidence for the systems that control torpor entry. However, nowhere in the manuscript is there any critical consideration of qualities that enhance rigor, or mention of which studies followed practices that enhance rigor, such as blinding, inclusion of positive and negative controls, and a priori power analysis. A critical review of studies supporting various models and which models are supported by papers with appropriate control groups and blinding would have a positive impact on the field.

3. The authors suggest that because fasting-induced torpor persists in mice lacking $A 1 R$ and A3R that adenosine represents a candidate signal for torpor initiation, but once again, must be designating as 'contributing' or 'permissive' and not a necessary and sufficient master switch. Again, the authors miss an opportunity to "critically" review existing evidence by failing to acknowledge the potential for compensatory mechanisms in the KO strains used by Carlin et al. ${ }^{1}$, and the call for further study using conditional KO experiments.

4. The authors propose two key features of torpor; 1. Reduced body temperature with active, ongoing thermogenesis to defend a lower $\mathrm{Tb}$, and 2. Characteristic hysteresis of heart rate and core body temperature. Unfortunately, they do not offer any rationale for selecting these two 
features other than that they are easily measured. I agree that a decrease in metabolic rate, for which heart rate is a proxy during entrance, should precede a decline in body temperature. However, the same signal that induces torpor may not be involved with arousal. While the classic hysteresis may be easy to measure using it to identify torpor, importantly experimentally-induced torpor, assumes that torpor onset and arousal are regulated by the same mechanism. No evidence that I am aware of would suggest this is the case. Indeed, despite the recent focus and progress in identifying circuits involved with the onset of fasting-induced torpor in mice, few studies have focused on mechanisms or circuits involved in arousal. The hysteresis curve illustrates two processes, onset of torpor and arousal from torpor. I would suggest that a combination of metabolic suppression and vasoconstriction would be a better characteristic to distinguish torpor from hypothermia because a warm defense response suppresses thermogenesis and increases vasodilation, while energy conserving torpor suppresses thermogenesis while limiting heat loss through vasoconstriction.

5. The review is missing mention of thermoregulatory inversion, a model that describes the phenomenon of altered thermoregulation during torpor onset (see Tupone et al. 20172). The description of this phenomenon could prove to be the characteristic that defines torpor and would likely be of interest to readers.

6. The section on Sleep and Torpor is missing an alternative interpretation that sleep debt does not accumulate during torpor (for example see Larkin and Heller, 1999³).

7. Lacking is any attention to the phenotype of an animal prior to torpor onset. Should pharmacological manipulation of fed mice be expected to replicate effects in fasted mice?

\title{
Other concerns:
}

1. Reference to Fig. 1 (page 2, $2^{\text {nd }}$ paragraph) suggests that Fig. 1 should include a phylogenic tree, but instead we see a schematic of the thermal defense circuit.

2. The authors write, “For a given body temperature, pharmacologically-induced hypothermia generates a less profound bradycardia than that seen in torpor..." - What kind of pharmacologically-induced hypothermia? In what species? Under what conditions?

\section{References}

1. Carlin J, Jain S, Gizewski E, Wan T, et al.: Hypothermia in mouse is caused by adenosine A1 and A3 receptor agonists and AMP via three distinct mechanisms. Neuropharmacology. 2017; 114: 101 113 Publisher Full Text

2. Tupone D, Cano G, Morrison S: Thermoregulatory inversion: a novel thermoregulatory paradigm. American Journal of Physiology-Regulatory, Integrative and Comparative Physiology. 2017; 312 (5): R779-R786 Publisher Full Text

3. Larkin JE, Heller HC: Sleep after arousal from hibernation is not homeostatically regulated.Am J Physiol. 276 (2): R522-9 PubMed Abstract | Publisher Full Text

\author{
Is the topic of the review discussed comprehensively in the context of the current \\ literature? \\ Yes
}

Are all factual statements correct and adequately supported by citations? 
Partly

Is the review written in accessible language?

Yes

Are the conclusions drawn appropriate in the context of the current research literature? Partly

Competing Interests: I have financial interest in Be Cool Pharmaceutics

Reviewer Expertise: Hibernation, neural control of hibernation

I confirm that I have read this submission and believe that I have an appropriate level of expertise to state that I do not consider it to be of an acceptable scientific standard, for reasons outlined above.

Author Response 24 Jan 2022

Mike Ambler, University of Bristol, Bristol, UK

We thank the reviewer for their comments and will incorporate them into an updated manuscript.

Competing Interests: No competing interests were disclosed.

Author Response 09 Mar 2022

Mike Ambler, University of Bristol, Bristol, UK

Kelly Drew

This is a comprehensive review aimed at introducing readers to torpor and bringing them up to speed on current knowledge of the central processes that coordinate torpor onset. Overall, the manuscript is well written, easy to follow and provides a timely update on the CNS control of torpor. Major concerns stem primarily from an attempt to squeeze all types of torpor into a single box and errors made in describing some of the nuances of hibernation.

Major concerns that must be addressed to make the article sound are as follows:

1. The authors write, "...an assumption is that the torpor during these hibernation periods is mechanistically equivalent to the brief torpor bouts seen in daily hetereotherms such as the mouse. However, this assumption has not been experimentally proven."

This statement distracts from the otherwise careful consideration of the literature that is reviewed. A preferred approach would be to create a table that compares and contrasts daily torpor, facultative hibernation and obligate hibernation and identify what, if any, attributes these three types of torpor share.

We have revised the manuscript to highlight some of the differences between daily 
torpor and hibernation.

2. The authors discuss hibernation in hamsters as "seasonal" and suggest that hibernation is a response to environmental challenge:

Syrian hamsters are termed facultative hibernators. The authors should investigate this term, define it for readers and apply the definition in their review. In particular, consider describing facultative and obligate hibernation with reference to gonadal regression; one of many features the authors will find distinguishes hibernation from daily heterothermy.

Note that obligate hibernators do NOT 'respond" to environmental challenge. No degree of environmental challenge will induce hibernation in the summer season in an obligate hibernator.

We have added some discussion of daily torpor vs hibernation (including a table comparing these phenomena).

Alternatively, limit the review to fasting-induced torpor in mice.

The authors suggest in the abstract that they offer a "critical' view of evidence for the systems that control torpor entry. However, nowhere in the manuscript is there any critical consideration of qualities that enhance rigor, or mention of which studies followed practices that enhance rigor, such as blinding, inclusion of positive and negative controls, and a priori power analysis. A critical review of studies supporting various models and which models are supported by papers with appropriate control groups and blinding would have a positive impact on the field.

We have removed this comment.

3. The authors suggest that because fasting-induced torpor persists in mice lacking $A 1 R$ and A3R that adenosine represents a candidate signal for torpor initiation, but once again, must be designating as 'contributing' or 'permissive' and not a necessary and sufficient master switch. Again, the authors miss an opportunity to "critically" review existing evidence by failing to acknowledge the potential for compensatory mechanisms in the KO strains used by Carlin et al. ${ }^{1}$, and the call for further study using conditional KO experiments. We have acknowledged this point regarding KO strains.

4. The authors propose two key features of torpor; 1 . Reduced body temperature with active, ongoing thermogenesis to defend a lower Tb, and 2. Characteristic hysteresis of heart rate and core body temperature. Unfortunately, they do not offer any rationale for selecting these two features other than that they are easily measured.

\section{Our rationale was wanting to identify characteristics of torpor that were relatively easily measured experimentally.}

I agree that a decrease in metabolic rate, for which heart rate is a proxy during entrance, should precede a decline in body temperature.

In our opinion, a reduced heart rate is more than a proxy for reduced metabolic rate but represents a fundamental component of torpor.

However, the same signal that induces torpor may not be involved with arousal. While the 
classic hysteresis may be easy to measure using it to identify torpor, importantly experimentally- induced torpor, assumes that torpor onset and arousal are regulated by the same mechanism. No evidence that I am aware of would suggest this is the case. Indeed, despite the recent focus and progress in identifying circuits involved with the onset of fasting-induced torpor in mice, few studies have focused on mechanisms or circuits involved in arousal. The hysteresis curve illustrates two processes, onset of torpor and arousal from torpor.

We agree that torpor arousal may be under the control of distinct neural circuits. Our proposed definition is not making any comment on the mechanisms of control, rather we are trying to identify characteristic features of torpor (entry and arousal) against which experimental models might be compared. The data that suggest a characteristic hysteresis curve of heart rate versus temperature is derived from mice entering natural torpor compared to pharmacologically or physically-induced hypothermia (Vicent, Borre and Swoap, 2017), hence these data reflect the natural processes of torpor induction and arousal.

I would suggest that a combination of metabolic suppression and vasoconstriction would be a better characteristic to distinguish torpor from hypothermia because a warm defense response suppresses thermogenesis and increases vasodilation, while energy conserving torpor suppresses thermogenesis while limiting heat loss through vasoconstriction.

We agree that vasoconstriction is probably a crucial component of natural torpor (Swoap and Gutilla, 2009), and that crucially some experimental models of chemo- or optogenetic torpor induction appear to demonstrate vasodilatation (at least in the early phase), which may not represent natural torpor induction (Takahashi et al., 2020; Zhang et al., 2020). However, demonstrating vasoconstriction is not easy experimentally, and for this reason we did not include initially. We have now added this component to the manuscript.

5. The review is missing mention of thermoregulatory inversion, a model that describes the phenomenon of altered thermoregulation during torpor onset (see Tupone et al. 2017²). The description of this phenomenon could prove to be the characteristic that defines torpor and would likely be of interest to readers.

In the interest of keeping to manuscript to a reasonable length, we did not include this. We do not necessarily feel that thermoregulatory inversion represents a fundamental characteristic of torpor. During torpor thermoregulation is maintained albeit with a lower resulting body temperature: torpid mice will defend a minimum temperature, which is not predicted by thermoregulatory inversion model.

6. The section on Sleep and Torpor is missing an alternative interpretation that sleep debt does not accumulate during torpor (for example see Larkin and Heller, 1999³).

We have included a discussion of this paper.

7. Lacking is any attention to the phenotype of an animal prior to torpor onset. Should 
pharmacological manipulation of fed mice be expected to replicate effects in fasted mice?

This is an interesting question, we have discussed the triggers for torpor, and made some comparison between daily torpor and hibernation. We have a separate paper in press that explores some of the question regarding interventions in fed vs calorierestricted mice (preprint https://www.biorxiv.org/content/10.1101/2021.09.05.458994v1).

Other concerns:

1. Reference to Fig. 1 (page $2,2^{\text {nd }}$ paragraph) suggests that Fig. 1 should include a phylogenic tree, but instead we see a schematic of the thermal defense circuit.

Thank you, we have corrected this error.

2. The authors write, "For a given body temperature, pharmacologically-induced hypothermia generates a less profound bradycardia than that seen in torpor..." - What kind of pharmacologically-induced hypothermia? In what species? Under what conditions?

In mice given CHA - we have clarified in the manuscript.

Competing Interests: No competing interests were disclosed.

Reviewer Report 21 December 2021

https://doi.org/10.21956/wellcomeopenres.19215.r47148

(C) 2021 Madden C. This is an open access peer review report distributed under the terms of the Creative Commons Attribution License, which permits unrestricted use, distribution, and reproduction in any medium, provided the original work is properly cited.

\section{Christopher Madden}

Department of Neurological Surgery, Oregon Health \& Science University, Portland, OR, USA

This manuscript is a well-written, timely, and extensive (although not comprehensive) review of torpor physiology. One major assumption stated in the introduction is that "the torpor during these hibernation periods is mechanistically equivalent to the brief torpor bouts seen in daily heterotherms such as the mouse", there are data throughout the manuscript that may contradict this assumption (as acknowledged by the authors). Please see the work of Geiser et al for additional discussions of this issue (Ann rev physiol 2004ㄹ ; Phys Zoology 1995²). At a minimum this statement that the mechanistics are "equivalent" should be tempered, if not excluded altogether. Below are additional suggestions:

1. Figure 1. There are data to suggest that many of the BDNF/PACAP neurons express Vglut2 and may be glutamatergic. This possibility should at least be acknowledged.

2. Page 4, first paragraph of the Cardiovascular function during torpor section. The statement 
is made that slower heart rates during entry into torpor vs arousal from torpor "indicates a dominance of parasympathetic ...during entry, followed by sympathetic...during arousal" . Please provide a reference showing parasympathetic involvement during entry, as a lower heart rate could simply be a withdrawal of sympathetic activity. Or at a minimum, use "suggests" instead of "indicates".

3. Page 5. The idea of moving away from a set-point model to one of multiple independent mechanisms each with their own thresholds was largely initiated by Romanovsky, it would be appropriate to include a citation to his influential work.

4. Page 5. While relatively little is known about the thermosensitive inputs arriving to the CNS via vagal and splanchnic afferents, there is a more detail description of this issue in my review, Madden \& Morrison, (Neurosci Lett 2019) ${ }^{3}$.

5. Page 6. TRPM2 contributes to temperature sensing in POA neurons. However, genetic deletion of TRPM2 does not affect normal body temperature, therefore it is not necessary for normal euthermia, possibly suggesting that other temperature sensing mechanisms contribute. In addition, TRPM2 has a very broad expression pattern and likely has additional roles beyond temperature sensing. Perhaps these points are beyond the scope of this manuscript, but as this section currently reads, it could be misleading, leading to the possible misinterpretation the TRPM2 are the only mediator of central thermosensing.

6. Page 6 second column first section. "Opto-activation of the warm-sensing GABAergic BDNF and PACAP-expressing cell bodies". Care should be taken when referring to "warm-sensing" vs. warm-responsive neurons. The BDNF/PACAP cells are responsive to thermal inputs but are not directly warm sensitive (see Tan et al $2016^{4}$ "In contrast, we found no evidence that VMPOBDNF/PACAP neurons were more intrinsically thermosensitive than neighbouring cells when we performed whole-cell patch clamp recordings from acute brain slices (Figures S2L and S2M).")

7. The short-hand "DMH-Raphe-BAT" is potentially confusing since there are synapses between the Raphe and BAT.

8. Page 6 last section. The concept of a maintenance of body weight is perhaps inappropriate. How would a biological system be configured to regulate body weight? It seems likely that the regulated variable would be some other correlate of body weight such as fat mass. Furthermore, the concept that calorie excess increases body temperature is controversial and complicated, and may depend on acute vs. chronic conditions. For example, rats maintained chronically on a high fat diet have reduced sympathetic outflow to BAT (Levin et al AJP, 1985' ; Sakaguchi et al Physiol Behav, 19896; Madden \& Morrison AJP, $2016^{7}$ (my paper)).

9. Figure 2. The suggestion that the DMH contributes to energy expenditure and the PVH contributes to food intake is oversimplified. Clearly the paraventricular hypothalamus also influences energy expenditure (BAT) (see, Billington et al, 19948; Madden \& Morrison, $2009^{9}$ (my paper); Nakamura, 2017 ${ }^{10}$ ).

10. Page 8. "Selective reintroduction of melanocortin 4 receptors in the PVH normalizes the 
excess food intake but not the suppressed energy expenditure". The selective reintroduction of MC4R in the cited work would be in the cell bodies in $\mathrm{PVH}$ not in afferent terminals to the PVH so the statement the MC4R is normalized in the PVH is an overinterpretation.

11. Page 10. Again the concept that the Arc to PVH projection is relevant to feeding and that the $\mathrm{DMH}$ projection modulates EE is overly simplistic. See the work of Shi et al J Neuroendo 2021 11; Billington ${ }^{8}$; Nakamura ${ }^{10}$.

12. Page 12 , numbered point 2 . Beta3 activation would not only activate WAT to suppress leptin but would also activate BAT to generate thermogenesis.

13. The issue of the role of leptin in torpor is of high importance. Here again it calls into question the assertion that torpor in daily heterotherms and longer duration hibernation bouts are equivalent. Hibernation requires preparatory fattening which would result in elevated leptin levels, on the other hand daily torpor bouts appear to be blocked by leptin administration.

14. Page 14. Please provide a reference for the statements regarding the incidence of asystoles in torpor and following $\mathrm{CHA}$.

15. The role of endogenous opioids in thermoregulation might benefit from a discussion of the role of kappa opioid receptors in high fat diet induced impairment of BAT activation. (see Conceicao et al, eNeuro, $2021^{12}$ (my paper)) and the parallels between animals maintained on a high fat diet and hibernation (see my paper, Madden, Temperature, 2017 ${ }^{13}$ ).

16. The suggestion that hypothermia-inducing DMH neurons are cholinergic is insightful and interesting. Nonetheless, the DMH neurons that express fos at torpor initiation are not cholinergic (Hitrec, 201914).

\section{References}

1. Geiser F: Metabolic rate and body temperature reduction during hibernation and daily torpor. Annu Rev Physiol. 2004; 66: 239-74 PubMed Abstract | Publisher Full Text

2. Geiser F, Ruf T: Hibernation versus Daily Torpor in Mammals and Birds: Physiological Variables and Classification of Torpor Patterns. Physiological Zoology. 1995; 68 (6): 935-966 Publisher Full Text 3. Madden C, Morrison S: Central nervous system circuits that control body temperature. Neuroscience Letters. 2019; 696: 225-232 Publisher Full Text 4. Tan CL, Cooke EK, Leib DE, Lin YC, et al.: Warm-Sensitive Neurons that Control Body Temperature.Cell. 2016; 167 (1): 47-59.e15 PubMed Abstract | Publisher Full Text 5. Levin BE, Finnegan M, Triscari J, Sullivan AC: Brown adipose and metabolic features of chronic diet-induced obesity.Am J Physiol. 1985; 248 (6 Pt 2): R717-23 PubMed Abstract | Publisher Full Text 6. Sakaguchi T, Arase K, Fisler J, Bray G: Effect of a high-fat diet on firing rate of sympathetic nerves innervating brown adipose tissue in anesthetized rats. Physiology \& Behavior. 1989; 45 (6): 11771182 Publisher Full Text

7. Madden C, Morrison S: A high-fat diet impairs cooling-evoked brown adipose tissue activation via a vagal afferent mechanism. American Journal of Physiology-Endocrinology and Metabolism. 2016; 311 (2): E287-E292 Publisher Full Text 
8. Billington $\mathrm{CJ}$, Briggs JE, Harker S, Grace $\mathrm{M}$, et al.: Neuropeptide $\mathrm{Y}$ in hypothalamic paraventricular nucleus: a center coordinating energy metabolism.Am J Physiol. 1994; 266 (6 Pt 2): R1765-70 PubMed Abstract | Publisher Full Text

9. Madden CJ, Morrison SF: Neurons in the paraventricular nucleus of the hypothalamus inhibit sympathetic outflow to brown adipose tissue.Am J Physiol Regul Integr Comp Physiol. 2009; 296 (3): R831-43 PubMed Abstract | Publisher Full Text

10. Nakamura Y, Yanagawa Y, Morrison S, Nakamura K: Medullary Reticular Neurons Mediate Neuropeptide Y-Induced Metabolic Inhibition and Mastication. Cell Metabolism. 2017; 25 (2): $322-$ 334 Publisher Full Text

11. Shi Z, Bonillas AC, Wong J, Padilla SL, et al.: Neuropeptide $Y$ suppresses thermogenic and cardiovascular sympathetic nerve activity via $\mathrm{Y} 1$ receptors in the paraventricular nucleus and dorsomedial hypothalamus.J Neuroendocrinol. 33 (8): e13006 PubMed Abstract | Publisher Full Text 12. Conceição EPS, Reynolds CA, Morrison SF, Madden CJ: Activation of Transient Receptor Potential Vanilloid 1 Channels in the Nucleus of the Solitary Tract and Activation of Dynorphin Input to the Median Preoptic Nucleus Contribute to Impaired BAT Thermogenesis in Diet-Induced Obesity.eNeuro. 8 (2). PubMed Abstract | Publisher Full Text

13. Madden CJ: Brown fat in obesity: Uncoupling protein-1 versus thermogenic activity. Temperature (Austin). 2017; 4 (2): 126-127 PubMed Abstract | Publisher Full Text 14. Hitrec T, Luppi M, Bastianini S, Squarcio F, et al.: Neural control of fasting-induced torpor in mice. Scientific Reports. 2019; 9 (1). Publisher Full Text

Is the topic of the review discussed comprehensively in the context of the current literature?

Partly

Are all factual statements correct and adequately supported by citations?

Partly

Is the review written in accessible language?

Yes

Are the conclusions drawn appropriate in the context of the current research literature? Partly

Competing Interests: No competing interests were disclosed.

Reviewer Expertise: Thermoregulation, autonomic function, brown adipose tissue

I confirm that I have read this submission and believe that I have an appropriate level of expertise to confirm that it is of an acceptable scientific standard, however I have significant reservations, as outlined above.

Author Response 24 Jan 2022

Mike Ambler, University of Bristol, Bristol, UK

We thank the reviewer for their comments and suggestions. We will update the manuscript 
to incorporate these points.

Competing Interests: No competing interests were disclosed.

Author Response 09 Mar 2022

Mike Ambler, University of Bristol, Bristol, UK

Christopher Madden:

This manuscript is a well-written, timely, and extensive (although not comprehensive) review of torpor physiology. One major assumption stated in the introduction is that "the torpor during these hibernation periods is mechanistically equivalent to the brief torpor bouts seen in daily heterotherms such as the mouse", there are data throughout the manuscript that may contradict this assumption (as acknowledged by the authors). Please see the work of Geiser et al for additional discussions of this issue (Ann rev physiol 2004; Phys Zoology $1995^{2}$ ). At a minimum this statement that the mechanistics are "equivalent" should be tempered, if not excluded altogether.

We have revised how we discuss these data and acknowledged some fundamental differences between torpor and hibernation particularly with respect to the state of calorie deficit vs excess prior to imitation.

Below are additional suggestions:

1. Figure 1. There are data to suggest that many of the BDNF/PACAP neurons express Vglut2 and may be glutamatergic. This possibility should at least be acknowledged.

We have updated both the figure and the text to discuss this.

1. Page 4, first paragraph of the Cardiovascular function during torpor section. The statement is made that slower heart rates during entry into torpor vs arousal from torpor "indicates a dominance of parasympathetic ...during entry, followed by sympathetic...during arousal" . Please provide a reference showing parasympathetic involvement during entry, as a lower heart rate could simply be a withdrawal of sympathetic activity. Or at a minimum, use "suggests" instead of "indicates".

We have provided references for the role of the parasympathetic nervous system in torpor and also adjusted the language.

1. Page 5. The idea of moving away from a set-point model to one of multiple independent mechanisms each with their own thresholds was largely initiated by Romanovsky, it would be appropriate to include a citation to his influential work.

We have included a reference to this work and adjusted the wording of the context.

1. Page 5 . While relatively little is known about the thermosensitive inputs arriving to the CNS via vagal and splanchnic afferents, there is a more detail description of this issue in my review, Madden \& Morrison, (Neurosci Lett 2019) ${ }^{3}$.

Thank you we have added this useful reference.

1. Page 6. TRPM2 contributes to temperature sensing in POA neurons. However, genetic deletion of TRPM2 does not affect normal body temperature, therefore it is not necessary for normal euthermia, possibly suggesting that other temperature sensing mechanisms contribute. In addition, TRPM2 has a very broad expression pattern and 
likely has additional roles beyond temperature sensing. Perhaps these points are beyond the scope of this manuscript, but as this section currently reads, it could be misleading, leading to the possible misinterpretation the TRPM2 are the only mediator of central thermosensing.

We have updated the manuscript to acknowledge that TRPM2 is only part of a system that detects local brain temperature.

1. Page 6 second column first section. "Opto-activation of the warm-sensing GABAergic BDNF and PACAP-expressing cell bodies". Care should be taken when referring to "warm-sensing" vs. warm-responsive neurons. The BDNF/PACAP cells are responsive to thermal inputs but are not directly warm sensitive (see Tan et al $2016^{4}$ "In contrast, we found no evidence that VMPOBDNF/PACAP neurons were more intrinsically thermosensitive than neighbouring cells when we performed whole-cell patch clamp recordings from acute brain slices (Figures S2L and S2M).")

Thank you we have clarified this section.

1. The short-hand "DMH-Raphe-BAT" is potentially confusing since there are synapses between the Raphe and BAT.

We have clarified this section.

1. Page 6 last section. The concept of a maintenance of body weight is perhaps inappropriate. How would a biological system be configured to regulate body weight? It seems likely that the regulated variable would be some other correlate of body weight such as fat mass. Furthermore, the concept that calorie excess increases body temperature is controversial and complicated, and may depend on acute vs. chronic conditions. For example, rats maintained chronically on a high fat diet have reduced sympathetic outflow to BAT (Levin et al AJP, 19855; Sakaguchi et al Physiol Behav, 1989 ; Madden \& Morrison AJP, $2016^{7}$ (my paper)).

We have updated this section and included these references.

1. Figure 2. The suggestion that the $\mathrm{DMH}$ contributes to energy expenditure and the $\mathrm{PVH}$ contributes to food intake is oversimplified. Clearly the paraventricular hypothalamus also influences energy expenditure (BAT) (see, Billington et al, 1994; Madden \& Morrison, $2009^{9}$ (my paper); Nakamura, 2017 ${ }^{10}$ ).

We have revised the figure to acknowledge that the distinction is relative rather than absolute.

1. Page 8. "Selective reintroduction of melanocortin 4 receptors in the PVH normalizes the excess food intake but not the suppressed energy expenditure". The selective reintroduction of MC4R in the cited work would be in the cell bodies in PVH not in afferent terminals to the PVH so the statement the MC4R is normalized in the PVH is an overinterpretation.

We have revised this section.

1. Page 10. Again the concept that the Arc to PVH projection is relevant to feeding and that the DMH projection modulates EE is overly simplistic. See the work of Shi et al J Neuroendo $2021^{11}$; Billington ${ }^{8}$; Nakamura ${ }^{10}$.

We have updated this section to acknowledge the complexity and that our description is a simplification.

1. Page 12 , numbered point 2 . Beta3 activation would not only activate WAT to suppress leptin but would also activate BAT to generate thermogenesis.

Yes, this is of course a good point we have included.

1. The issue of the role of leptin in torpor is of high importance. Here again it calls into 
question the assertion that torpor in daily heterotherms and longer duration hibernation bouts are equivalent. Hibernation requires preparatory fattening which would result in elevated leptin levels, on the other hand daily torpor bouts appear to be blocked by leptin administration.

We agree and have revised our comments regarding hibernation and torpor to highlight this key difference.

1. Page 14. Please provide a reference for the statements regarding the incidence of asystoles in torpor and following $\mathrm{CHA}$.

Included.

1. The role of endogenous opioids in thermoregulation might benefit from a discussion of the role of kappa opioid receptors in high fat diet induced impairment of BAT activation. (see Conceicao et al, eNeuro, $2021^{12}$ (my paper)) and the parallels between animals maintained on a high fat diet and hibernation (see my paper, Madden, Temperature, $2017^{13}$ ).

We have included reference to this paper.

1. The suggestion that hypothermia-inducing DMH neurons are cholinergic is insightful and interesting. Nonetheless, the DMH neurons that express fos at torpor initiation are not cholinergic (Hitrec, 2019 ${ }^{14}$ ).

We have acknowledged this caveat.

Competing Interests: No competing interests were disclosed.

Reviewer Report 15 December 2021

https://doi.org/10.21956/wellcomeopenres.19215.r47147

(C) 2021 Hrvatin S et al. This is an open access peer review report distributed under the terms of the Creative Commons Attribution License, which permits unrestricted use, distribution, and reproduction in any medium, provided the original work is properly cited.

\section{Sinisa Hrvatin}

${ }^{1}$ Whitehead Institute for Biomedical Research, Cambridge, MA, USA

2 Massachusetts Institute of Technology, Cambridge, MA, USA

\section{Senmiao Sun}

Harvard Medical School, Boston, MA, USA

This article is an excellent review of the literature covering mechanisms that regulate the hypothermic and hypometabolic state of torpor. The review focuses on mouse torpor and neuronal mechanisms and makes relevant connections to literature on animal hibernation.

Here are some specific comments/suggestions:

Alongside hypothermia are commensurate reductions in metabolic, heart, and respiratory rates The term "commensurate" suggests to me that the change in metabolic and heart rate is 
either proportional or caused by the change in temperature. Perhaps replace term. Torpor (or aestivation in the case of fish, reptiles, and amphibians) is a remarkably conserved behaviour seen in all classes of vertebrate life, including the three oldest branches of mammals: monotremes, marsupials, and placentals including primates, as illustrated in Figure 1:

We would not only briefly compare the biology of torpor with aestivation - the extent of the similarities and differences is not well understood. We suggest either not mentioning aestivation or elaborating much more on the differences/similarities.

Figure 1 seems unrelated to this sentence.

Figure 1

As you discuss later in the review, PACAP/BDNF neurons are predominantly glutamatergic (see Hrvatin, Sun et al 20201, Takahashi et al 2020², Moffit 201833).

or simply increasing the energy costs of foraging (Schubert et al., 2010).

The observations in this story could be elaborated so they are not misunderstood by the reader. It appears that in this story mice lost weight during high-cost foraging which would have resulted in an energy deficient state that might be the reason animals entered torpor. Hence, this behaviour may represent a fundamental physiological response that has been relatively recently switched off in those animals for which it is not an extant behaviour.

Cite references supporting this view and elaborate on term distant.

torpor is engaged in any situation where the available food is insufficient for the metabolic demands of euthermia.

We would not agree with this statement as it implies that placing a mouse in a cage with no food would immediately engage torpor since this is a situation in which the food is nonexistent (insufficient) to meet metabolic demands. Since hours of fasting or caloric deficit are required in WT mice, it is not sufficient to expose an animal to a situation in which the food is insufficient.

We also find it is difficult to generally state "any situation".

By many definitions, thermoneutrally-housed animals do not enter torpor.

These gender differences might reflect the relatively lower energetic burden that normal activity and reproduction place on male compared to female mice, hence the need to conserve adipose tissue energy reserves may be greater for females

We believe "sex" is more appropriate than "gender".

Do male mice have more adipose tissue - could this be contributing as well?

Although the trigger for torpor entry in mice usually originates from a fluctuating rather than predictable environmental stimulus, the timing of torpor entry is under circadian control.

We are sure which trigger the author is referring to. Lack of food in the environment might be predictable cue.

with some evidence that torpor is engaged when food restriction or fasting decreases body weight to approximately $20 \mathrm{~g}$

There is literature on large and small mice entering torpor - $20 \mathrm{~g}$ seems far from generalizable.

Torpor typically persists for between four and six hours, often preceded by shallow, aborted or shorter bouts

If it is preceded by shorter bouts, it may be more accurate to say that it lasts minutes to 
hours.

What is the difference between a short and an aborted bout?

Hypothermia in a torpid animal could be achieved through three distinct mechanisms: increased thermal conductance to the environment; reduced target temperature; or reduced gain in the regulatory feedback system.

These concepts would need to be elaborated if the authors would like to discuss them. What is the meaning of target temperature (temperature setpoint)? What is the meaning of the gain of the feedback system? Which system? Although it is unclear whether it reflects the biology, We personally like the feedback framework with a temperature setpoint and gain. We don't think however that this is an easily understood framework without further elaboration.

The suppression of metabolism associated with torpor allows animals to tolerate profound reductions in cardiac output, respiratory rate, and, presumably, organ perfusion

Is it a suppression or could it simply be a decrease?

This indicates a dominance of the parasympathetic nervous system during entry, followed by sympathetic nervous system activation during arousal from torpor, at least in terms of the heart.

For those less familiar with the functioning of the ANS elaborate on why this is the conclusion of the observation.

More recently, the application of agonists or antagonists to cultured POA neurons that express calciumsensitive fluorescent dyes established that central temperature-sensing mechanisms are mediated by the transient receptor potential M2 channel (TRPM2)

Mediated in part by this.

Chemo- or optogenetic excitation of a warm-activated GABAergic projection from the ventral part of the lateral POA (VLPO) to the dorsomedial hypothalamic nucleus (DMH) suppresses thermogenesis and locomotion, while inhibiting the same projection induces the opposite effects.

Reference?

Opto-activation of the warm-sensing GABAergic BDNF and PACAP-expressing cell bodies in the VMPO induces a drop in core body temperature, vasodilatation, and preference for a cooler environment.

See News and Views article by Saper, Machado ${ }^{4}$ and single cell data/MERFISH by Moffit et al $2018^{3}$ - these neurons are likely glutamatergic and co-express Gad1.

One population responds to leptin, which is released from white adipose tissue (WAT) to signal satiety and replete WAT stores

Broadly the paragraph on Agrp/Pomc should make the point that ghrelin and leptin are but two signals that these cells sense/integrate.

Ghrelin signals recent food intake and time since last meal. Sensory inputs signal the approaching likelihood of food.

Kindly add citation.

These signals are generated by leptin, ghrelin, and sensory inputs, respectively.

There are also other humoral signals that these neurons sense.

Given that leptin acts on POMC/a-MSH neurons in the arcuate, blocking this pathway should mimic a drop in leptin and therefore be pro-torpor. However Ay mice, which display ectopic AgRP production and through the antagonist effect of AgRP on melanocortin 4 receptors, impaired a-MSH - melanocortin signalling, in fact show a reduced tendency to torpor (Gluck et al., 2006).

Mention a caveat that compensation may play a role when examining these genetic models. However, while the core temperature of both leptin-treated and control male WT mice during 24 hours 
of fasting did decrease, it remained above $30^{\circ} \mathrm{C}$, and therefore above commonly accepted thresholds for torpor.

The authors correctly note earlier in the paper that there is no standard definition for torpor. We would not consider $30^{\circ} \mathrm{C}$ a commonly accepted threshold for torpor.

The arcuate is a key locus for NPY signalling, and selective ablation of ARC neurons with monosodium glutamate (MSG), supports a role for this nucleus in torpor.

We are not familiar with the earliest work on MSG and ARC neurons this but we've wondered since reading this original story how selective MSG actually is.

RE torpor and sleep: Kindly add to discussion the recent story: "The relationship between fasting-induced torpor, sleep, and wakefulness in laboratory mice" ${ }^{5}$.

The data presented in the studies of Hrvatin, Takahashi, and Zhang represent significant advances in our understanding of torpor.

The Saper, Machado article "Flipping the switch on the thermoregulatory system" indicates that these neurons may also express EP3R (Machado J.Neurosci 2020) ${ }^{6}$.

We propose that there are two key features of torpor, which are relatively easily measured, and which might serve as a pragmatic proxy for identifying torpor: reduced body temperature with ongoing active thermoregulation such that a minimum (albeit adjusted) core temperature is defended; and controlled cardiovascular depression such that a characteristic heart rate versus body temperature hysteresis curve is observed

These two measures may not be sufficient and other measures like a change in movement/activity and posture may be relevant.

The discussion at the end can further highlight the fact that no stimulation of a neuronal population has recapitulated the full spectrum of natural torpor, including the animal posture. Therefore none of the identified neurons are likely to be the master switch controlling the entirety of the behavior and more work is needed to identify other neurons that regulate this process.

\section{References}

1. Hrvatin S, Sun S, Wilcox OF, Yao H, et al.: Neurons that regulate mouse torpor.Nature. $\mathbf{5 8 3}$ (7814): 115-121 PubMed Abstract | Publisher Full Text

2. Takahashi TM, Sunagawa GA, Soya S, Abe M, et al.: A discrete neuronal circuit induces a hibernation-like state in rodents.Nature. 583 (7814): 109-114 PubMed Abstract | Publisher Full Text 3. Moffitt J, Bambah-Mukku D, Eichhorn S, Vaughn E, et al.: Molecular, spatial, and functional single-cell profiling of the hypothalamic preoptic region. Science. 2018; 362 (6416). Publisher Full Text

4. Saper C, Machado N: Flipping the switch on the body's thermoregulatory system. Nature. 2020; 583 (7814): 34-35 Publisher Full Text

5. Huang Y, Flaherty S, Pothecary C, Foster R, et al.: The relationship between fasting-induced torpor, sleep, and wakefulness in laboratory mice. Sleep. 2021; 44 (9). Publisher Full Text 6. Machado N, Bandaru S, Abbott S, Saper C: EP3R-Expressing Glutamatergic Preoptic Neurons Mediate Inflammatory Fever. The Journal of Neuroscience. 2020; 40 (12): 2573-2588 Publisher Full Text

Is the topic of the review discussed comprehensively in the context of the current literature?

Yes

Are all factual statements correct and adequately supported by citations? 


\section{Partly}

Is the review written in accessible language?

Yes

\section{Are the conclusions drawn appropriate in the context of the current research literature?} Yes

Competing Interests: No competing interests were disclosed.

Reviewer Expertise: Torpor, hibernation, neuronal circuits regulating temperature and torpor

We confirm that we have read this submission and believe that we have an appropriate level of expertise to confirm that it is of an acceptable scientific standard.

Author Response 15 Dec 2021

Mike Ambler, University of Bristol, Bristol, UK

We thank the reviewer for their comments and suggestions. We broadly agree with what is said, and will update the manuscript to incorporate these points once further reviews are returned (in keeping with the guidance from the editors).

Regarding the specific point of the nature of the BDNF/PACAP projection from POA to DMH, we agree that recent evidence suggests a role for glutamatergic neurons particularly in torpor, but point out that earlier work from Tan et al (Cell, 2016) indicates that GABAergic neurons play a role in the context of thermoregulation. We will update the manuscript to include the suggestion that there is evidence for both.

Competing Interests: none

Author Response 09 Mar 2022

Mike Ambler, University of Bristol, Bristol, UK

This article is an excellent review of the literature covering mechanisms that regulate the hypothermic and hypometabolic state of torpor. The review focuses on mouse torpor and neuronal mechanisms and makes relevant connections to literature on animal hibernation.

Here are some specific comments/suggestions:

Alongside hypothermia are commensurate reductions in metabolic, heart, and respiratory rates

The term "commensurate" suggests to me that the change in metabolic and heart rate is either proportional or caused by the change in temperature. Perhaps replace term

We have removed the term to "commensurate". 
Torpor (or aestivation in the case of fish, reptiles, and amphibians) is a remarkably conserved behaviour seen in all classes of vertebrate life, including the three oldest branches of mammals: monotremes, marsupials, and placentals including primates, as illustrated in Figure 1:

We would not only briefly compare the biology of torpor with aestivation - the extent of the similarities and differences is not well understood. We suggest either not mentioning aestivation or elaborating much more on the differences/similarities.

In the interest of keeping the manuscript to a manageable length we have removed reference to aestivation.

Figure 1 seems unrelated to this sentence.

We have removed this error.

Figure 1

As you discuss later in the review, PACAP/BDNF neurons are predominantly glutamatergic (see Hrvatin, Sun et al $2020^{1}$, Takahashi et al $2020^{2}$, Moffit $2018^{3}$ ).

We have adjusted the discussion in this section to acknowledge that the use of GAD to identify GABAergic cells might misidentify neurons as inhibitory and have referred to the article from Saper \& Machado.

or simply increasing the energy costs of foraging (Schubert et al., 2010).

The observations in this story could be elaborated so they are not misunderstood by the reader. It appears that in this story mice lost weight during high-cost foraging which would have resulted in an energy deficient state that might be the reason animals entered torpor.

We have adjusted the text to clarify.

Hence, this behaviour may represent a fundamental physiological response that has been relatively recently switched off in those animals for which it is not an extant behaviour.

Cite references supporting this view and elaborate on term distant.

We have adjusted this paragraph to include the references at the correct position.

torpor is engaged in any situation where the available food is insufficient for the metabolic demands of euthermia.

We would not agree with this statement as it implies that placing a mouse in a cage with no food would immediately engage torpor since this is a situation in which the food is non-existent (insufficient) to meet metabolic demands. Since hours of fasting or caloric deficit are required in WT mice, it is not sufficient to expose an animal to a situation in which the food is insufficient.

We also find it is difficult to generally state "any situation".

By many definitions, thermoneutrally-housed animals do not enter torpor.

Have removed this statement.

These gender differences might reflect the relatively lower energetic burden that normal activity and reproduction place on male compared to female mice, hence the need to 
conserve adipose tissue energy reserves may be greater for females

We believe "sex" is more appropriate than "gender".

Do male mice have more adipose tissue - could this be contributing as well?

Have replaced gender with sex.

Although the trigger for torpor entry in mice usually originates from a fluctuating rather than predictable environmental stimulus, the timing of torpor entry is under circadian control.

We are sure which trigger the author is referring to. Lack of food in the environment might be predictable cue.

We have rephrased this sentence to indicate that lack of food might be an unpredictable cue (while acknowledging that it could also be predictable).

with some evidence that torpor is engaged when food restriction or fasting decreases body weight to approximately $20 \mathrm{~g}$

There is literature on large and small mice entering torpor - $20 \mathrm{~g}$ seems far from generalizable.

We have highlighted the fact this may not be generalizable.

Torpor typically persists for between four and six hours, often preceded by shallow, aborted or shorter bouts

If it is preceded by shorter bouts, it may be more accurate to say that it lasts minutes to hours.

What is the difference between a short and an aborted bout?

We have removed the word aborted.

Hypothermia in a torpid animal could be achieved through three distinct mechanisms: increased thermal conductance to the environment; reduced target temperature; or reduced gain in the regulatory feedback system.

These concepts would need to be elaborated if the authors would like to discuss them. What is the meaning of target temperature (temperature setpoint)? What is the meaning of the gain of the feedback system? Which system? Although it is unclear whether it reflects the biology, We personally like the feedback framework with a temperature setpoint and gain. We don't think however that this is an easily understood framework without further elaboration.

We have expanded somewhat but in the interest of keeping the manuscript at a manageable length we have not included a detailed discussion, believing that the interested reader will follow the citations.

The suppression of metabolism associated with torpor allows animals to tolerate profound reductions in cardiac output, respiratory rate, and, presumably, organ perfusion

Is it a suppression or could it simply be a decrease?

We believe metabolism is actively suppressed beyond the reduction that occurs purely due to Q10 effects - although we acknowledge that the evidence for this comes 
largely from hibernating bears and not from daily torpor.

This indicates a dominance of the parasympathetic nervous system during entry, followed by sympathetic nervous system activation during arousal from torpor, at least in terms of the heart.

For those less familiar with the functioning of the ANS elaborate on why this is the conclusion of the observation.

We believe the interested reader can follow the citations for a detailed discussion of this topic.

More recently, the application of agonists or antagonists to cultured POA neurons that express calcium-sensitive fluorescent dyes established that central temperature-sensing mechanisms are mediated by the transient receptor potential M2 channel (TRPM2)

Mediated in part by this.

We have revised this sentence.

Chemo- or optogenetic excitation of a warm-activated GABAergic projection from the ventral part of the lateral POA (VLPO) to the dorsomedial hypothalamic nucleus (DMH) suppresses thermogenesis and locomotion, while inhibiting the same projection induces the opposite effects.

Reference?

\section{Zhao 2017}

Opto-activation of the warm-sensing GABAergic BDNF and PACAP-expressing cell bodies in the VMPO induces a drop in core body temperature, vasodilatation, and preference for a cooler environment.

See News and Views article by Saper, Machado 4 and single cell data/MERFISH by

Moffit et al $2018^{3}$ - these neurons are likely glutamatergic and co-express Gad1 Have updated this section to include the nuances of the possibility that GAD is not a useful marker of GABAergic neurons in isolation, and hence thee neurons may in fact be glutamatergic.

One population responds to leptin, which is released from white adipose tissue (WAT) to signal satiety and replete WAT stores

Broadly the paragraph on Agrp/Pomc should make the point that ghrelin and leptin are but two signals that these cells sense/integrate.

Ghrelin signals recent food intake and time since last meal. Sensory inputs signal the approaching likelihood of food.

Kindly add citation.

We have added a citation, although this paragraph really represents a synthesis of the preceding paragraphs.

These signals are generated by leptin, ghrelin, and sensory inputs, respectively.

There are also other humoral signals that these neurons sense.

We have acknowledged that this is just a part of the story.

Given that leptin acts on POMC/a-MSH neurons in the arcuate, blocking this pathway should 
mimic a drop in leptin and therefore be pro-torpor. However Ay mice, which display ectopic AgRP production and through the antagonist effect of AgRP on melanocortin 4 receptors, impaired a-MSH - melanocortin signalling, in fact show a reduced tendency to torpor (Gluck et al., 2006).

Mention a caveat that compensation may play a role when examining these genetic models.

\section{Have included.}

However, while the core temperature of both leptin-treated and control male WT mice during 24 hours of fasting did decrease, it remained above $30^{\circ} \mathrm{C}$, and therefore above commonly accepted thresholds for torpor.

The authors correctly note earlier in the paper that there is no standard definition for torpor. We would not consider $30^{\circ} \mathrm{C}$ a commonly accepted threshold for torpor.

\section{We have removed this statement.}

The arcuate is a key locus for NPY signalling, and selective ablation of ARC neurons with monosodium glutamate (MSG), supports a role for this nucleus in torpor.

We are not familiar with the earliest work on MSG and ARC neurons this but we've wondered since reading this original story how selective MSG actually is.

RE torpor and sleep: Kindly add to discussion the recent story: "The relationship Added. between fasting-induced torpor, sleep, and wakefulness in laboratory mice" 5 .

The data presented in the studies of Hrvatin, Takahashi, and Zhang represent significant advances in our understanding of torpor.

The Saper, Machado article "Flipping the switch on the thermoregulatory system"

indicates that these neurons may also express EP3R (Machado J.Neurosci 2020) ${ }^{6}$.

We propose that there are two key features of torpor, which are relatively easily measured, and which might serve as a pragmatic proxy for identifying torpor: reduced body temperature with ongoing active thermoregulation such that a minimum (albeit adjusted) core temperature is defended; and controlled cardiovascular depression such that a characteristic heart rate versus body temperature hysteresis curve is observed

These two measures may not be sufficient and other measures like a change in movement/activity and posture may be relevant.

Agreed, however we propose that a pragmatic approach might focus on these characteristics.

The discussion at the end can further highlight the fact that no stimulation of a neuronal population has recapitulated the full spectrum of natural torpor, including the animal posture. Therefore none of the identified neurons are likely to be the master switch controlling the entirety of the behavior and more work is needed to identify other neurons that regulate this process.

\section{We have highlighted this point.}


Competing Interests: No competing interests were disclosed. 